Portland State University

PDXScholar

$1-1-2011$

\title{
Runaway and Homeless Youth: Changing the Discourse by Legitimizing Youth Voice
}

Donald Dale Schweitzer

Portland State University

Follow this and additional works at: https://pdxscholar.library.pdx.edu/open_access_etds Let us know how access to this document benefits you.

\section{Recommended Citation}

Schweitzer, Donald Dale, "Runaway and Homeless Youth: Changing the Discourse by Legitimizing Youth Voice" (2011). Dissertations and Theses. Paper 292.

https://doi.org/10.15760/etd.292

This Dissertation is brought to you for free and open access. It has been accepted for inclusion in Dissertations and Theses by an authorized administrator of PDXScholar. Please contact us if we can make this document more accessible: pdxscholar@pdx.edu. 
Runaway and Homeless Youth:

Changing the Discourse by Legitimizing Youth Voice

by

Donald Dale Schweitzer

A dissertation submitted in partial fulfillment of the requirements for the degree of

\author{
Doctor of Philosophy \\ in \\ Social Work and Social Research
}

Dissertation Committee:
Pauline Jivanjee, Chair
Ann Curry-Stevens
Thomas E. Keller
Laura B. Nissen
Melissa A. Thompson

Portland State University

(C)2011 


\title{
RUNAWAY AND HOMELESS YOUTH
}

\begin{abstract}
Undoubtedly, runaway and homeless youth (RHY) are one of the most vulnerable, yet underserved groups in our country. Well-meaning advocates have developed programs and services in an attempt to remedy this, yet there is little evidence of their effectiveness. Moreover, according to the research literature, a low utilization rate of current services by youth is a major concern. From a constructivist theoretical position, this study posits that the missing element is youth voice and the researcher hired formerly homeless youth to conduct the analysis of focus group data gathered from RHY who were participating in a range of services funded by the Runaway and Homeless Youth Act. By employing participatory action research (PAR) methods, this study privileges youth voice and asks two research questions; 1) what are current program models doing right with regards to RHY services, and 2) what can be learned by employing youth analysts in research. Findings indicate that how services are offered is as important as what services are offered. Additionally, by privileging youth and providing meaningful participation, youth are exceptionally capable to develop and evaluate services, programs and policy. Youth workers must continue to privilege youth voice if they hope to effect change in the lives of young people. If not, services will continue to play a key role in keeping RHY as one of the most marginalized groups in our society.
\end{abstract}




\section{RUNAWAY AND HOMELESS YOUTH}

\section{Acknowledgements}

I would like to thank all my committee members for their individual perspectives and their insistence on pushing me to continually look further and dig deeper. I would specifically like to acknowledge my chair, Pauline Jivanjee. I am deeply indebted to her for hours of reading and editing as well as her tireless enthusiasm. I can not imagine having completed this project without her insight and support. I would also like to acknowledge Katharine Cahn for inviting me to be part of the CEY project. Moreover, Dr. Cahn afforded me hours of introspective dialogue, helping me articulate what I was discovering throughout this project.

I also wish to acknowledge those who provided financial support for portions of this project: "Communities Empowering Youth", a Family and Youth Services Bureau grant administered by a collaborative partnership based at Looking Glass Youth and Family Services in Eugene, Oregon, and also Pacific University Oregon. In addition, I wish to thank my colleagues and the social work students at Pacific University for their encouragement and support.

Finally, I wish to thank my family for their love and support. They, more than anyone, understand the sacrifices required for such an undertaking. 


\section{RUNAWAY AND HOMELESS YOUTH}

\section{Table of Contents}

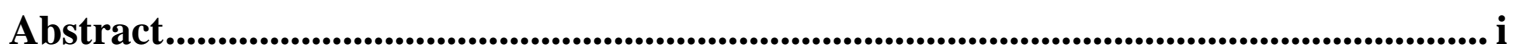

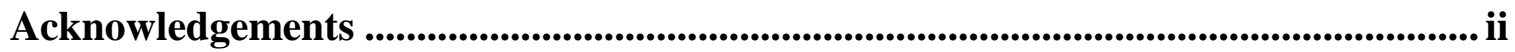

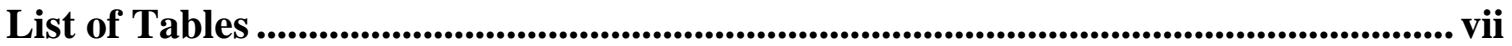

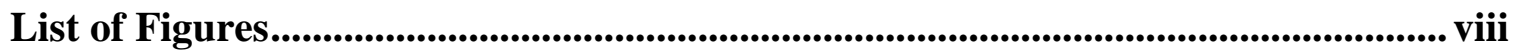

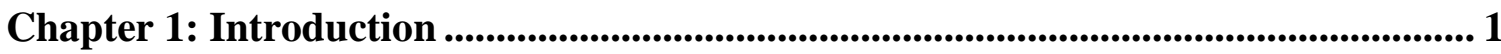

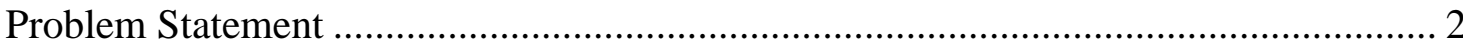

Research Question to be Addressed .................................................................... 3

Motivation for the Study .................................................................................. 4

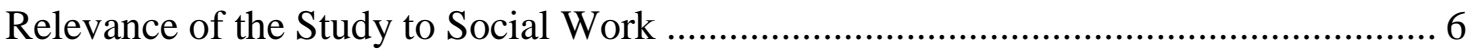

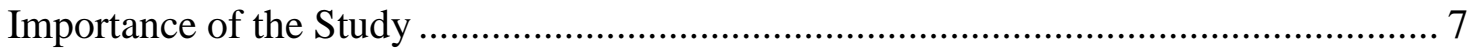

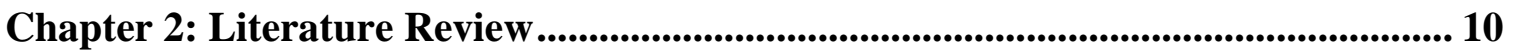

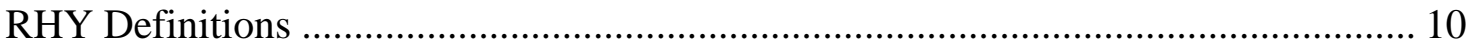

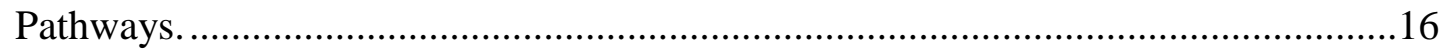

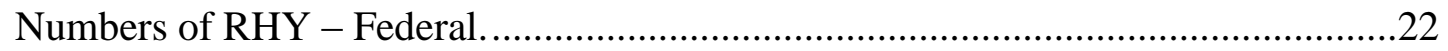

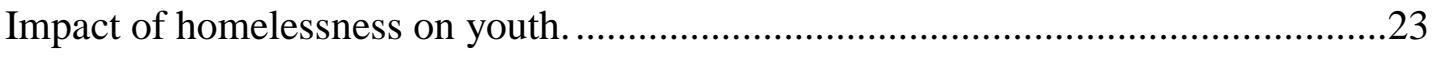

Impact of youth homelessness on communities. ...............................................26

Policies to Address Youth Homelessness ................................................................. 33

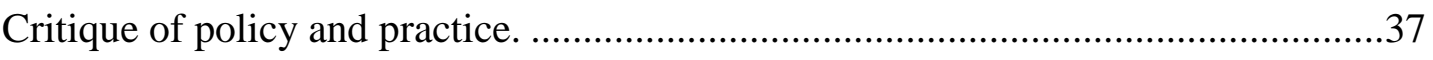

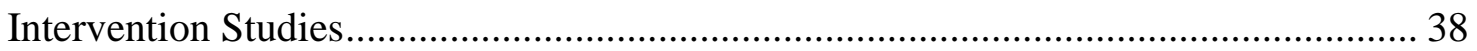

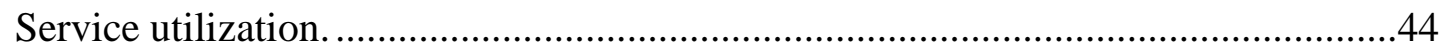

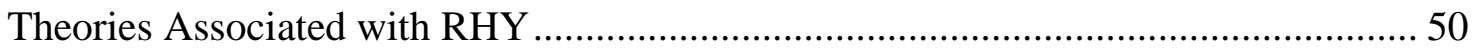

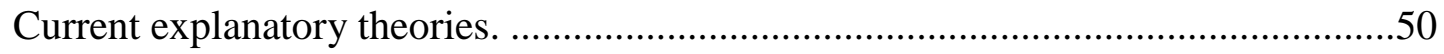




\section{RUNAWAY AND HOMELESS YOUTH}

Challenges and limitations of explanatory theories..................................................66

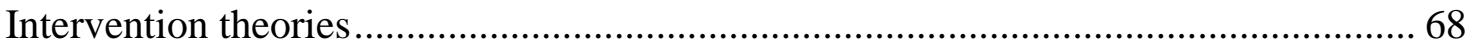

Positive youth development perspective. ...........................................................68

Challenges and limitations of intervention theories. ................................................70

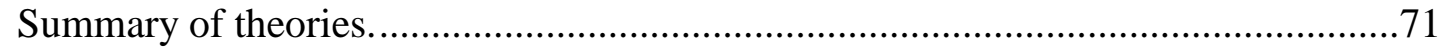

Summary of Literature Review ………………………......................................... 72

Research Questions and Hypotheses ....................................................................... 74

Chapter 3: Methods ............................................................................................................................... 75

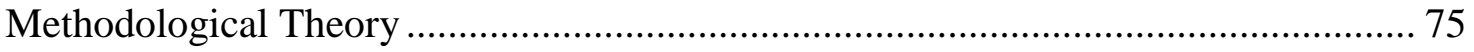

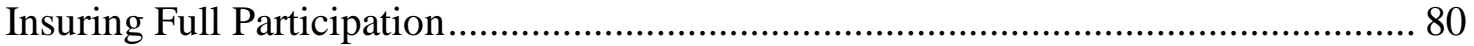

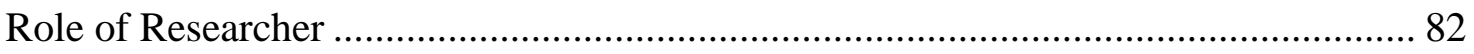

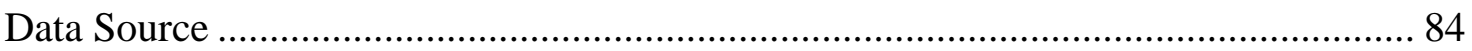

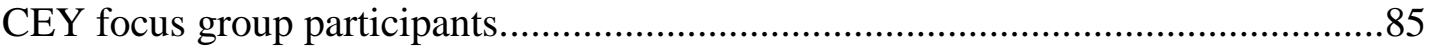

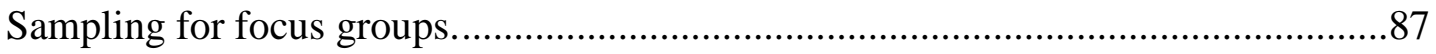

Recruitment of Youth Advisory Group...................................................................... 89

YAG orientation and training meetings......................................................................93

YAG analysis meetings. ........................................................................................94

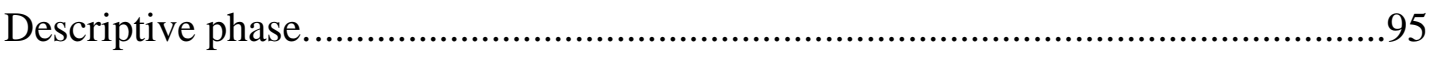

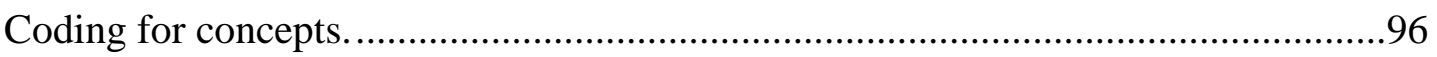

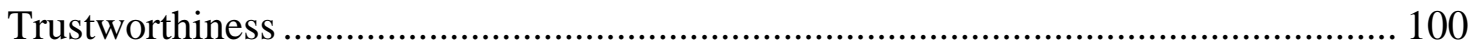

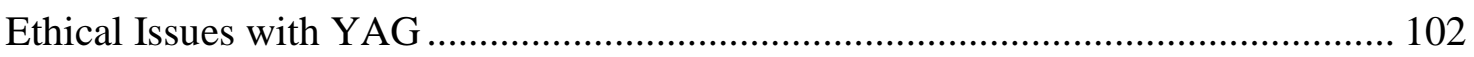

Chapter 4: Results........................................................................................................................... 104

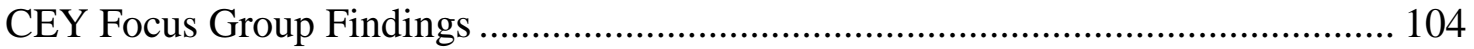

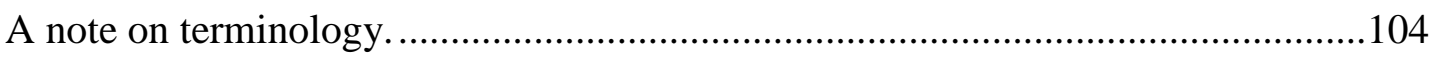




\section{RUNAWAY AND HOMELESS YOUTH}

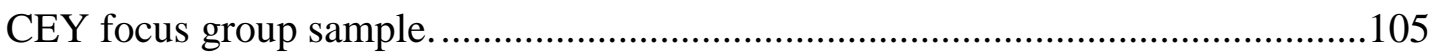

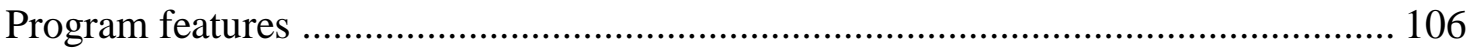

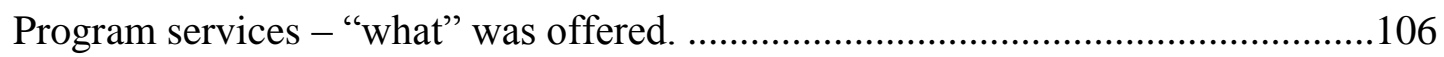

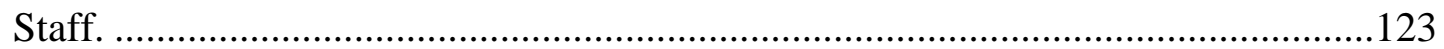

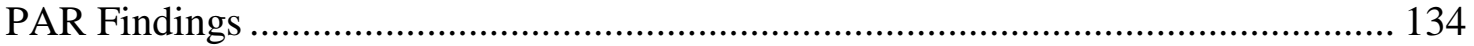

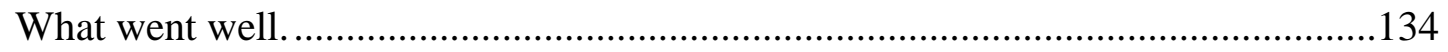

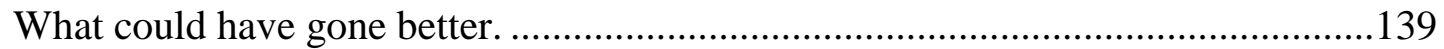

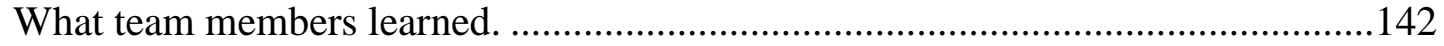

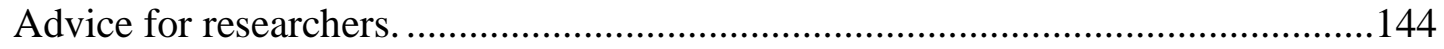

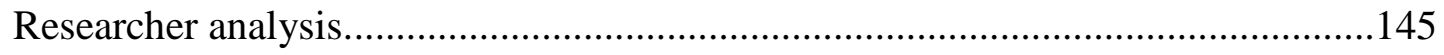

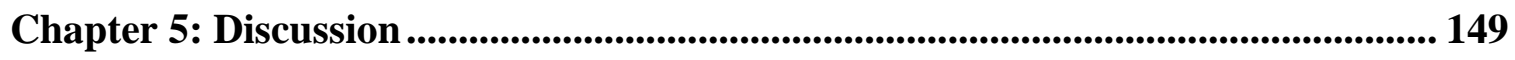

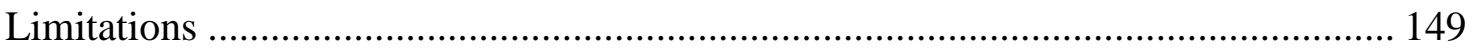

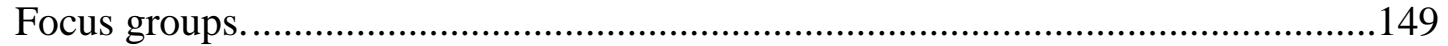

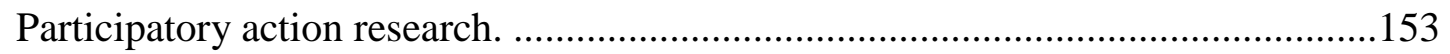

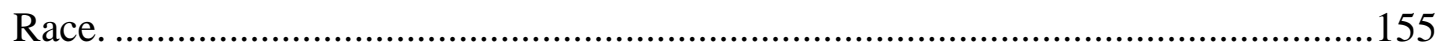

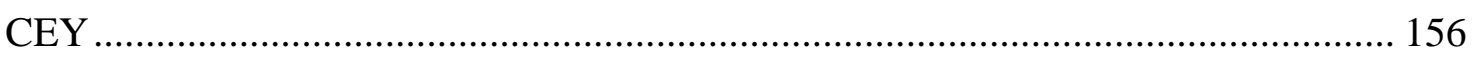

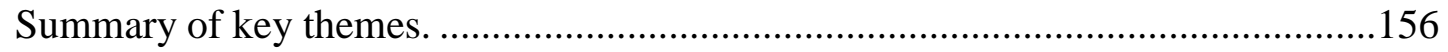

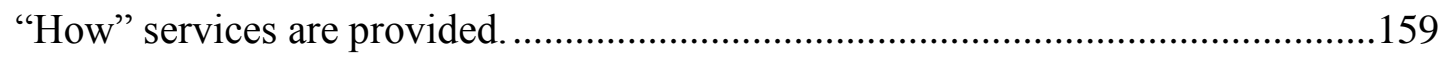

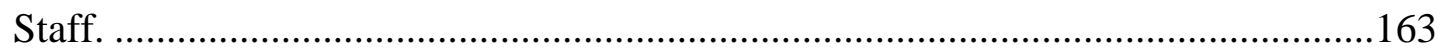

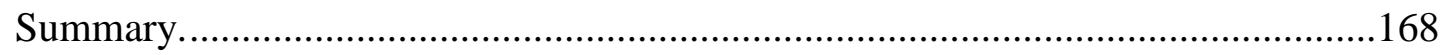

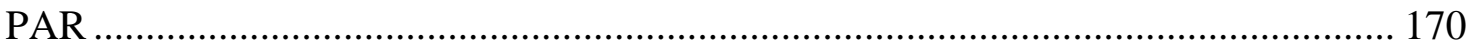

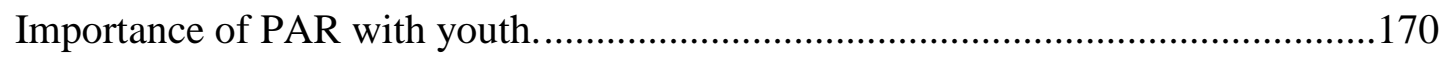

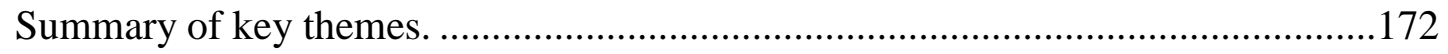

Additional findings beyond the research question. ............................................177 


\section{RUNAWAY AND HOMELESS YOUTH}

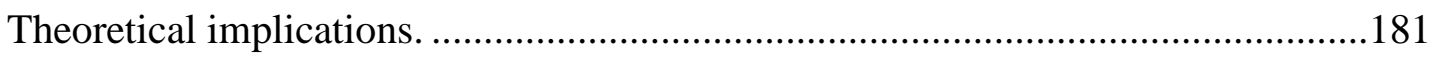

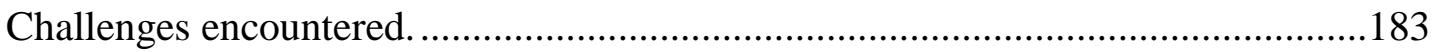

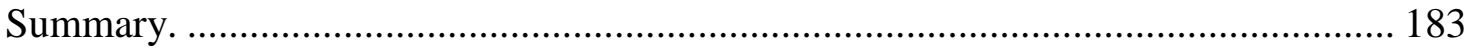

What do these Findings Mean for Policy, Practice, Programming ........................... 184

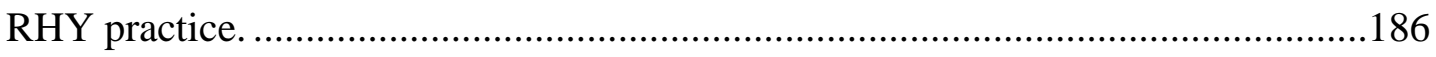

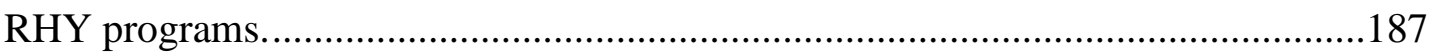

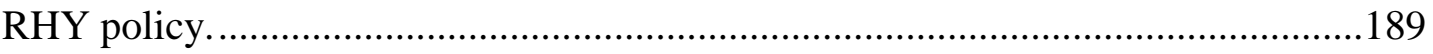

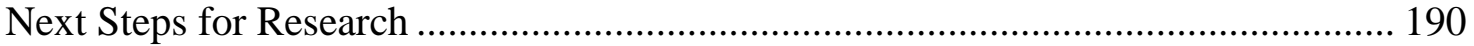

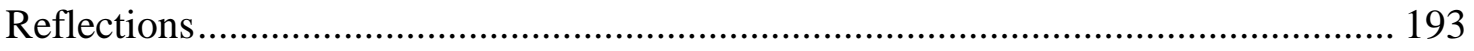

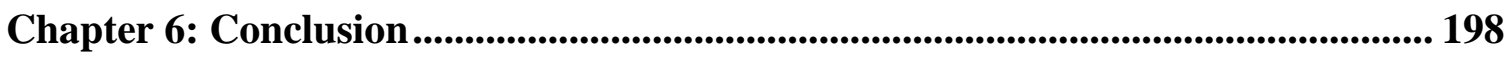

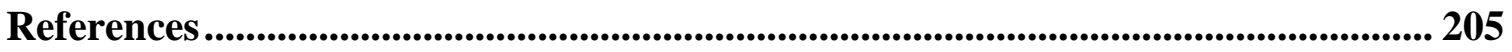

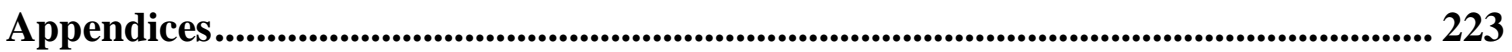

Appendix A: Evolution of Federal RHY Policy, 1912-2003 .................................. 224

Appendix B: Federal Funding for Runaway and Homeless Programs ..................... 227

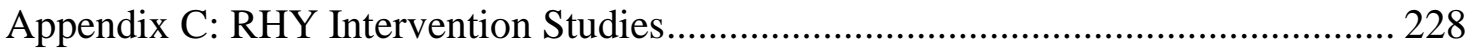

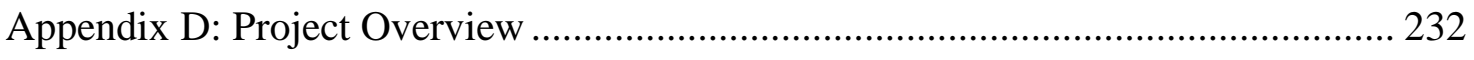

Appendix E: Interview Checklist and Questions ................................................ 234

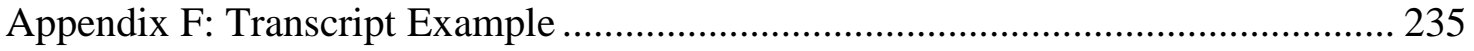

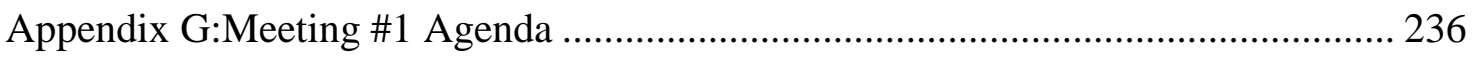

Appendix H: Meeting \#2 Agenda ................................................................. 237

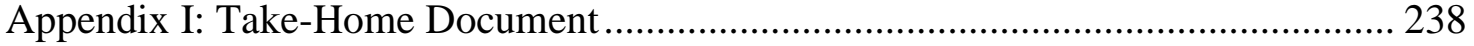

Appendix J: Analysis Review Sheet .......................................................... 241

Appendix K: Draft of Human Subjects Application ............................................ 242 
RUNAWAY AND HOMELESS YOUTH

\section{List of Tables}

Table 1: Characteristics of Runaways/Thrownaways $\ldots \ldots \ldots \ldots \ldots \ldots \ldots \ldots \ldots \ldots \ldots$

Table 2: Dedicated Homelessness Funding - Federal Government................ 21

Table 3: Estimates of Potentially Endangered Runaways/Thrownaways........... 25

Table 4: Summary of the Monetary Value of Saving a High-Risk Youth.......... 28

Table 5: Drug Use Prevalence among Street Youth and High School Seniors...... 30

Table 6: Abuse by an Adult Caregiver Prior to Running Away................... 53

Table 7: Overview of Focus Group Sample............................... 106

Table 8: Recommendations.......................................... 185 
RUNAWAY AND HOMELESS YOUTH

\section{List of Figures}

Figure 1: Hart's Ladder of Young People's Participation.................................................82 


\section{RUNAWAY AND HOMELESS YOUTH}

\section{Chapter 1: Introduction}

No guarantees come with children's liberation. But neither the promise of great benefits to all nor the prediction of great difficulties ahead can serve as the reason for granting or denying rights to children. Rights will be granted because without them children are incapacitated, oppressed, and abused.

Richard Farson in Birthrights, 1974

Runaway and homeless youth are among the most disadvantaged and underserved groups in the United States. While historically, these youth have been viewed as delinquent, troubled, or worse - the fact that most of them run to escape appalling environments, perhaps makes them the most courageous and sensible youth in our communities. However, with scant research or youth input to guide them, wellmeaning advocates and policy makers have developed programs they feel will meet these youths' needs. Yet, the underutilization of these services by runaway and homeless youth has frustrated providers and signals the need for a system redesign. To do this effectively, to create a system that youth will engage in and use, requires youth to be involved in its formation.

This study is twofold. First, focus group data were collected from youth who were participating in federally funded runaway and homeless youth (RHY) programs. To analyze this data, RHY were hired. The second part of this study assesses what can be learned from collaborating with youth in this manner. Findings will aid researchers, 


\section{RUNAWAY AND HOMELESS YOUTH}

and subsequently policy makers and service providers, to understand youths' perspectives on programs and services and, most importantly, how services can truly meet youths' needs.

\section{Problem Statement}

Each year an estimated 1.7 million American youth run away from home, are thrown out of their homes, or otherwise end up homeless (Fernandes, 2007; National Collaboration for Youth, 2006; National Crime Justice Reference Service [NCJRS], 2002; Thompson, Safyer, \& Pollio, 2001). The magnitude of these numbers is better understood when compared with that of entire U.S. foster care system, which works with approximately 500,000 children each year.

As concerning as these vast numbers are, the risks runaway and homeless youth are exposed to when they find themselves on the street are even more so.

Studies have consistently reported that nationally, almost half of the runaways left home to escape abuse, yet running away from home dramatically increases the risk of victimization, both physically and sexually. Because runaway youth find themselves lacking skills and resources necessary to fully engage in employment, they are left with few legally permissible options for survival. Additionally, research has shown that youth living on the streets exhibit much higher health risks including higher rates of substance abuse, suicide attempts, pregnancy and death. 


\section{RUNAWAY AND HOMELESS YOUTH}

Complicating this social problem is that researchers, youth advocates, and most service providers all agree the vast majority of runaway and homeless youth reject the services and programs designed to meet their needs and keep them safe (Garrett, Higa, Phares, Peterson, Wells, \& Baer, 2008; Slesnick, Dashora, Letcher, Erdem, \& Serovich, 2009). This dynamic exacerbates an already perilous situation for youth who find themselves on the streets. Service providers, advocates, and policy makers have developed programs and services they feel meet the need of runaway and homeless youth but services will have little effect on this social problem if youth reject them. In regards to programs, important questions include, what service components do youth feel are necessary? How should services be delivered according to youth? What should programs really be doing to help youth? This project was designed to address these questions from the youths' perspectives.

\section{Research Question to be Addressed}

Service providers, advocates, and policy makers have developed programs and services they feel meet the needs of runaway and homeless youth. Yet the literature is clear about the underutilization of community services by these youth (Garrett et al., 2008; Slesnick et al. 2009).The critical missing element in program development is youth voice. This project was developed to elicit information from youth to improve runaway and homeless youth programs by partnering with youth being served in those 


\section{RUNAWAY AND HOMELESS YOUTH}

programs. Therefore, there are two research questions for this project: 1) according to youth, what are programs currently doing right in regards to RHY service provision and, 2) what can learned by employing youth analysts in research?

\section{Motivation for the Study}

The Communities Empowering Youth (CEY) project, born of research on Oregon's homeless and runaway youth conducted in response to House Bill $2202^{1}$, strives to enable runaway and homeless youth (RHY) agencies and their community partners throughout Oregon to develop a community-based capacity building and sustainability model, permitting the state to responsibly address the needs of RHY. Partners across the state have united to address this issue holistically, understanding that building capacity to serve RHY adequately involves every member of the community at every level. The overall purpose of the CEY project is to build a culture of engagement with the understanding that RHY-serving agencies must engage in relationships with each other, community partners, and the youth they serve to identify what services are needed, how those services should be provided, and how partners can contribute to an overall system of care for RHY.

\footnotetext{
${ }^{1}$ In 2005, House Bill 2202 authorized the Oregon Commission on Children and Families to be the state agency responsible for planning and coordination of RHY services.
} 


\section{RUNAWAY AND HOMELESS YOUTH}

Concurrently, having worked with the chronic homeless and runaway and homeless youth populations for over twelve years, I have developed a profound awareness of the day-to-day struggles homeless people endure. From this work, I have come to recognize that communities are predominantly naïve to the real issues surrounding homelessness and relatively unmotivated to learn what those are. From the political structures to the legal systems, from social service organizations working not to "eliminate inequalities, domination, and exploitation...but merely to reduce and fine-tune their intensity, so that people could survive somehow, and established ways of life could be conserved" (Gil, 1998, p. 67) to the medical professions, and from the religious establishments to the impacted families, all seem to not only not help the homeless, but actually exacerbate the problem. It has been my experience that most homeless people, both youth and adults, want to belong to communities and succeed in life. They desire jobs and dream of having homes, owning cars, and creating and raising healthy families. However, there simply are not enough jobs, trainings, affordable housing, and other vital supports in our communities to provide opportunities for most homeless youth to move beyond their dire situation. Because of their position of distinction and power, researchers have a responsibility to educate the naïve and motivate the apathetic to resolve these issues. Recognizing this, I felt compelled to include RHY in this project in some capacity, though it was not clear early on, what that would look like. 


\section{RUNAWAY AND HOMELESS YOUTH}

\section{Relevance of the Study to Social Work}

Social workers have a long and storied past working with homeless people as well as other oppressed groups. From the founders of the profession working with immigrant families in the Settlement Houses of New York, Chicago and other major U.S. cities to providing critically needed services to homeless people with serious and persistent mental illness of today, social workers understand homelessness, the oppressive systems that maintain it, and its negative long-term effects on individuals, families and communities. Because of the high needs, high risks, and complex issues associated with these youth, the field of social work has much to contribute to the resolution of these problems and service development for runaway and homeless youth. The Person-in-Environment perspective as well as the generalist practice focus prepares social workers with Bachelor's degrees in Social Work (BSW) to be especially well-qualified to work effectively with runaway and homeless youth in a variety of settings, i.e. street outreach, emergency shelters, and long-term transitional housing programs. Concurrently, the skills and knowledge of the Masters degree in Social Work (MSW) are particularly suited to assist runaway and homeless youth with any mental health and/or substance abuse needs. Additionally, the profession of social work understands the need for inclusion of service users' perspectives and is uniquely 


\section{RUNAWAY AND HOMELESS YOUTH}

skilled in collaborating with communities to conduct research, evaluation, affect public policy, and apply community-based interventions.

It is well known, though not well documented, that not all youth who run away from home become incarcerated, experience extreme repressive responses from social institutions, or end up exhibiting delinquent behaviors the rest of their lives. In fact most do not. Yet far too many runaway and homeless youth, attempting to merely survive in an unforgiving environment, do encounter difficult and dangerous situations and engage in high-risk behaviors while on the streets that can bring them into contact with social workers. RHY could be affected by addictions, or be victims of sexual or physical abuse, or experiencing PTSD or other mental or emotional health issues. Social workers in schools, child welfare agencies, youth serving organizations, juvenile justice, drug and alcohol treatment, victims' services, and other community based settings require effective engagement techniques and interventions to work with this unique population and their families. Yet the field is sorely lacking the knowledge of what those techniques and interventions should be.

\section{Importance of the Study}

The literature has addressed many aspects of the lives of runaway and homeless youth: the history, policy, practice and research. Much has changed since the need to serve "street urchins" arose in the $19^{\text {th }}$ century. The complexities associated 


\section{RUNAWAY AND HOMELESS YOUTH}

with the RHY population such as age, pathways to running away and/or homelessness, mental health, abuse, neglect, etc. make this a challenging field to work in. Yet understanding these complexities and evaluating the interventions used by community social service programs designed to help youth return home, or enter other safe, stable housing, are critical to helping the field of social work develop and improve interventions, programs, and prevention strategies that will actually be used by this uniquely vulnerable population.

At the same time, the literature also reflects significant gaps in our understanding of RHY and the services for them. Because of this, the field is limited in its ability to accurately gauge the scope of the problem, create meaningful policies, and develop effective practices to meet their needs. For example, it is unclear how many incidents of running away go unreported. There are challenges associated with finding RHY and the methods used to gather that census data is problematic. Additionally, older RHY (18-24) are generally excluded from census efforts, available data on RHY is commonly gathered from youth who are in programs excluding the experiences of those who do not utilize services, and the social stigma and legal implications associated with running away inhibit youth from self-identifying (BassRubenstein, 2008). Moreover, understanding the impact of race on this social problem is, in essence, completely absent in the research literature. 


\section{RUNAWAY AND HOMELESS YOUTH}

Much of the research to date has focused on the pathology of youth and/or their families (Garrett et al. 2008; Raleigh-DuRoff, 2004; Slesnick, 2009). But to concentrate only on these "failings" misses the mark and prevents the field from ever having the opportunity to effectively provide services and, perhaps, one day be able to prevent this social problem. Additionally, while understanding how youth get in to this situation is important, it is equally important to understand how to help youth get out. Social science must continue to identify repressive systemic barriers to full participation in communities by these youth and their families, especially when those barriers exist in the programs designed to serve them. As such, what are programs doing that work for RHY? Which services or practices do the youth feel are most important? Is there a way to merge these practices, codify them, and begin to build the evidence base for working effectively with RHY? This study begins this process by asking youth being served in a RHY program, what is it about this program that works for you? Then the researcher hired RHY to analyze those responses. Findings hold the potential to begin filling the chasm that exists in the literature around effective practice with RHY. 


\section{RUNAWAY AND HOMELESS YOUTH}

\section{Chapter 2: Literature Review}

This chapter begins by examining definitions of RHY and how varied definitions impede the ability to conduct valid research. Next, the Federal response to RHY and associated policies will be reviewed. This chapter will then explore theoretical constructs and how they attempt to explain the phenomenon of running away and youth homelessness. Finally, historical and current models of intervention will be assessed.

\section{RHY Definitions}

In the course of describing the social problem of homeless among youth, it is useful to understand the definitions and types of the various subgroups of the homeless youth population. Such definitions often appear to overlap, leading to confusion among communities, policy makers, and researchers. The purpose of this section is to provide as much common understanding as is possible (Fernandes, 2007; Sanchez, Waller, \& Greene, 2006). The first clarification is that, for the purposes of this project, RHY does not include those homeless youth who are members of an intact, homeless family unit. 


\section{RUNAWAY AND HOMELESS YOUTH}

Because RHY are, by the legal ${ }^{2}$ definition, both "youth" (17 and younger) as well as adults (18-24), systems struggle to provide services that can effectively meet the broad range of their developmental needs. In advocating for changes in the juvenile justice system, Scott and Steinberg (2008) described how challenging this can be when they state, "Adolescence and adulthood are not tidy developmental categories; the transition to adulthood is a gradual process" (p. 237). They go on to describe how a youth may have fully developed psychologically by age 15 or 16 ("logical reasoning and information processing capacities" [p. 236]), but their psychosocial capacities ("impulse control, future orientation, [and] resistance to peer influence" [p. 236]) might not fully develop until age 24 or 25 .

Researchers, service providers, and advocate organizations often recognize "youth" from a developmental perspective, while policy makers and federal and state laws frequently define youth from the chronological perspective in years old.

Therefore 18 year olds and older are adults while 17 year olds and younger are youth. This creates challenges to creating effective policies and programs that meet the unique needs of RHY (Sanchez et al., 2006). Davis (2003) describes this as a conflict between the, "two forces [of] institutional and developmental transitions" (p. 496),

\footnotetext{
${ }^{2}$ It is important to note that even the "legal" definition is problematic. How youth are treated by age varies from system to system and state to state and, perhaps, even by jurisdiction within states. State truancy laws, city curfew ordinances, and school district zero tolerance policies are a few examples of a chaotic and disjointed system.
} 


\section{RUNAWAY AND HOMELESS YOUTH}

where institutional transition refers to a status change based on age and "developmental transition refers to the natural process of maturation, increased competence, and the social changes that are associated with this natural process" (p. 496).

Disagreements around arbitrary cutoff ages, young people's capacity for thoughtful decision making, and which system is best suited to serve people aged 1824 result in a disjointed system of care, split between adult services and youth services (that often compete for the funding to serve 18-24 year olds) and rife with gaps through which the vast majority of RHY fall.

The Runaway and Homeless Youth Act (2008), the sole piece of Federal legislation pertaining specifically to these youth, defined this population as "individuals under age 18 who are unable to live in a safe environment with a relative and lack safe alternative living arrangements, as well as individuals aged 18 to 21 without shelter" (Fernandes, 2007, p. 3). However, Moore (2006) stated the term homeless youth is often used to describe youth between the ages of 12 and 24 and refers to youth who have been thrown out of their homes, are unaccompanied, have run away from home and include "street youth and systems youth" (p. 2). Yet Haber and Toro (2004) feel the key criteria for a homeless youth are being unable to secure appropriate stable housing coupled with the lack of, "supervision of a guardian or other primary caretaker" (p. 124). 


\section{RUNAWAY AND HOMELESS YOUTH}

Still other definitions attempt to delineate specific characteristics in hopes of providing clarity to specific policy requirements. One example is from the Office of Juvenile Justice and Delinquency Prevention (OJJDP), which differentiates between runaway and thrownaway youth by whether they meet the following criteria:

Runaway youth

1. A child leaves home without permission and stays away overnight.

2. A child 14 years old or younger (or older and mentally incompetent) who is away from home chooses not to come home when expected to and stays away overnight.

3. A child 15 years old or older who is away from home chooses not to come home and stays away two nights (Hammer, Findelhor, \& Sedlak, 2002, p. 2).

\section{Thrownaway youth}

1. A child is asked or told to leave home by a parent or other household adult, no adequate alternative care is arranged for the child by a household adult, and the child is out of the household overnight.

2. A child who is away from home is prevented from returning home by a parent or other household adult, no adequate alternative care is arranged for the child by a household adult, and the child is out of the household overnight (Hammer, Findelhor, \& Sedlak, 2002, p. 2). 


\section{RUNAWAY AND HOMELESS YOUTH}

Bass-Rubenstein (2008) concurs with these definitions yet adds an additional designation for homeless youth, "Homeless youth are unaccompanied youth between the ages of 16 and 21 who cannot safely live with a relative and have no safe alternative living situation" (Definitions section, para. 3). Still another definition from the National Coalition for the Homeless (2008) seems to reject the developmental perspective with the statement: "Homeless youth are individuals [only] under the age of eighteen who lack parental, foster, or institutional care. These youth are sometimes referred to as 'unaccompanied' youth" (Definitions and Dimensions section, para.1).

Slesnick and colleagues (2009) suggested there should be another distinction made between shelter youth and street living youth. They reported that the majority of shelter youth (92 percent) have never spent a night on the streets and most (72-87 percent) return home. Conversely, street living youth experience vastly higher exposure to a wide range of health risks and victimization. The authors further pointed out that these youth are often prevented from seeking services out of fear of being forced to return home or to the foster care system. They add, "When youths' needs and goals do not match those of service providers, the likelihood of youth rejecting services increases" (p. 2).

Finding specific demographic information for the entire RHY population is challenging. In her report to Congress, Fernandes (2007) states: 


\section{RUNAWAY AND HOMELESS YOUTH}

Differences in methodology for collecting data on homeless populations may also influence how the characteristics of the runaway and homeless youth population are reported...According to researchers that study [RHY], these studies appear to be biased toward describing individuals who experience longer periods of homelessness (p. 5).

Because of this, reports vary widely and study samples are such that generalizing to the entire population is not feasible. Table 1 reflects the characteristics of the RHY population found by combining three large national studies ${ }^{3}$ (Hammer, Finkelhor \& Sedlak, 2002).

\footnotetext{
${ }^{3}$ The National Household Survey of Adult Caretakers, the National Household Survey of Youth, and the Juvenile Facilities Study.
} 


\section{RUNAWAY AND HOMELESS YOUTH}

Table 1

Characteristics of Runaways/Thrownaways

\begin{tabular}{lccc}
\hline \multicolumn{1}{c}{ Characteristic } & Estimate & $\begin{array}{c}\text { Percent } \\
(\mathrm{n}=1,682,900)\end{array}$ & $\begin{array}{c}\text { Percent of U.S. Child } \\
\text { Population Ages 7-17* } \\
(\mathrm{N}=43,372,500)\end{array}$ \\
\hline Age (years) & 70,100 & 4 & 46 \\
$7-11$ & 463,200 & 28 & 27 \\
$12-14$ & $1,149,400$ & 68 & 27 \\
$15-17$ & $200^{\ddagger}$ & $<1^{\ddagger}$ & - \\
No Information & & & 51 \\
Gender & 841,300 & 50 & 49 \\
Male & 841,600 & 50 & 66 \\
Female & & & 15 \\
Race/Ethnicity & 963,500 & 57 & 14 \\
White, non-Hispanic & 283,300 & 17 & 5 \\
Black, non-Hispanic & 244,300 & 15 & - \\
Hispanic & 188,900 & 11 & \\
Other & $3,000^{\ddagger}$ & $<1^{\ddagger}$ & \\
No Information & & &
\end{tabular}

Note. Because all estimates have been rounded to the nearest 100, percentages may not sum to 100 . Adapted from "Runaway/Thrownaway Children: National Estimates and Characteristics by H.

Hammer, D. Finkelhor, and A.J. Sedlak, October 2002, National Incidence Studies of Missing, Abducted, Runaway, and Thrownaway Children (NISMART), Retrieved http://www.ncjrs.gov/html/ojjdp/nismart/04/, p. 6.

* Age, gender, and race for the U.S. population were based on the average monthly estimates of the population ages 7-17 years for 1999 (U.S. Census Bureau, 2000).

*Estimate is based on too few sample cases to be reliable.

\section{Pathways.}

Further complicating this issue are the varying pathways in which youth become runaway and homeless youth. The chief reason provided by youth for running away or being thrown out of their homes was family conflict (Toro et al., 2007). The 


\section{RUNAWAY AND HOMELESS YOUTH}

literature reported that $36-50$ percent of runaways stated they ran away from home to escape sexual abuse, physical abuse, neglect and other forms of maltreatment.

Additionally, youth reported family conflict around a variety of issues, e.g. rejection by family due to sexual activity, pregnancy, or coming out as GLBT, etc. (National Runaway Switchboard, 2006; Rew, 2008; Stiffman, 1989a).

In addition to youth who run away from a family are those youth who run away from an out-of-home placement. According to Nesmith (2006), several studies reported " $16-46 \%$ of runaways resided in out-of-home placements prior to running, whereas children in foster care comprise only $0.23 \%$ of the general population" ( $p$. 586-587). Fernandes (2007) found that based on state reports, the number of foster youth who have run away from placement averaged 11,000 annually from FY2003 FY2005.

Also, youth from the child welfare system often end up homeless after aging out of care. Osgood, Foster, Flanagan, and Ruth (2005) reported on several studies indicating out-of-home placements greatly increased the likelihood of a young adult experiencing housing instability and/or homelessness. One study they reported on interviewed $18-23$ year old former foster youth who had been out of care for $30-48$ months and found that 32 percent had lived in a minimum of six homes and 25 percent had been, for at least one night, homeless. The authors reported on another study of 18 - 23 year olds who had left care $12-18$ months prior and found 12 percent had been 


\section{RUNAWAY AND HOMELESS YOUTH}

homeless at least one night and 22 percent, "had lived in four or more places" (p. 40). Moreover, in her study on adult homelessness, Burt and colleagues (2001) found that of those ages $20-24,34$ percent had been placed in foster care, a group home, or

other similar institution (or combination of all three) before the age of 18. For those in her study who were 18 - 20 years old, 61 percent had been placed in these systems as well.

Though a search of the literature failed to produce concrete figures, most advocates confirmed the link between RHY and the juvenile justice system.

Accordingly, the National Alliance to End Homelessness (NAEH) (2006a) states that as an essential function to prevent youth homelessness;

Mainstream programs, like child welfare, juvenile corrections, mental health, etc. that provide care and services to youth, [must] consistently assess and respond to their housing needs. Discharge planning includes placement in stable housing for all young people being released from public institutions ( $\mathrm{p}$. 4).

There is also scarce literature on the impact of racial disparity in the RHY system, yet it has been well documented in other youth serving systems. For example, youth of color are overrepresented in juvenile justice (Piquero, 2008) and treated differently once entangled in that system (Aarons, Brown, Garland, \& Hough, 2004). Additionally, youth of color are less likely to have been receiving mental health 


\section{RUNAWAY AND HOMELESS YOUTH}

services immediately prior to a mental health crisis and more likely to have to use emergency care to access those services (Snowden, Masland, Fawley, \& Wallace, 2009). After transitioning from foster care, youth of color are more likely to have an income below the poverty line and less likely to have stable housing than those youth who were White (Harris, Jackson, O’Brien, Pecora, 2009). In another study, American Indian/Alaska Native youth were found to have,

Higher levels of involvement... in physical altercations, higher injury rates when in a fight, and higher likelihood of carrying a weapon... and they use tobacco, alcohol, and marijuana at younger ages. Substance abuse and suicidal ideation and attempts, are higher compared to other racial groups (Pavkov, Travis, Fox, King, \& Cross, 2010, p. 130-131).

Specific to RHY, federally funded RHY programs are required to gather data on service users and enter it in the Runaway and Homeless Youth Management Information System (RHYMIS). Using data from the 1997 RHYMIS, Thompson, Kost, and Pollio (2003) found that both race and ethnicity are important variables with regards to family reunification after accessing runaway shelter services. The authors report the race and ethnicity of those youth who entered services as White $(59.7 \%)$, African American (21.9\%), Hispanic (12.7\%), Native American (3.1\%), and Asian American (2.6\%). The authors also found that youth of color had a lower probability of family reunification (African American, 29.1\%; Native American 29.6\%; and 


\section{RUNAWAY AND HOMELESS YOUTH}

Hispanic 31.2\%) than those youth who were White or Asian (40\%). One additional study by Courtney and Zinn (2009) found that in the state of Illinois child welfare system, Black youth and Hispanic youth ran away from care at higher rates than youth who were White (1.3 and 1.24 times respectively).

Another group the literature suggests is overrepresented in the RHY population are those youth who identify as lesbian, gay, bisexual or transgender (LGBT). According to the National Gay and Lesbian Task Force (2006), while people who are LGBT only make up $3-5$ percent of the entire U.S. population, they make up $20-40$ percent of homeless youth. Because family conflict is the leading reason for young people leaving home, these youth are exceptionally vulnerable. According to this report, in one study the Task Force reviewed, "50 percent of gay teens experienced a negative reaction from parents when they came out and 26 percent were kicked out of their homes" (p. 2). Van Leeuwen and colleagues (2006) substantiated these findings and noted that LGBT homeless youth are at higher risk than non-LGBT homeless youth for substance abuse, suicide, pregnancy, physical and sexual abuse as well as they "experience [additional] obstacles to healthcare and mental health treatment" (p. 154).

Other vulnerable populations whose needs are not addressed in the RHY literature include those youth with disabilities, severe mental illness, and youth with other serious health concerns. 


\section{RUNAWAY AND HOMELESS YOUTH}

Table 2 reflects the many Federal departments that have some type of program that could assist RHY. However, varying department missions, the confusion over definitions, varying characteristics identified to describe RHY, combined with the lack of a standardized methodology for counting RHY and the varying pathways by which youth become RHY creates a strenuous and exasperating environment for developing useful policy, effective interventions, and meaningful research.

Table 2

Dedicated Homelessness Funding - Federal Government

\begin{tabular}{lcc}
\hline & Federal & 2006 \\
& Agency & Funding \\
\hline Homeless Assistance Grants & HUD & 1,327 \\
Health Care for the Homeless & HHS & 155 \\
Runaway and Homeless Youth & HHS & 103 \\
Emergency Food and Shelter Program & DHS & 151 \\
Education for Homeless Children and Youth & ED & 62 \\
Projects to Assist in the Transition from Homelessness (PATH) & HHS & 54 \\
Homeless Veterans Reintegration Program & DOL & 22 \\
SSI HOPE Outreach Grants & SSA & 8 \\
Treatment for Homeless (GBHI and other discretionary) & HHS & 46 \\
Total & & 1,928
\end{tabular}

Notes. The table is presented in real dollars (2006). Shown in Millions of Dollars. The numbers represent budget authority, not budget outlays. This table includes federal programs with funding streams dedicated to homeless individuals and families. The U.S. Department of Housing and Urban Development (HUD), U.S. Department of Health and Human Services (HHS), the Department of Education (ED), the Department of Homeland Security (DHS), the Social Security Administration (SSA), and the Department of Labor (DOL). 


\section{RUNAWAY AND HOMELESS YOUTH}

\section{Numbers of RHY - Federal.}

Because this population tends to be "hidden in plain sight", due in large part to the challenges of definitions as well as the difficulties in locating and counting, the exact number of RHY is difficult to obtain (Fernandes, 2007: Sanchez et al. 2006). Another challenge to counting RHY is the transitory nature of their situation, (i.e. short-term periods out-of-home repeated several times over several years), and their reluctance to interact with "counters" for fear of being taken into state custody or forced to return to the family from which they ran (Fernandes, 2007). In a recent report to Congress, Fernandes (2007) acknowledged this difficulty and added, "Determining the number...is further complicated by the lack of a standardized methodology for counting" (p. 4).

Because of this, estimates of RHY, as with definitions, vary widely. One such estimate places the number of RHY at 1 million each year (Thompson et al., 2001). However, according to the National Collaboration for Youth (2006), the total in 2005 was as high as 1.6 million RHY in the United States. That estimate aligns with the Office of Juvenile Justice and Delinquency Prevention's more specific estimate of $1,682,900$ runaway and homeless youth (NCJRS, 2002). However, a report to Congress stated that just those youth under 18 amounted to 1.7 million "Of these

youth, 68\% were between the ages of 15 and 17" (Fernandes, 2007, p. 6). Studies also 


\section{RUNAWAY AND HOMELESS YOUTH}

reported high incidence rates of running away among all adolescents ranging from 5 to 14 percent (Cheung, Liu, \& Lee, 2005; Haber \& Toro, 2001; NAEH, 2007; Sanchez et al., 2006). These rates indicated that somewhere between 1.0 and 2.8 million adolescents experience homelessness each year, which does not include youth ages 18-24 (NAEH, n.d.a). When compared to the number of youth in the entire of U.S. foster care system (approximately 500,000 children annually), the magnitude of these numbers is staggering.

\section{Impact of homelessness on youth.}

While researchers are striving to develop methodologies that will accurately account for all RHY, the literature is clear that while a large portion of runaways are escaping abuse, the reality is that in all likelihood the "cycle of abuse they experienced at home will continue on the streets" (Tyler, Cauce, \& Whitbeck, 2004, Abst.). While running away from home can be a desperate call for help, it dramatically increases the risk of youth being victimized, both physically and sexually, by either friends or strangers (Fisher \& Wilson, 1995; Kurtz, Kurtz, \& Jarvis, 1991; Rew, 2008; Tyler, Whitbeck, Hoyt, \& Cauce, 2004). Because runaway youth find themselves lacking skills and resources necessary to fully engage in employment, they are left with few options outside of "prostitution, drug dealing, and other criminal behavior to survive" (Thompson et al., 2001, p. 163). 


\section{RUNAWAY AND HOMELESS YOUTH}

Additional risks associated with being a runaway are higher rates of substance abuse (Fisher \& Wilson, 1995; Thompson, Zittel-Palamara \& Forehand., 2005; Yoder, Whitbeck \& Hoyt, 2003), a decrease in emotional health and coping skills which leads to increased rates of suicide attempts (Rew, 2008; Stiffman, 1989b; Yoder et al., 2003), and higher rates of pregnancy (Rew, 2008). Additionally, the younger youth are when they first run away, the more likely they are to become involved in gangs (Yoder et al., 2003) and they have higher rates of mortality than their counterparts in the general population (Roy, Haley, Leclerc, Sochanski, Boudreau \& Boivin, 2004). Furthermore, Rew (2008) listed higher rates of, "sexually transmitted infections, uncontrolled asthma, tuberculosis, and skin disorders" (p. S45) among homeless youth as additional risks.

Where a youth lives and/or where they run to can greatly impact the level of risk they are exposed to while on the streets. Hammer and her colleagues (2002) found that whether or not a youth ran to a location known to them, where they were provided safety, or were roaming the unknown streets of an urban city made an important difference as to the levels of risk to which the youth were exposed. Table 3 displays the authors' estimates of potential risks to RHY from information gathered from a household survey on children ages $10-18$ years old. 


\section{RUNAWAY AND HOMELESS YOUTH}

\section{Table 3}

Estimates of Potentially Endangered Runaways/Thrownaways

Percent

Characteristic of Episode

Estimate $\quad(n=1,682,900)$

Child had been physically or sexually abused at home in the year prior to the episode or was afraid of abuse upon return

Child was substance dependent

350,400

21

Child was 13 years old or younger

317,800

19

Child was in the company of someone known to be abusing drugs

305,300

Child was using hard drugs

302,100

Child spent time in a place where criminal activity was known to occur

292,000

17

Child engaged in criminal activity during the course of the episode

256,900

12

Child was with a violent person

197,400

11

Child had previously attempted suicide

125,400

7

Child who was enrolled in school at the time of the episode missed at least 5 days of school

Child was physically assaulted or someone attempted to physically assault child during the course of the episode

Child was with a sexually exploitative person

70,500

70,500

Child had a serious mental illness or developmental disability at the time of the episode

Child was sexually assaulted or someone attempted to sexually assault child during the course of the episode

Child's whereabouts were unknown to the caretaker for at least 30 days (and the episode was unresolved or no information was available)

Child engaged in sexual activity in exchange for money, drugs, food, or shelter during the episode

Child had or developed a serious or life-threatening medical condition

69,100

\footnotetext{
Note: The total number of endangered runaway/thrownaway youth was 1,190,900. The individual estimates and percents do not sum to the total because the youth were counted in each category that applied. For this reason, the numbers and percentages cannot be combined to create aggregates. Adapted from "Runaway/Thrownaway Children: National Estimates and Characteristics by H. Hammer, D. Finkelhor, and A.J. Sedlak, October 2002, National Incidence Studies of Missing, Abducted, Runaway, and Thrownaway Children (NISMART), Retrieved http://www.ncjrs.gov/html/ojjdp/nismart/04/,p. 8.

* Estimate based on too few sample cases to be reliable.

${ }^{\ddagger}$ No cases were identified.
} 


\section{RUNAWAY AND HOMELESS YOUTH}

Today, after decades of media stories, documentation, and research on the issues of runaways (though the runaway population remains woefully understudied), social workers and RHY advocates see running away as a behavior resulting from complex systems issues, that then exposes youth to risks such as those listed above. Abuse, neglect and other forms of child maltreatment, along with the effects of generational poverty, family instability and conflict are seen as antecedents to running away from home. This information is beginning to help society see the runaway not as

a criminal, but as a child fighting back at an unhealthy environment (Whitbeck, Hoyt, Yoder, Cauce, Paradise, 2001).

\section{Impact of youth homelessness on communities.}

Aside from the personal impacts experienced by a youth who does not fully engage in our society, there are direct monetary consequences for communities as well. Examples of the financial costs associated with homeless youth are loss of wages and productivity due to dropping out of high school, criminal activity, and costs associated with chronic homelessness. Though not specific to RHY, Cohen (1998) calculated the costs associated with these behaviors, which are widespread in an RHY population simply trying to survive. 


\section{RUNAWAY AND HOMELESS YOUTH}

\section{Education and employment.}

Research has long shown the connection between dropping out of high school and juvenile delinquency. For runaway and homeless youth, the barriers to education are great, resulting in most dropping out of school, especially those whose return home is not facilitated quickly. Estimates of a 75 percent dropout rate have been reported (Cohen, 1998). Dropping out of school not only limits employment opportunities, but limits expected wage earning as well. According to Cohen (1998), costs associated with dropping out of school include lost wages and productivity, loss of fringe benefits, and "nonmarket" losses, i.e. education benefits individuals through improved social connections, technology development, and other types of knowledge formation that improves communities. Table 4 (Cohen, 1998) illustrates the factors Cohen used to estimate costs. 


\section{RUNAWAY AND HOMELESS YOUTH}

Table 4

Summary of the Monetary Value of Saving a High-Risk Youth

\begin{tabular}{lcc}
\hline & Total Cost & Present Value \\
& & $(2 \%$ discount rate $)$ \\
\hline High school dropout & $\$ 606,000-\$ 966,000$ & $\$ 313,000-\$ 500,000$ \\
Career criminal & $\$ 1.9-\$ 2.3$ million & $\$ 1.7-\$ 1.9$ million \\
Heavy drug user & $\$ 622,000-\$ 1.6$ million & $\$ 477,000-\$ 1.25$ million \\
Less duplication* & $\$ 364,690-\$ 1.0$ million $)$ & $(\$ 284,000-\$ 781,000)$ \\
Total & $\$ 2.8-\$ 3.9$ million & $\$ 2.2-\$ 3.0$ million \\
\hline
\end{tabular}

Note. Numbers may not add due to rounding. All costs are in 2007 dollars. *Crimes committed by heavy drug users. Adapted from "The Monetary Value of Saving a High-Risk Youth," by M.A. Cohen, 1998, Journal of Quantitative Criminology, 14(1), p. 27.

\section{Criminal justice.}

Cohen (1998) described a juvenile career criminal as one who begins his/her criminal career as an adolescent and carries it into adulthood. A career criminal, as defined by Cohen commits one to four crimes per year for six years and will spend approximately eight years in jail for a total of 14 years of costs. In calculating the costs associated, Cohen took into account the cost to the victim, the cost to the system (i.e. investigation, arrest, adjudication, etc.), cost of incarceration, and average time served. Additionally, he calculated the opportunity costs of the offender's time, i.e. lost wages while incarcerated. To do this, he estimated legitimate earnings of $\$ 7,542$ (1997 dollars), which, when multiplied by the years of incarceration equals approximately $\$ 60,000$. This would be over $\$ 77,000$ in 2007 dollars (see Table 4). 


\section{RUNAWAY AND HOMELESS YOUTH}

\section{Heavy drug use.}

The literature is clear about the connection of substance use and RHY (Baer, Peterson, \& Wells, 2004; Slesnick, \& Prestopnik, 2005; Thompson et al., 2001). Table 5 compares the rates of substance use by RHY who participated in project STARRS a substance use program for homeless youth - and high schools seniors in the general population. 


\section{RUNAWAY AND HOMELESS YOUTH}

Table 5

Drug Use Prevalence among Street Youth and High School Seniors

\begin{tabular}{lcc}
\hline Drug & $\begin{array}{c}\text { Project STARRS } \\
\text { (\% Annually) }\end{array}$ & $\begin{array}{c}\text { HS Seniors } \\
\text { (\% Annually) }\end{array}$ \\
\hline Marijuana & 95.4 & 37.0 \\
Alcohol & 94.7 & 73.3 \\
Speed & 70.3 & 10.9 \\
Hallucinogens & 68.4 & 8.4 \\
Opiates (not heroin) & 54.4 & 6.7 \\
Cocaine/Crack & 49.2 & 4.8 \\
Heroin & 35.5 & 0.9 \\
Tranquilizers & 31.6 & 6.5 \\
Inhalants & 29.8 & 4.5 \\
Barbiturates & 21.7 & 5.7 \\
\hline
\end{tabular}

Note. Adapted from "Rationale and Design of a Brief Substance Use Intervention for Homeless Adolescents," by J.S. Baer, P.L. Peterson, and E.A. Wells, 2004, Addiction Research \& Theory, 12(4), p. 318.

As with crime, drug abuse costs not only the user, but their family, friends, and the community around them. For his cost calculation, Cohen (1998) made the assumption that drug use for a "heavy drug user" begins at age 15 and lasts until age 60 , with heavy drug use lasting roughly 14 years. To determine costs, the author took into account lost labor productivity, treatment expenses, medical expenses both emergencies and routine, risk of death, drug-related crimes, arrests, and third-party risks and costs such as those associated with children of drug abusing parents (see Table 5). 


\section{RUNAWAY AND HOMELESS YOUTH}

There are two key points that should be considered when using these cost estimates. The first is that many assumptions and hypotheses went into developing the equations for these calculations. Therefore, according to Cohen (1998), the costs should be used "as order of magnitude estimates" (p. 26). Secondly, money invested in programs that will help prevent these costly behaviors is based on future benefits, perhaps as far out as 20 years or more. Therefore, the costs should be discounted by approximately $2 \%$ to take this into account (see Table 5 for dollar amounts).

\section{Chronic homelessness.}

The federal government's definition of chronic homelessness includes homeless individuals with a disabling condition (substance use disorder, serious mental illness, developmental disability, or chronic physical illness or disability) who have been homeless either 1) continuously for one whole year, or 2) four or more times in the past three years (NAEH, 2007). Chronic homelessness creates a costly burden for communities and states. People who are homeless for extended periods use more social services and more shelter beds, and stay in programs for longer periods of time. Research with the adult homeless population reflects increased utilization of emergency rooms and hospitalizations compared to the low-income, housed populations, and longer hospital stays. Further research shows that the those most chronically homeless people with serious mental illnesses, approximately 20-25 


\section{RUNAWAY AND HOMELESS YOUTH}

percent of the adult homeless population, the average annual costs of inpatient care ranged from $\$ 25,010$ to $\$ 32,605$ (1996 dollars) depending on location and level of additional support services (Rosenheck, 2000).

In the only study located that examined the association between running away as an adolescent and chronic homelessness, Burt and her colleagues (2001) found that among homeless individuals, 51 percent of those age 18 and 19 years old, 38 percent of 20 to 24 year olds, and 32 percent who were 25 years old and older had run away from home. Additionally, for those in her study which she categorized as episodically homeless, 40 percent first experienced homelessness under the age of 18. Likewise, of those she categorized as chronically homeless, 25 percent first experienced homelessness as a minor. Consequently, the federal definition of chronic homelessness encompasses Burt's definitions of episodic and chronic.

Federal, state and local governments, and communities understand the need to end chronic homelessness. Proposed by the National Alliance to End Homelessness in 2000 as a strategy to organize service efforts, many communities and states have been developing 10 Year Plans to End Homelessness, yet to effectively accomplish this, plans must include programs that prevent chronic homelessness by preventing or eliminating initial homelessness among RHY. 


\section{RUNAWAY AND HOMELESS YOUTH}

\section{Policies to Address Youth Homelessness}

Federal policy responses to youth who run away or otherwise becoming homeless are generally based on a perception that these youth are in some way delinquent. Consequently, returning a youth to their family of origin tends to the focus of this policy. From allowing the use of child welfare dollars to pay for a youth's return in the 1950's to reauthorizing the Runaway and Homeless Youth Act in 2008 funding emergency shelter models that focus on returning runaway youth to their families, these policies have both responded to, as well as reinforced, the public persona of runaway and homeless youth.

From the turn of the last century through the 1960s, policy responses were based on the perception of RHY as juvenile delinquents that should be dealt with by local child welfare agencies and/or the juvenile justice system (Bass-Rubenstein, 2008). In 1912, the Federal Government established the Children's Bureau that was tasked with the nation's child welfare issues. In 1950, returning youth under the age of 16 who had run away from home became an allowed expenditure for federal child welfare funds and in 1958 the age limit was raised to 18. In 1968, Congress provided funding for the development of four RHY centers around the country (Fernandes, 2007). Although Federal policy adjusted to include mandated funding to provide for runaways and essentially decriminalized running away, these new policies continued 


\section{RUNAWAY AND HOMELESS YOUTH}

to view the runaway as a juvenile delinquent (Fernandes, 2007; Staller, 2006). (See Appendix A for a complete timeline of Federal involvement with runaway/disconnected youth.)

In 1974, Congress responded to increased concerns about the risks for RHY by passing legislation titled the Runaway Youth Act (RYA) that provided funding for community shelter programs (called Basic Centers). Although concern for runaways resulted in this legislation, the RYA was part of the Juvenile Justice and Delinquency Prevention Act, keeping delinquency prevention as the premise to this problem's solution. The RYA of 1974, later titled the Runaway and Homeless Youth Act (RHYA) and today administered through the Families and Youth Services Bureau (FYSB) of the Administration for Children and Families (ACF) is currently the only federal funding source specifically and solely for RHY (Fernandes, 2007).

The RHYA spelled out the program model for which it would provide funds, such as the Basic Center Program (BCP), which provided a maximum of 2 weeks of shelter access to youth ages 11-17 and focused on returning the youth home. When the Act was reauthorized in 1988, Congress added the Transitional Living Program (TLP) as an option for services. The TLP was developed to meet the meet the needs of older youth (16-24 years old) who could not return home. This legislation, understanding that older youth need more than two weeks to make a healthy transition to adulthood, allowed youth to stay in transitional living arrangements for up to 18 months (24 


\section{RUNAWAY AND HOMELESS YOUTH}

months in certain circumstances) with an emphasis on skill development needed to transition to adulthood. Finally, in 1994 the RHYA added the Street Outreach Program (SOP), which focused on meeting the needs of youth who were living on the streets and who refused to utilize the BCPs and/or the TLPs. The SOP is the first line of intervention for RHY. SOPs are designed to, "provide education and prevention services to runaway, homeless and street youth" (U.S. Department of Health and Human Services [USDHHS], n.d.). The emphasis in this program is on providing services to prevent sexual exploitation and assist street youth who have been, or are at risk of being sexually exploited. In September of 2008, the Act, whose name was changed to the Reconnecting Homeless Youth Act, was once again reauthorized. Changes to the new legislations, among other things, included extending the allowable stay of youth in BCPs to 21 days and in TLPs to 24 months (see Appendix $B$ for flowchart of Federal allocations for RHY services) (NAEH, n.d.b).

From the perspective of the federal government, these three programs are designed to work together as a continuum to assist RHY to transition back into the community. Ideally, a youth would access a BCP right after running away where services would facilitate the youth returning home and staying there. The alternate idea is that SOPs could engage youth who have become involved in the street culture to enter a BCP or TLP and then transition home or to independence in the community. Just as important to the government, is preventing these youth from participation in 


\section{RUNAWAY AND HOMELESS YOUTH}

delinquent behavior and ultimate involvement with the juvenile justice system and/or the child welfare system (ACF, 2008; Fairman-Cooper, 2006). While these programs have been the foundation for serving the RHY population over the past three decades, they are extremely underfunded, resulting in a system of care that can only serve approximately 45,000 youth annually (Fernandes, 2007; NAEH, n.d.a).

In 1987, when the McKinney-Vento Homeless Assistance Act was first written into law, it provided federal funding for shelter programs serving homeless adults (18 years of age and older) and families. Also included in this Act were targeted areas for education, which afforded those RHY under the age of 18, as well as those youth who are members of a homeless family, extra services to improve their likelihood of accessing public education (Jozefowicz-Simbeni \& Israel, 2006). Yet there are barriers that make accessing these services increasingly difficult for an unaccompanied homeless youth. For example, Jozefowicz-Simbeni and Israel (2006) found that, "difficulty indentifying homeless students, lack of awareness of the needs of homeless students and families, staff turnover, high staff to student ratios, and limited funding were primary barriers to implementing the act" (p. 40). The act did however, lay the foundation for changes in the 2003 reauthorization of the RHYA, which became the Runaway, Homeless, and Missing Children Protection Act (yet still referred to as the RHYA). The new RHYA sought to specify necessary services for runaway and homeless children through guaranteed access to services, specifically public education. 


\section{RUNAWAY AND HOMELESS YOUTH}

\section{Critique of policy and practice.}

Though Federal policy has targeted RHY through the RHYA and the McKinney-Vento Act, barriers still exist. With the McKinney-Vento Act, the homeless youth has to be enrolled in school in order to receive services. Contrary to the NAEH report, this alone prevents access to services for the vast majority of homeless youth. As for the RHYA, while establishing a continuum of services for RHY, it appears the implied assumption for the Basic Center Program (BCP) is that youth who return home are better off.

The BCP dictates a 14-day maximum stay for youth, consequently leaving service providers few options other than working to persuade youth to return home. This dynamic has the potential to take staff out of a "youth ally" role and into a role that aligns with solely with the parents and manipulates the youth into returning home, which has the potential for serious consequences. Although the policy also provides for aftercare services, the resource strains on programs rarely afford these services. Consequently, if youth who are accessing shelters are in fact first-time runners, compelling them to return home without the resources to support them could potentially result in another run away episode with the youth now reluctant to return to the shelter, making intervention more complicated and costly. Furthermore, this policy directly contradicts what research suggests, which is that, "fears [of]...being 


\section{RUNAWAY AND HOMELESS YOUTH}

returned home or to foster care prevent many [youth] from seeking services" (Slesnick et al., 2009, p. 2).

The limited information on the effects of racial disparities in the RHY system creates an even more troubling scenario. The data that does exist suggests that current service models are not as effective for youth of color. In the instance of running away from an out of home placement, youth of color are running away at higher rates and when youth of color do utilize runaway services, family reunification seems less likely.

\section{Intervention Studies}

Generally, the literature presents intervention studies in distinct categories based on the target sub-population of RHY: youth in shelters and street youth. Currently the chief resource for runaway shelter services are federal funds for community youth shelter programs (BCPs), whose stated goal is reuniting the youth with their families, when abuse is not an issue. While Basic Centers vary in service delivery from location to location, all are required to provide the following minimum services (ACF, 2008a):

1. 14 days of shelter ${ }^{4}$

\footnotetext{
${ }^{4}$ Increased to 21 days with 2008 reauthorization of the Runaway and Homeless Youth Act
} 


\section{RUNAWAY AND HOMELESS YOUTH}

2. Food, clothing, medical care, or other services that youth need, offered either directly or by referral

3. Individual, group, and family counseling

4. Recreation programs

5. Outreach targeting both youth who may need assistance and other public or private agencies that work with youth and families

6. Aftercare services for youth after they leave the shelter Studies on the effectiveness of interventions used in youth shelters are limited (Thompson, Pollio, Constantine, Reid, \& Nebbitt, 2002), and tend to evaluate the "shelter" as the intervention versus the services being provided in the shelter. For those studies that have been completed, positive outcomes for youth are often reported (see Appendix C, p. 228, for a table of RHY intervention studies) (Hurley, Ingram, Czyz, Juliano \& Wilson, 2006; Kidd, 2003; Peled, Spiro \& Dekel, 2005; Pollio, Thompson, Tobias, Reid \& Spitznagel, 2006; Slesnick \& Prestopnik, 2005; Teare, Peterson, Furst, Authier, Baker, \& Daly, 1994; Thompson, Pollio \& Bittner, 2000; Thompson, Pollio, Constantine, Reid \& Nebbitt, 2002).

While studies such as these suggest that RHY achieve some positive outcomes if they enter a community shelter, the outcomes tend to focus on measuring youths' change in behaviors. For example, decline in critical incidents in shelter (Hurley et al., 2006), improved coping strategies (Kidd, 2003), decreases in substance use (Slesnick 


\section{RUNAWAY AND HOMELESS YOUTH}

\& Prestopnik, 2005), and reduced sexual activity (Thompson, Pollio \& Bittner, 2000). However, these effects appear to be short-lived (Pollio et al., 2006) with no measurable difference between improvements of RHY and a control group (Thompson et al., 2002). Moreover, there are many unanswered questions. What were the assumptions of change (theories)? What exactly did these programs do with the youth while they were in the shelter's care (process)? Additionally, if positive outcomes are achievable from shelter programs, getting youth to access these programs is problematic and efforts to engage youth into services need to be prioritized (Garrett et al, 2008).

The only intervention found with a detailed theoretical foundation was that of Baer, Peterson and Wells (2004). Developed from the Transtheoretical Model (TTM), the authors designed a substance use intervention for homeless youth. TTM proposes that behavior change is a process that included six stages; precontemplation, contemplation, preparation, action, maintenance, and termination, and that individuals must progress through each stage for sustained change to occur (Prochaska, DiClemente \& Norcross, 1992).

- Precontemplation is the stage at which there is no intention to change behavior in the foreseeable future. Many individuals in this stage are unaware or underaware of their problems. 


\section{RUNAWAY AND HOMELESS YOUTH}

- Contemplation is the stage in which people are aware that a problem exists and are seriously thinking about overcoming it but have not yet made a commitment to take action.

- Preparation is a stage that combines intention and behavioral criteria.

Individuals in this stage are intending to take action in the next month and have unsuccessfully taken action in the past year.

- Action is the stage in which individuals modify their behavior, experiences, or environment in order to overcome their problems. Action involves the most overt behavioral changes and requires considerable commitment of time and energy.

- Maintenance is the stage in which people work to prevent relapse and consolidate the gains attained during action (p. $1103-1104)$.

A specific intervention designed to assist individuals move through the stages of change is Motivational Interviewing (MI). MI is, "a collaborative, person-centered form of guiding to elicit and strengthen motivation for change" (Motivational Interviewing, 2011, $3^{\text {rd }}$ para). The principles of MI are; express empathy, support selfefficacy, roll with resistance, and develop discrepancies between goals and behaviors.

MI techniques have been coupled with Brief Intervention strategies (a single session) to develop a widely recognized treatment model for substance abuse. Baer, Peterson and Wells (2004) apply this treatment model to homeless youth and evaluate 


\section{RUNAWAY AND HOMELESS YOUTH}

the outcomes. Key to their rationale for applying this model is their understanding of how homeless youth rarely seek out social services, based upon previous negative interactions with service providers. In their discussion of the challenges to service delivery, they determine that "a model of addiction and treatment based on adult clientele, coupled with homeless adolescents' life on the streets, makes treatment entry unlikely" (p 320). The authors feel MI, with its client-centered approach, is well suited for engaging homeless youth who are distrustful of service providers. Furthermore, they suggest providing MI in brief sessions can be seen, "as the first step in a series of progressively more intensive interventions" (p 322).

Sample criteria included:

- Homeless youth age 13-19

- Had "drank heavily" once in the past 30 days

- Had used a substance once per week over the past 30 days

- Had not been in any treatment program in the past 30 days.

Youth were randomly assigned to the treatment group or control group.

Subsequently, data collection occurred at baseline, one month, and three months and consisted of "self-reported stages of change" (p 327).

This study's first attempt at demonstrating the effectiveness of their approach provided mixed results. Taking feedback from the therapists who delivered the treatment, the authors have since modified the intervention to reduce initial assessment 


\section{RUNAWAY AND HOMELESS YOUTH}

time, providing more than one intervention, i.e. meeting more than once to facilitate development of the therapeutic alliance and condensing the time of the meeting a youth spends with the clinician. While evaluation is still underway, preliminary results are promising at showing a reduction in rates of substance use (Baer, Peterson \& Wells, 2004).

While homelessness is not a new social problem, intervention strategies seem to have changed little over the years, especially those based on Federal policy. Because current interventions are often, if not always, contingent upon some type of behavior change tied to continued participation in the program, programs effectively become a means of social control, do little to alleviate, much less resolve, the underlying causes of RHY, and worse, could be exacerbating this social problem (Gil, 1998; Trattner, 1999).

The chief critique of the intervention studies is the limited information about specifics of program services. Whereas some of the studies provided some level of detail around the specific intervention, there is no discussion of potential moderating variables, of which a shelter environment and life on the streets provide in abundance.

Furthermore, program interventions focused on the behavioral changes that RHY "need" to make, so they will be "able" to return home or other safe housing are contradictive of core social work principles of Person in Environment (Rogers, 2010) and the Strengths Perspective (Saleebey, 2009). While current practice with RHY may 


\section{RUNAWAY AND HOMELESS YOUTH}

work for a small number of unique sub-populations, it is far from the "rule". Although the literature presents no clear picture on the specifics of programs or effectiveness of services for RHY, what it does seem to indicate is that by coercing youth into goals that conflict with the youths' preferences and self-interest, adhering to state and federal policies that disempower youth, and creating housing programs with rigid rules and inflexible staff, they actually create more barriers for youth transitioning off the streets than they remove (Garrett et al., 2008).

\section{Service utilization.}

Research shows that getting homeless street youth into services continues to be a challenging endeavor (Garrett et al., 2008; ORHWG, 2005). A League of Women Voters' (2006) report examined RHY demographics, service delivery, barriers to services, and youth needs using multiple interviews with runaway and homeless youth throughout the state of Oregon through public forums held in 2005. These forums identified the kinds of service approaches that work well for RHY as (a) voluntary participation in programs, (b) non-judgmental services, (c) friendly, trusting professionals, and (d) consistent rules and structure (p. 17).

Conversely, the report also listed findings of the specific service approaches youth would reject, which included (a) living with rigid rules, (b) living with a homeless adult, (c) preaching and condescending approaches, (d) scare tactics, and (e) 


\section{RUNAWAY AND HOMELESS YOUTH}

having treatment forced on them (p. 17). Additionally, the most common statements made by youth in these focus groups centered on the importance of having one relationship with an adult role model for the provision of advocacy, mentoring, and guidance.

As stated earlier, as important as it is to develop effective programs and services to intervene with RHY, understanding how to eliminate barriers to services is perhaps even more significant. In a study by Raleigh-DuRoff (2004), ten previously homeless youth ${ }^{5}$ were interviewed to: (a) identify the common factors that help homeless youths to make the transition off the street, (b) determine if hope was part of the process, and (c) identify reasons why some youths remain on the street (p. 564).

Summarized findings from a content analysis of these interviews indicated participants identified both internal and external factors necessary to assist youth transition off the streets. From the findings, the author described ways to assist youth develop internal factors:

1. Identify ways they can feel connected with a supportive group,

2. Help them set small, daily, achievable goals to enhance their self-esteem,

3. Celebrate each small success,

\footnotetext{
${ }^{5}$ Youth were 13-18 years old when homelessness first occurred, 17-23 years old when they transitioned off the streets, and had spent at least 6 months on the streets as an adolescent.
} 


\section{RUNAWAY AND HOMELESS YOUTH}

4. Help them identify their passions and interests,

5. Give them an opportunity to talk about their dreams. (p. 571).

In regards to external factors, the author stated that, "There were at least one adult and one organization that helped each of the participants leave the streets" (RaleighDuRoff, 2004, p. 571).

This study provided insight into practices that may prove to be effective assisting RHY leaving the streets. It suggested there are two domains in which service providers would need to address engagement: those internal to the youth (e.g., sense of community, goal achievement, successes, interests, and a vision for the future) and those external to the youth (e.g. support and opportunities to succeed).

While these findings could prove to be useful for service development, there are several limitations. The author lists the small sample and cautions generalizing the findings because of this. Additional limitations include the sampling recruitment method, "flyers were posted in youth shelters and in a newspaper advertisement" (Raleigh-DuRoff, 2004, p. 563). This method excludes any formerly homeless youth who no longer maintain active contact with shelters or read the newspaper. An additional limitation, because this was a qualitative study, was there was no mention of steps taken to assist with trustworthiness of the findings.

In a more rigorous study, Garrett and colleagues (2008) sought, "the perspectives of young homeless people about factors that serve as facilitators and 


\section{RUNAWAY AND HOMELESS YOUTH}

barriers to service use as well as their perspectives on how homeless young people transition off the streets" (p. 437). Purposive sampling methods were employed to recruit 27 participants across a continuum of service involvement. This included street youth who were not accessing services (unconnected), youth who were currently accessing services (connected), and youth who had utilized services and were now no longer homeless (formerly homeless).

Participants were interviewed about five subject areas:

1. Meeting basic needs

2. Opinions about services

3. Deciding where to stay at night

4. Deciding whether to leave or remain on the streets

5. Perceptions of faith-based agencies. (Garrett et al., p. 437).

Transcribed interviews were analyzed using Atlas.ti software through consensual qualitative research methods, which consisted of, "using a consensus process within and then across cases to generate themes that represent the sample" (Garrett et al., p. 438).

In regards to RHY services, key findings included characteristics of staff attributes/relationships, safety and health, structural barriers, and independence/selfreliance. Positive attributes of staff were described as, “open, accepting, and caring [and] were especially noted as helping young people engage in services" (Garrett et 


\section{RUNAWAY AND HOMELESS YOUTH}

al., p. 438). Additionally, youth stated that more important than the specific service being provided were staff who offered useful help and respected youths' autonomy. Additionally, as prior research and practice experience indicates, "staff whom young people perceive as judgmental or as having ulterior motives for helping them may prevent them from accessing services" (Garrett et al., p. 438).

On the theme of safety and health, youth indicated the need for programs, especially shelters, "to truly provide for and protect the safety of the people, their health, and their belongings" (Garrett et al., p. 438). The inability of programs to provide this would directly impact youths' willingness to engage in the services. Structural barriers were also mentioned by participants as hindering service utilization. Specifically listed were, "location, waiting lists, operating hours, maximum capacity, and age restrictions" (Garrett et al., p. 438). The authors also stated that youth were keenly aware of the differences between the youth serving system and services for homeless adults and, "expressed trepidation about receiving services alongside homeless adults in a setting in which they felt more vulnerable" (Garrett et al., p. 439). Restrictions around program rules and regulations were also mentioned as inhibiting service utilization. Interrelated with this was the importance participants placed on the value of independence/self-reliance. Skills required to survive on the streets provided youth with a sense of pride and garnered respect from others. Youth felt they would have to give this up in order to access services and, just as anyone 


\section{RUNAWAY AND HOMELESS YOUTH}

would resist giving up something that provides a sense of worth, youth were reluctant to do so.

Study limitations listed by the authors were that connected youth were recruited from only one agency; formerly homeless youth made up a disproportionately small part of sample size and had all utilized a program to transition off the streets; low numbers of youth of color; and failure to specifically recruit GLBT youth. One additional key limitation listed was that this study failed to detect, "what services are most effective in the transition to stable housing" (p. 443).

Studies that evaluate the effectiveness of interventions with RHY are limited. Those that are present in the literature have severe methodological limitations (e.g., lack of control group) and are theoretically misaligned (e.g., focus on reducing behaviors associated with pathology). Yet, concerning service utilization, there are exceptions. Two studies suggest that program policies and staff behaviors could be creating barriers for youth (Garrett et al., 2008; LWV, 2006), while a third detailed specific practices that also could improve utilization rates (Raleigh-DuRoff, 2004). Implicit in these findings is the premise that perhaps intervention studies should focus on programs and staff as key variables. 


\section{RUNAWAY AND HOMELESS YOUTH}

\section{Theories Associated with RHY}

Why do youth run away from home? Is it a delinquent response to reasonable societal requests? Is it a sensible decision in response to abuse, neglect or other maltreatment by a caregiver or a "normal" response to an unsupportive environment? Or do a chain of negative developmental interactions, beginning while the youth is still in her/his mother's womb, converge leaving RHY with too few prosocial opportunities? Though no one theory can provide an explanation all for all runaway behavior, an examination of relevant theoretical frameworks will assist in shedding some light on these complex questions.

\section{Current explanatory theories.}

Since RHY have historically been seen as delinquent in our society, early attempts at developing theory as to why youth would run away from home tended to focus on the youth and why they were behaving antisocially. This paradigm resulted in theories that focused on the criminal behavior of youth and were inadequate for explaining why youth were running away from home. In their study of homeless youth, Schweitzer, Hier \& Terry (1994) stated, "Early psychological and sociological theorists tended erroneously to equate homelessness of young people with delinquency, thus the terms homeless, runaway, and delinquent were often used interchangeably" (para. 4). 


\section{RUNAWAY AND HOMELESS YOUTH}

Orten \& Soll (1980) hypothesized there are three distinct types of runaway youth which "focus[es] on the degree of alienation between home and child and how much the child has internalized running as response to stressful situations" (p. 253). First-degree runners are identified as youth who are running away from some condition, event, or situation, i.e. abuse, family conflict, parental substance use, etc. These youth tend to remain emotionally connected to their families, even while on the run, and readily return home. Second-degree runners are described as youth who have previously run away and are running away from and to some circumstance. These repeat runaway youth tend to be more emotionally disconnected from their families and are less enthusiastic about returning to them. Because they have run away before, they have a sense of where they are running to and feel it is more acceptable than their current situation. Finally, third-degree runners are depicted as youth who are only running to something. These youth are mostly older adolescents who have connected to the street culture and have no desire to engage with social services or return home, i.e. homeless/street youth (Miller, 1990; Orten \& Soll, 1980).

Additionally, categories have been developed to differentiate why youth run away from home in the first place. Barth (1986) listed three distinct motives of youth running away from home. The first is running from family conflict due to a new family stressor, i.e. a new stepparent, wage-earner job loss, divorce, etc. The second group runs from a strict authoritarian parenting style, where at least one parent is 


\section{RUNAWAY AND HOMELESS YOUTH}

excessively overbearing and there is continuous family conflict. The third group runs from abuse, both physical and/or sexual in nature. If one thinks of Orten and Soll's hypothesis as a continuum of running away, then Barth's hypothesis sheds some light on the beginning of that continuum, i.e. the first-degree runner, and may be helpful in the design of runaway prevention work.

The families of runaway youth are commonly characterized in the literature by, “conflict, disorganization, neglect and rejection” (Crespi \& Sabatelli, 1993, p. 7; Haber \& Toro, 2004). In their report on research findings and interventions with RHY, Toro, Dworsky and Fowler (2007) stated that family conflict was consistently identified by youth as the primary reason they run from home. They go on to describe the most common conflicts as, “step-parent relationships, sexual activity, pregnancy, sexual orientation, school problems, and alcohol or drug use" (p. 6), as well as physical and sexual abuse, and neglect. The Congressional Research Services, in a report to Congress, reported that many of these youth are fleeing from abusive homes have been abandoned or "thrown out" by their caregivers, or are searching for a life outside of the institutional and foster care systems (Fernandes, 2007). Table 6 reflects the intensity and variation of family violence. 


\section{RUNAWAY AND HOMELESS YOUTH}

Table 6

Abuse by an Adult Caretaker Prior to Running Away

\begin{tabular}{lcccc}
\hline & \multicolumn{4}{c}{$\begin{array}{c}\text { Percentage of Total Cases } \\
\text { (N=974) }\end{array}$} \\
\cline { 2 - 5 } Variable & Once & Few Times & $\begin{array}{c}\text { Many } \\
\text { Times }\end{array}$ & Ever \\
\hline Threw Something & 11.4 & 29.6 & 22.0 & 62.9 \\
Pushed & 10.1 & 27.2 & 39.4 & 76.7 \\
Slapped & 11.9 & 25.9 & 31.4 & 69.2 \\
Hit with an object & 7.6 & 19.5 & 35.7 & 62.8 \\
Beaten up & 10.1 & 11.4 & 14.1 & 35.5 \\
Threatened with a weapon & 11.7 & 7.0 & 4.4 & 23.1 \\
Wounded with a weapon & 4.4 & 1.7 & 0.8 & 7.0 \\
Asked to have sex & 5.5 & 5.9 & 6.5 & 17.9 \\
Forced to have sex & 5.9 & 6.3 & 7.0 & 19.1 \\
\hline Note. Adapted from "Deviant Behavior and Victimization among Homeless and Runaway \\
Adolescents," by L. Whitbeck et al., 2001, Journal of Interpersonal Violence, 16 (11), p. \\
1187.
\end{tabular}

Although most who work with RHY disagree, for many years explanations of runaway and homeless youth behavior were directly linked with delinquency research. Cohen's Strain Theory (1955) depicted delinquent youth (which included RHY) as lashing out in dissatisfaction with the dominant class structure. Because they (delinquents) failed to achieve social status, in large part due to education failures which then lead to low-skilled, low-paying work, they attempted to obtain status by illicit means (Cohen, 1955; Livesey, n.d.). Matza's (1964) Drift Theory portrayed delinquent youth as "drifting" into antisocial behaviors. Matza theorized that youth gradually drift into criminal behaviors over time when feelings of desperation, i.e. feeling a loss of control over one's life, are present (Florida State University, n.d.). 


\section{RUNAWAY AND HOMELESS YOUTH}

Crespi and Sabatelli (1993) suggested Conflict Theory describes why youth run away from families. The authors described how, "the developmental needs of children for intimacy, nurturance, and guidance are in conflict with the parents" (p. 7), which results in the running away.

Still another delinquent-focused theory is Empey's Control Theory (1982), which described RHY as lacking internal controls that would allow them to cope with their environment. Even the Diagnostic and Statistical Manual of Mental Disorders, second edition (DSM-II) contained "runaway reaction" as a mental health diagnosis (Schweitzer et al., 1994) and the most current edition, the DSM-IV, lists one of the diagnostic criteria for Conduct Disorder as, "Has run away from home overnight at least twice while living in a parental or parental surrogate home (or once without returning for a lengthy period)" (American Psychiatric Association, 2000, p. 99).

These theories not only helped create but continue to perpetuate the myth that RHY are delinquents or mentally ill. They also fail to fully explain why a youth would want to run away from home, only take in environmental factors through the lens of youth subjugation, and most have been invalidated empirically (Schweitzer et al., 1994). 


\section{RUNAWAY AND HOMELESS YOUTH}

\section{Risk amplification model (RAM).}

Whitbeck and colleagues (2001) build upon the work of Elder (1998) and Bandura (1973) and apply their theoretical formulations for understanding to RHY in what has become known as the Risk Amplification Model (RAM) (Haber \& Toro, 2004; USDHHS, 2007).

In his work titled Life Course as Developmental Model, Glen Elder Jr. (1998) drew upon the work he had been involved with since the 1930s to describe a model of development that hinged on, "the notion that changing lives alter developmental trajectories". The four main principles to Elder's theory were (Elder, 1998);

1. Historical time and place: "the life course of individuals is embedded in and shaped by the historical times and places they experience over their life-time"

2. Timing in lives: "the developmental impact of a succession of life transitions or events is contingent on when they occur in a person's life"

3. Linked lives: "lives are lived interdependently, and social and historical influences are expressed through this network of shared relationships"

4. Human agency: "Individuals construct their own life course through the choices and actions they take within the opportunities and constraints of history and social circumstances" (p. 3-4). 


\section{RUNAWAY AND HOMELESS YOUTH}

Elder had seen firsthand the varying impacts of the Depression - a major stressor for families resulting in harsher treatment of children by their fathers. Elder posited this had a profound effect on children and their ability to transition into adulthood and lead "successful" lives. He noted that the age of children when they experienced the Depression directly affected their ability to transition at other key points in their lives (Elder, 1998). Elder's model provides a framework to understand how environmental factors impact child development and subsequently adult transitions and can be applied to the experiences of RHY.

In his defense of social learning theory Bandura (1973) states, "it is evident from informal observation that human behavior is to a large extent socially transmitted, either deliberately or inadvertently, through the behavioral examples provided by influential models" (p. 68). Modeling behavior, according to Bandura, has the ability to generate three types of effects on those observing: acquisition of new behaviors; already learned yet inhibited behaviors are moderated; and modeling behavior can, "serve as social prompts that facilitate similar behavior in observers" (p. 69). Additionally, the influence of modeling is dependent upon subprocesses: the observer must attach value to the behavior being observed; the model's behavior must be retained by the observer; there must be skill development of the modeled behavior by the observer; and there must be a level of motivation development through reinforcements of the behavior, e.g. incentives. As such, learned behaviors can be 


\section{RUNAWAY AND HOMELESS YOUTH}

either prosocial or antisocial, depending on the modeling behavior being observed in combination with the subprocesses described above.

Whitbeck and colleges (2001) build upon the work of Elder and Bandura by adding a key concept, which is the idea that stressors "pile up" or have a collective effect, i.e. cumulative disadvantage. Cumulative disadvantage, or the Risk Amplification Model (RAM), explains that a "disadvantage" experienced at an early age (timing in life) will build upon those later in childhood and adolescence (historical time and place) until ultimately there are few viable options (human agency) left for the youth to engage in society (linked lives). In addition, difficult children elicit inconsistent, often aggressive/coercive parenting. These children are socialized to be aggressive (social learning theory), and these aggressive interactions lead to academic troubles and rejection by conventional peers. Negative chains of events are put into motion that gain momentum across time and become more and more difficult to alter. School failure reduces options, as do alcohol/drug use, early arrest, and early assertion of adult status. As the consequences of negative behaviors accumulate, prosocial options diminish (Whitbeck et al, 2001).

A principle concept of RAM is that there are four institutions of social control; family, school, peers, and the state. As cumulative disadvantages begin to affect a child, the child reacts antisocially, i.e. delinquent behavior. As the child acts in a delinquent manner, the family reacts in a repressive manner attempting to modify the 


\section{RUNAWAY AND HOMELESS YOUTH}

behavior. This begins to socialize the child toward aggression (social learning theory) which then results in more delinquent behavior by the child. This cycle continues "incrementally over time to produce [negative] developmental effects" (Sampson \& Laub, 1997, p. 144; USDHHS, 2007).

As the child ages and begins to encounter other social institutions, i.e. school and peers, the child's delinquent behavior elicits repressive responses from them as well. The cumulative consequences for deviant behavior result in, "negative chains of events [that] develop momentum over time and become[s] progressively more difficult to alter" (Whitbeck et al., 2001, p. 1176). As the child transitions to adolescence s/he experiences the need to obtain autonomy and adult status. Because the youth has developed patterns of antisocial behavior, s/he expresses the need for independence in delinquent ways since prosocial options have diminished or have been completely eliminated, "every curfew violated, car stolen, drug taken, and baby conceived is a statement that one has left childhood behind" (Moffitt, 1997, p. 31; Whitbeck et al. 2001). This may result in the youth encountering the final institution of social control - the state. According to Whitbeck and colleagues (2001), running away from home is an attempt by youth to gain independence not only from parents, but also from all forms of social control. However, with few prosocial options available, runaways find themselves in an environment rife with "deviant peers (potential victimizers) and high- 


\section{RUNAWAY AND HOMELESS YOUTH}

risk interactions involving violence (mugging, robberies) or a very high risk of violence (drug dealing, survival sex)" (Whitbeck et al., 2001, p. 1178).

Youth who encounter the juvenile justice system at an early age, coupled with the effects of cumulative disadvantage, find it difficult to escape this pattern of deviant behavior. This too, has a circular effect. As their delinquent behaviors increase, the repressive responses from the state are amplified which lead to increased maladaptive behaviors (Moffitt, 1997; Sampson \& Laub, 1997; Whitbeck et al., 2001).

A significant disadvantage experienced by youth is child maltreatment and more specifically child abuse. Youth who experience abuse are more likely to run away (first-degree runners) and participate in deviant behaviors - both disadvantages (USDHHS, 2007; Whitbeck et al., 2001). Once a youth begins to acclimate to the streets (second-degree runner), disadvantages accumulate, resulting in increasingly repressive responses from social institutions and decreased prosocial options leading to increasing deviant behavior of the youth. If the youth is returned home, the cycle continues and accelerates, resulting in youth who become chronic runaways (thirddegree runners), leaving social institutions with few options other than confinement or total exclusion by conventional society. 


\section{RUNAWAY AND HOMELESS YOUTH}

\section{Ecological-developmental perspective.}

In his work on the ecology of the family, Bronfenbrenner (1986) asks the question, "How are intrafamilial processes affected by extrafamilial conditions" (p. 723)? He addresses that question by describing three environmental systems that can affect the parent-child relationship. The mesosystem, (systems in which the child interacts, e.g. daycare, school, etc.), the exosystem (systems in which the parent interacts and which affect the child indirectly, e.g. work, social networks, etc.), and the chronosystem, (developmental changes of the individual which can be, "normative [school entry, puberty, entering the labor force, marriage, retirement] and nonnormative [death or severe illness in the family, divorce, moving, winning the sweepstakes]" (p. 724). The ecological perspective recognizes the need for change at the micro, mezzo, and macro levels of social policy for the eradication of homelessness among all populations, i.e. adult, family and adolescent (Bronfenbrenner, 1979; 1986).

The ecological-developmental perspective, as described by Haber \& Toro (2004) starts from the premise that homelessness, "results from inadequate resources" (p. 145). It also, "recognizes the importance of the family system in mediating the resource losses that result or manifest as homelessness" (p. 145). Haber and Toro go on to discuss how the ecological-developmental perspective counters the current 


\section{RUNAWAY AND HOMELESS YOUTH}

pejorative terms to identify adolescents who are homeless, i.e. runaway, which suggests behavioral problems with the youth and thrownaway, which assigns fault with the parent(s) or other caregiver. The ecological-developmental perspective suggests there are environmental/system issues that are exacerbating the issue. Bronfenbrenner's (1979) writings support this supposition as he wrote of his frustration with the field of science continuing to focus on, "the properties of the person and only the most rudimentary conception and characterization of the environment in which the person is found" (p. 16).

The ecological-developmental perspective provides a strengths-based alternative to how one views a homeless situation. According to Haber and Toro (2004), this view begins with the premise that, "homelessness is a manifestation of a lack of resources, because a stable home is certainly a critical resource in itself" ( $p$. 145 ) and that the family unit is critical in the process of managing those resources. With homeless youth, a loss of resources resulting in family stress may increase family conflict - a predictor of youth homelessness. Moreover, a youth who intermittently leaves home and returns may in fact be providing a respite for the family preventing the complete dissolution of the unit. Concurrently, a family that requests services from a RHY shelter for their youth may see that as a safer environment than the one they are currently housed in with the youth (Haber and Toro, 2004). 


\section{RUNAWAY AND HOMELESS YOUTH}

The ecological-developmental view suggests that running away by the youth or throwing away by the parent are not maladaptive behaviors but normal responses to environmental stimuli, such as a breakdown in the child-parent relationship brought on by strain in resources, i.e. economic difficulties, job loss, loss of social supports, etc. In defending this perspective of homelessness, Haber and Toro (2004) cite several studies which have concluded that, "the extent of personal, social, and/or service resources available (e.g., subsidized housing), rather than the degree of pathology, is the best predictor of successful long-term adaptation among people who are homeless" (p. 148).

The ecological-developmental perspective, because of its "more comprehensive understanding of homelessness among adolescents" (Haber \& Toro, 2004, p. 147), alters the focus of intervention from the individual to the community. Instead of focusing on substance abuse, mental health, and other individual pathology this perspective suggests that interventions should be focused on the community, state, and national realm with its shrinking availability of affordable housing units, widening gap in income distribution, limited educational options and job training, and lack of policies that support healthy family functioning and the subsequent healthy development of youth. 


\section{RUNAWAY AND HOMELESS YOUTH}

\section{Life cycle model of youth homelessness.}

To understand what happens to homeless youth once they leave home, Auerswald and Eyre (2002) developed what they called the life cycle model of youth homelessness. Interviewing homeless youth in the San Francisco area to determine why so few youth accessed social services, authors identified seven stages of homelessness that encompass the model: mainstream, the first on the street, initiation, stasis, disequilibrium, extrication, and recidivism (USDHHS, 2007).

In the mainstream stage, youth reported they had little choice but to run away and head to the streets. As discussed earlier, most youth described a significant event with their family that immediately preceded them leaving home, "such as a parental arrest or death, or being thrown out of the house" (Auerswald \& Eyre, 2002, p. 1501). In the first on the street stage youth struggled with fulfilling two basic types of needs: loneliness and physical needs such as food and shelter. Auerswald and Eyre note that during this stage, youth will either return home out of fear or embrace the street culture and continue to the next stage of the model. Initiation stage describes the youth's, "acculturation to street life, its resources and economy, language and drugs" (Auerswald and Eyre, 2007, p. 1502). Also during this stage, youth will connect to "street mentors" (social learning theory) who will assist in their initiation to the street culture (Auerswald and Eyre, 2007; USDHHS, 2007). In the stasis stage, youth now 


\section{RUNAWAY AND HOMELESS YOUTH}

feel a sense of community and become highly suspicious of individuals and institutions - namely social service agencies - that are not part of their homeless world. The disequilibrium stage denotes homeless youth becoming aware of the difficulties living on the streets, victimization, exposure to the elements, and encounters with the criminal justice system, which result in youth reflecting on their choice to live on the streets. Depending on these experiences, youth may remove themselves from street life in the extraction stage, remain on the street, or, in the recidivism stage, "experience cycles of returning to mainstream life followed by running back to the streets" (USDHHS, 2007, p. 28).

In addition to the theoretical work such as RAM, the ecological-developmental perspective, and life-cycle model much of the research conducted over the past 10 years has attempted to develop predictors of why youth run away. An example of one such study was reported by McRee (2008). In a sample of 40,000 youth who had received services from RHY community shelters, McRee found that youth who had a non-related parent (step-parent/adopted parent) living in the household were 21.5 percent more likely to have been sexually abused and 18.8 percent more likely to have been physically abused than youth with two biological parents, one natural/one adult relative, or one biological parent only. 


\section{RUNAWAY AND HOMELESS YOUTH}

\section{The dominant discourse.}

The prominence of the delinquent youth discourse arose in the 1950s when it appeared that youth from the middle-class were increasingly engaging in acts considered delinquent, "Delinquency had spread to the suburbs" (Glassman, Karno, \& Erdem, 2010, p. 799). This fear became even more prominent in the 1960s as the mainstream media began negatively reporting on the hippie movement (Staller, 2006). Coupled with the development of social theories that attempted to explain delinquency (e.g. Strain Theory [Cohen, 1955]), it should not be surprising that runaway youth legislation is housed within the Juvenile Justice and Delinquency Prevention Act. This is not without its consequences on definitions, funding and services (Glassman, Karno, \& Erdem, 2010), and on how RHY see themselves and understand their relationship to communities (Snow, 2008).

Moreover, this discourse has led to increasingly harsh treatment of young people as, "youth are now demonized by the popular media and derided by politicians looking for quick-fix solutions to crime" (Giroux, p. 554). For example, studying the proliferation of school resource officer programs in schools, Theriot (2009) discusses how normal adolescent behaviors are becoming increasingly criminalized. The author reports substantial higher arrest rates in economically disadvantaged schools for disorderly conduct, which, he adds, "is the most subjective, situational, and 


\section{RUNAWAY AND HOMELESS YOUTH}

circumstantial of the charges studied" (p. 285). One of the most negatively impactful outcomes of the dominant discourse that directly affect homeless youth is their inability to sign contacts for housing. Glassman and Karno (2009) argue that, “denying a minor the right to contract...is not based on lack of social capital, cultural capital, or material capital, but is a complete repudiation of the youth based on fear" (p. 458). Understanding the dominant discourse and how it influences RHY policy, programming, and practices is essential to developing RHY services that work.

\section{Challenges and limitations of explanatory theories.}

While Barth (1986) and Miller (1990) provide the most current research on RHY typology, by focusing on the term "runner" the implication is that they are only referring to those youth under the age of 18. Additionally, the literature is missing the answers to key questions about this population, questions such as how many youth are associated with each of the types of homelessness? Is there a predominant group that makes up the overall RHY population? Certainly, much more work needs to be done in this area to fully understand the complexities of this population.

For a large number of runaways, the Risk Amplification Model (Whitbeck et al, 2001) provides an explanation of the antecedents of running away and how they build and accumulate over time. Yet it fails to explain all cases of running away. For the many youth who experience significant disadvantages (i.e. parental conflict, parental 


\section{RUNAWAY AND HOMELESS YOUTH}

substance use, physical/sexual abuse, etc.) and have not engaged in deviant behaviors, have remained actively enrolled in school, and have developed a positive peer support groups - this theory falls short of providing an adequate explanation as to why they do not run away. For the ecological-developmental perspective (Haber \& Toro, 2004) as intuitive as it may appear, the lack of research support limits its usefulness. Yet this seems to the only theory that addresses the repressive systems' issues.

The Life Cycle Model of Youth Homelessness (Auerswald and Eyre, 2002) provides a guide to critical points where RHY interventions could be focused to have the greatest impact. However, much more work is needed on this model. The authors state limitations of small sample size, lack of youth from local areas, and limited female participation that would require replication of this study. However, while these theories attempt to explain how youth get in to this situation, as, if not more, important is how we help youth get out of homelessness.

Especially troubling is the seemingly lack of motivation to look at the issue of RHY through a racial hypothesis such as critical race theory. Delgado \& Stefancic (2001) describe critical race theory (CRT) as having four basic tenets: 1) racism is embedded in the fabric of our society, 2) because it benefits both white elites and the working class, though for different reasons, motivation to eliminate it is difficult to garner, 3) race is a social construction, and 4) people of color have their own "unique voice... and may be able to communicate to their white counterparts matters that the 


\section{RUNAWAY AND HOMELESS YOUTH}

whites are unlikely to know" (p. 9). The absence of this awareness has undoubtedly led to lack of understanding of the various issues affecting homeless youth of color and disparities in RHY service systems.

\section{Intervention theories}

\section{Positive youth development perspective.}

At the $38^{\text {th }}$ Southwestern Psychological Association Conference, Moses and Kopplin (1992) stated;

Two primary reasons explain why programs for adolescent runaways have failed and each is embedded historically in American Culture. The first is that strict discipline and reform have been seen throughout history as the most appropriate manner by which to control youth. The second is the myth of the traditional American family as a supportive and enhancing environment for the growth of adolescents into mature adults (p. Abst).

They go on to say that even programs whose staff feel they are providing unconventional programs designed to create an environment where youth feel comfortable are unable to escape this mindset so deeply ingrained in the American psyche. The positive youth development (PYD) perspective runs counter to these ideals and begins to change the way RHY are seen as individuals and worked with. 


\section{RUNAWAY AND HOMELESS YOUTH}

The PYD perspective promotes the idea that to adequately prepare RHY for transition into adulthood "remediating and preventing negative behaviors is not enough" (USDHHS, 2007, p. 21). This perspective focuses on facilitating the promotion of protective factors that foster resiliency. Studies in resiliency demonstrated that those youth who are able to overcome disadvantages such as those described in RAM, "possess strong social skills, pleasing personalities, strong intellects, and possess a sense of independence and purpose" (USDHHS, 2007, p. 21). Moreover, they demonstrated the importance of caring and supportive relationships with, "adults who encourage them to aim high and [provide] opportunities to contribute through participation in meaningful activities" (USDHHS, 2007, p. 21).

The premise of PYD is that if youth are provided with healthy supports, they will develop in a healthy manner, make prosocial choices for themselves, and, "grow into healthy, happy, self-sufficient adults" (ACF, 2008b, para. 1). ACF (2008b), the agency that provides oversight to federally funded RHY programs, promotes PYD as a critical component of all funded services. They also acknowledge that PYD can take many forms such as:

1. Recruiting young people to volunteer for local grassroots organizations

2. Showing youth how to start their own newspapers or Web sites

3. Asking high school students to co-teach classes with their teachers 


\section{RUNAWAY AND HOMELESS YOUTH}

4. Teaching young people to conduct surveys on community and school resources

5. Encouraging local businesses to sponsor job fairs and job shadowing days

6. Inviting youth to serve on the board of a local nonprofit organization

7. Creating a youth board that advises State or local government on issues young people care about such as violence prevention, transportation, and after-school activities (Positive Youth Development Takes Many Forms section, para. 2).

As can be seen from the above list, PYD is about getting youth meaningfully involved in significant activities to promote self-worth because, according to Scales, Benson, and Mannes (2006), "involvement must come before attachment” (p. 402). This suggests that before a youth can acquire a sense of belonging at home, school, or in the community, or especially in the RHY program that is serving them, the youth must feel a sense of involvement and attachment to those social institutions. PYD is a marked departure from the deficiency models and practices and the delinquency theories of the past. PYD not only acknowledges the potential of each RHY (strengths perspective), but it also recognizes how valuable they are to our communities.

\section{Challenges and limitations of intervention theories.}

PYD is fast becoming the recognized model for working with RHY. Yet challenges abound. This model is probably more of a perspective than a set of applied 


\section{RUNAWAY AND HOMELESS YOUTH}

skills and therefore it tends to be interpreted in different ways, relying on local service providers to determine what constitutes a caring and supportive relationship with an adult. In addition, because of the age variances of RHY, providers who serve the spectrum of RHY from 11 to 21 years old struggle to develop meaningful participation in ways that account for the variances in the developmental needs of youth. However, even with these challenges, PYD has been written into the 2008 reauthorization of the Runaway and Homeless Youth Act (now called the Reconnecting Youth Act).

\section{Summary of theories.}

Interventions necessary to resolve the systems issues that result in running away and homelessness (e.g. eradication of economic stress on families, the ample availability of affordable housing, universal health care, adequately funded schools, etc.) are the sort of comprehensive responses that in the current political and economic environment can not be expected. Therefore, one should not anticipate the resolution of this social problem in the foreseeable future. In the meanwhile, what steps need to be taken to minimize the risks youth are exposed to when they run away and/or become homeless?

While explanatory theories provide context and understanding to the issue of RHY, they lack research support. Concomitantly, studies of RHY programs and interventions are absent much theoretical foundation. Researchers must work to 


\section{RUNAWAY AND HOMELESS YOUTH}

resolve this discrepancy. The first step to aid in this would be to develop an agreed upon typology of RHY. Current typologies are too focused on runaways, leaving out other dimensions such as thrownaway youth, youth who run from or age out of foster care, those released from juvenile detention, and all homeless youth aged 18 and over. Both theory and interventions need to be tailored to meet the needs of specific populations that make up RHY. For example, the theory and subsequent intervention for the 15 year old male who is running away for the first time from family conflict brought on by economic stress due to the primary wage earner losing their job, will be vastly different than the theory and intervention required for a 19 year old female homeless youth who has been surviving by means of prostitution for over a year.

Consequently, if preventing the root causes of runaway behavior is unlikely in the foreseeable future, the field of social work needs to focus its efforts on 1) developing new, and/or improving existing interventions that prevent the runaway youth from engaging in the street culture, and 2) for those youth who do engage with the street culture or otherwise experience longer term homelessness, intervening more effectively to assist them with transitioning off the streets.

\section{Summary of Literature Review}

Research shows that getting homeless street youth into services continues to be a challenging endeavor (Garrett et al., 2008; ORHWG, 2005). To assist with this, 


\section{RUNAWAY AND HOMELESS YOUTH}

research must determine what practices and policy changes are required that will afford better engagement of these youth and help transition them off the streets. The treatment philosophy of Motivational Interviewing described earlier seems to align with those characteristics youth in the Oregon focus groups requested of services (LWV, 2006). It seems intuitive that the same challenges posed to engagement of homeless youth in substance abuse treatment are similar, if not identical, to the challenges with engaging them in other interventions and in leaving the streets altogether. Consequently, it would appear the theory, model and strategy described by Baer, Peterson and Wells (2004) could be applied by street outreach workers who are attempting to develop therapeutic relationships with RHY living on the streets. Therefore, interventions applying MI techniques should be developed and evaluated.

Finally, a key challenge in this area is that the dynamics among policy, practice, research, and theory are dysfunctional. Currently, federal policy dictates practice, hoping research will "prove" its effectiveness, completely leaving the youth voice out of the discussion. To successfully create programs that engage and work for RHY, this relationship needs to be fundamentally modified. First, Federal research policy needs to support research to better understand RHY, particularly research that is conducted inclusive of youth, which would then inform both RHY policy and practice development. 


\section{RUNAWAY AND HOMELESS YOUTH}

\section{Research Questions and Hypotheses}

The purpose of this project is to improve RHY programs by partnering with youth being served in these programs. Service providers, advocates, and policy makers have developed programs and services they feel will meet the need of runaway and homeless youth. However, the literature is clear on underutilization of community services by RHY (Garrett et al., 2008; Slesnick et al. 2009). While notably difficult to substantiate, estimates of service utilization among this population range from barely 30 percent (Slesnick et al. 2009) to as low as eight percent (ORHWG, 2005). This dynamic exacerbates an already perilous situation for youth who find themselves in this situation. The best-evidenced services will have little effect on this social problem if youth reject them. The critical missing element is the youth voice. Therefore, the research question for this project is twofold; 1) according to youth, what are programs doing right in regards to services being provided to RHY and, 2) what can be learned by employing youth analysts in research? 


\section{RUNAWAY AND HOMELESS YOUTH}

\section{Chapter 3: Methods}

\section{Methodological Theory}

One chief distinction that helps to clarify one's philosophy of science is that of basic vs. applied research. Basic research is driven to discover knowledge that will help people understand how the world works. The objective of applied research, "is to provide information for solving an existing problem" [italics added] (Singleton \& Straits, 2005, p. 409). This contrast in purpose, understanding vs. solving, has major implications for RHY and other populations for whom merely understanding the social problem is not enough; solutions are urgently required (Singleton \& Straits, 2005).

However, a propensity for applied science should not result in a disregard of systematic scientific processes. Bad science results when ethics become blurred or contradictory to the study's outcome, "the need for ethical problem solving is particularly heightened when the researcher is dealing with highly political and controversial social problems" (Bickman \& Rog, 1998, p. xvi). Therefore, it is essential that while researchers have to be creative, and at times take risks, in performing applied research, they must also be diligent and use caution, understanding how their biases and desires to facilitate change may influence results.

It is from the basis of applied research that action research was developed. Also referred to as community-based action research (CBAR) or participatory action research (PAR), action research originated in the work of scientific philosophers such as Michael 


\section{RUNAWAY AND HOMELESS YOUTH}

Foucault, Stanley Fish, Paulo Freire, Andreas Huyssen, and Cornel West (McIntyre, 2008; Stringer, 2007). The postmodern ideas fashioned by these theorists have resulted in a shift from social science conducted in the halls of academic institutions to one that, "learns from experiences in community, organization[s], and family settings" (Stringer, 2007, p. 203). Action research, and more specifically PAR, provides an overarching approach from which researchers can construct methodology. McIntyre (2008) lists the tenets of PAR as:

A collective commitment to investigate an issue or problem, a desire to engage in self-and collective reflection to gain clarity about the issue under investigation, joint decision to engage in individual and/or collective action that leads to a useful solution that benefits the people involved, and the building of alliances between researchers and participants in planning, implementation, and dissemination of the research process (p. 1).

Citing the author Jonathan Kozol and his experiences collaborating with communities in New York City to develop literacy programs, Kamberelis and Dimitriadis (2008) add: There is a tremendous difference between knocking on a door to tell somebody of a program that has been devised already and which they are given the choice, at most, to join or else ignore - and, on the other hand, to ask them to assist in the creation of that plan (p. 381).

To attain the threshold of PAR, Stringer (2007) proposes the following criteria for research: 


\section{RUNAWAY AND HOMELESS YOUTH}

- It is democratic, enabling the participation of all people,

- It is equitable, acknowledges people's equality of worth,

- It is liberating, providing freedom from oppressive, debilitating conditions, and,

- It is life enhancing, enabling the expression of people's full human potential. (p. $11)$.

Reflecting on five years of applying PAR research methods with families,

Turnbull, Friesen, and Ramirez (1998) suggest additional advantages can be realized when employing PAR. For example, because PAR includes participants in problem identification, projects become much more significant and meaningful, which increases likelihood of community utilization of the findings. Moreover, with participants involved in developing measurement tools, implementation processes, sampling strategies, data analysis, etc., projects will likely experience improved viability resulting in fewer quandaries as well as enhanced rigor of the overall project.

Implementing these methods specifically with youth, Freeman and Mathison (2009) list the five beliefs one must have to enter into youth-led research:

1. Youth have abilities that can be tapped in developing and implementing a research project.

2. Youth bring to a research project a unique perspective or voice that cannot but help the process of answering questions about youth.

3. Youth are vital stakeholders in the process and outcome of research. 


\section{RUNAWAY AND HOMELESS YOUTH}

4. The knowledge and skills youth acquire through active participation in research can transfer to other aspects of their lives.

5. Youth-led research can help broaden and revitalize an activity that has a reputation as being boring, inconsequential, and of interest to only a small select group of adults. (p. 171).

A challenge to youth-led research is that society in the United States has

historically devalued youth and prevented their full participation in their environment. Velazquez and Grain-Jones (2003) emphasize this view when they note;

There is a portrait of youth that is not only misleading, but harmful. We ought to correct the record out of a sense of fairness, as well as accuracy. These young people desperately need a chance to get started in responsible careers. Instead, they are frequently saddled with the image of being uninterested and unwilling to assume responsibility. Complaining about youth is all too common (Adultism and cultural competence section, para. 1)

The authors go on to list three key mistakes adults make when working with youth: 1) adults feel youth are incapable, 2) adults disregard the environmental impact of challenges encountered by youth, and 3) adults avoid interacting with youth culture. Respectively, these lead to missed opportunities for youth accomplishments, blaming the youth for challenges they meet, and creating discomfort in youth when with adults.

Together, these mistakes continue a cycle of youth oppression and have severe consequences when working with RHY, and even more so when working with RHY of 


\section{RUNAWAY AND HOMELESS YOUTH}

color or LGBT. Seita and Brendtro (2003) reported that the benefits of a respectful collaboration with youth versus an adversarial one has been known for hundreds of years.

Traditionally, social science has not been immune from instigating oppression either. Stringer (2007) points out that the very way knowledge is constructed, and who controls it, is responsible for perpetuating power over groups of people. He specifically lists researchers as culpable for this when he states, "within these communities, individuals or groups in position of authority control what they consider to be valid knowledge" (p. 199).

For this project, RHY were not included in the steps leading up to and including gathering data. The research team members who developed the project all had extensive backgrounds working with this population, yet that is specifically a violation of the PAR principle of inclusion. Representatives are not an acceptable replacement for youth who are impacted by these services (McIntyre, 2008; Stringer, 2007). However, this should not prevent the project from including youth in the analysis and interpretation of findings.

In what Stringer (2007) refers to as a key principle of PAR, full participation in the design of services by those who receive the service is critical to the development of effective programs and services. He states, “As practitioners in many fields now realize, unless people come to understand procedures and practices by participating in their development, any program or service is likely to have limited effects on their lives" (p 33). One outcome of this is that youth continue to reject services and be exposed to the risks of homelessness. Therefore, to restore equity and work toward real program 


\section{RUNAWAY AND HOMELESS YOUTH}

improvement, this project employed homeless youth to conduct the analysis of the research data.

Finally, this method places the youth in the role of being responsible for the content. By performing the analysis, youth are accountable for the findings. With these methods, the youth are able to speak directly to the program leaders and policy-makers, which is appropriate so they can express their needs to those in these positions of power. The researcher is merely the catalyst, providing structure, for writing up the findings, and responsible for making this a healthy and safe process for the youth. The researcher essentially becomes a tool at the disposal of the youth.

\section{Insuring Full Participation}

An essential principle of PAR is that of participation. McIntyre (2008) describes the fundamental distinctiveness between PAR and other types of research as the difference between involvement and participation. She expands on this idea further by emphasizing the importance of, "the quality of the participation that people engage in, not the proportionality of that participation" (p. 15). Additionally, the level of participation directly affects a participant's willingness to engage with the project. The opportunity to accomplish tasks that feel important is critical to effective participation. In this respect, the role of the researcher becomes one of meeting people where they are at, ensuring that tasks are appropriate for the individual, and supporting participants in accomplishing tasks (Stringer, 2007). 


\section{RUNAWAY AND HOMELESS YOUTH}

Intimately linked to the quality of participation is the level of participation. A major premise underlying PAR is that participants are involved in every aspect of the project: identification of the problem, data gathering plan, development of questions, sampling requirements, etc. Yet simply participating in a set of tasks is not adequate for "full participation", youth must be given the power to shape the projects in significant ways. Arnstein (1969) developed the Ladder of Citizen Participation to help assess the quality of participation. Hart (2008) builds upon her work and develops a similar concept specific to youth participation. Hart's Ladder of Young People's Participation (see Figure 1 below) helps those working with youth determine if youth are really partners or merely tokens. Represented as rungs on a ladder, the author lists eight levels of youth participation, noting the first three rungs do not reflect participation: 


\section{RUNAWAY AND HOMELESS YOUTH}

Figure 1.

\section{Roger Hart's Ladder of Young People's Participation}

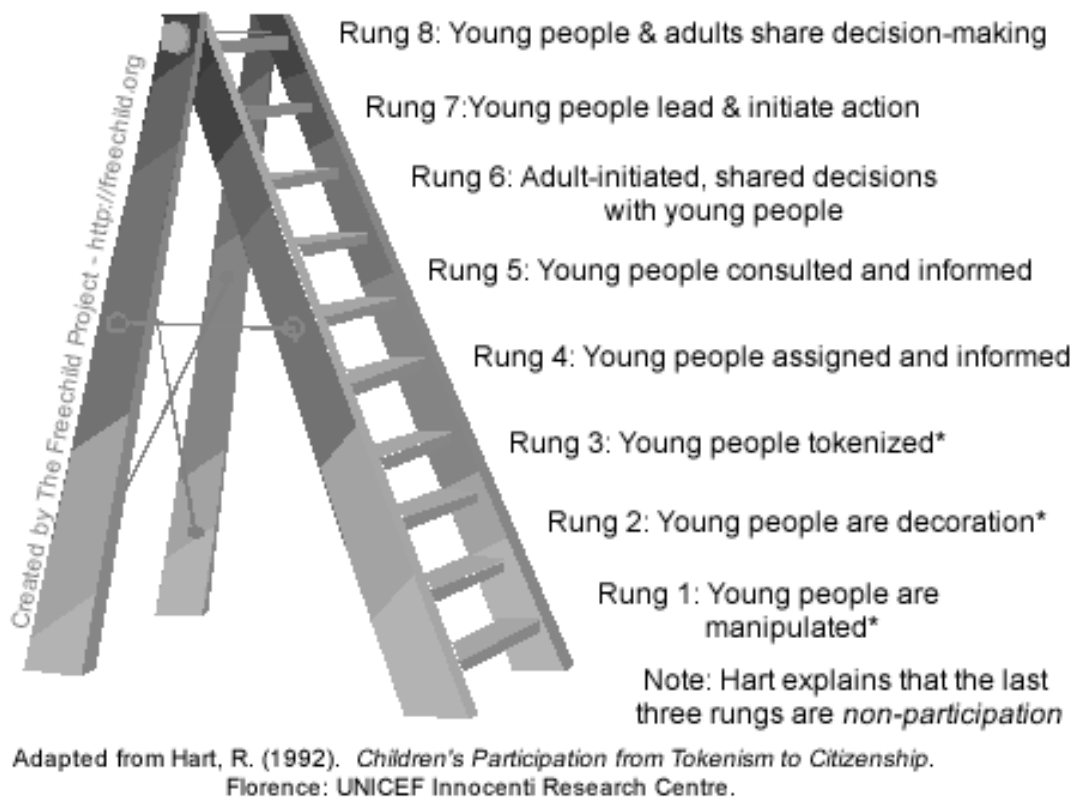

Because research has traditionally dismissed the youth outside of the role of being observed, caution must be taken so that one does not this process to "merely train kids to formulate themselves and their problems in out terms to answer out questions" (Stringer, 2007, p. 170). Real power sharing can be difficult for those holding positions of power, however, "participation without redistribution of power is an empty and frustrating process for the powerless... [and] maintains the status quo" (Arnstein, 1969, p. 216).

\section{Role of Researcher}

According to Stringer (2007), one conducts action research by facilitating the interactions with the participants in key spheres. Therefore, particular attention must be 


\section{RUNAWAY AND HOMELESS YOUTH}

made to the role of the researcher, relationships with the participants, how communication occurs between the researcher and participants, the quality of participation by participants, and the nature of inclusion, i.e. "Maximization of the involvement of all relevant individuals" (p. 35).

The role of the researcher in action research must be guided by the principles of power sharing. The researcher no longer takes the role as expert but that of a resource for participants and, "Titles such facilitator, associate, and consultant are more appropriate in community-based action research than director, chief, or head"' (Stringer, 2007, p. 2425). Understanding that youth, in this case, are the experts and the researcher's role is to utilize the knowledge and training they have acquired to assist youth in producing a product they feel will help resolve what they see as the issues facing RHY.

On the issue of how one develops relationships in action research, careful consideration of, "equality, harmony, acceptance, cooperation, and sensitivity" (Stringer, 2007, p. 28) must be adhered to. Utilizing social work skills for working with groups will provide a foundation for this to be carried out. To aid in the proper development of relationships with participants, Stringer (2007) lists the following as effective communication in action research:

1. Listens attentively to people

2. Accepts and acts on what they say

3. Can be understood by everyone

4. Is truthful and sincere 


\section{RUNAWAY AND HOMELESS YOUTH}

5. Acts in socially and culturally appropriate ways

6. Regularly advises other about what is happening (p. 30).

Drawing upon extensive social work field experience with a multitude and diversity of groups supported this project realizing this level of communication.

One key departure from the PAR principle of full participation is that this work was conducted as a requirement for a dissertation. Therefore, the youth's decisionmaking power is limited in that they are not be able to prevent that document from going forward. This limitation in authority was explained to the youth at the beginning of the project, affording them the opportunity to opt out of the project.

\section{Data Source}

Data for this study were collected under the Communities Empowering Youth (CEY) project, which was approved by the Human Subjects Review Board of Portland State University (HSRRC Proposal \# 07389). The CEY project developed from research on Oregon's homeless and runaway youth conducted for House Bill $2202^{6}$ (2005). The goal of this study was to gather data that would enable runaway and homeless youth agencies and their community partners throughout Oregon develop community based capacity building and sustainability models, permitting the state to responsibly address the needs of runaway and homeless youth. The role of this researcher was to manage the

\footnotetext{
${ }^{6}$ House Bill 2202 authorized the Oregon Commission on Children and Families to be the state agency responsible for planning and coordination of RHY services.
} 


\section{RUNAWAY AND HOMELESS YOUTH}

project in the field, which included recruiting agencies and facilitating focus groups. In 2008, this project conducted 14 focus groups at seven federally funded RHY service

providers in Oregon. During the focus groups, youth were asked five questions related to program design and program philosophy. Specific questions asked were;

Program Design

1. Think about everything (PROGRAM) does. What do you get out of being involved here?

2. How does the program give you that?

3. Who is this program ideal for?

4. How would someone from the outside know this program works?

\section{Program Philosophy}

5. Think about why (PROGRAM) does what it does. Why do you think they do it the way they do it?

These questions were written out on flip chart paper and displayed for all to read. Focus groups lasted less than an hour, were recorded, and then later transcribed thus providing qualitative data for this project.

\section{CEY focus group participants.}

Participants in the focus groups were youth who were being served by a federally funded RHY service provider in Oregon. At the time of this project, there were 10 such 


\section{RUNAWAY AND HOMELESS YOUTH}

agencies in Oregon that received federal funding to support one - three federal RHY programs. The three federal RHY programs include;

1. Basic Center Programs: provide outreach, short-term shelter, and counseling to runaway and homeless youth under the age of 18 . The programs attempt to reconcile youth and their families or if needed make arrangements to assist with their safety (ACF, 2008a).

2. Transitional Living Programs: assists homeless youth ages 16 through 21 with up to 18 months of shelter and skill development as part of a comprehensive program to help in the transition to independent living (ACF, 2008c).

3. Street Outreach Programs: work with runaway and homeless youth 21 years of age and younger, providing information and services to prevent sexual exploitation of youth living on the street. This service may also be delivered via a Drop-in Center, considered a stationary outreach (ACF, 2008d).

Participants as young as 14 years old were allowed to provide their own consent to participate in focus groups. In an attempt to provide an extra level of precaution to insure confidentiality and anonymity for these younger participants, the project did not gather socio-demographic data. The only information available on the sample is the program in which the focus group occurred, the type of program, the number of youth in each focus group, and the city in which the program operates. 


\section{RUNAWAY AND HOMELESS YOUTH}

\section{Sampling for focus groups.}

Because this project was exploratory in nature with one of its chief goals to ascertain how youth interpreted services in regards to program design and service delivery philosophy, and because obtaining a random sample of RHY in Oregon was not feasible, nonprobability purposive sampling methods were used to recruit youth for focus groups. Although considered a weak sampling strategy in most quantitative study methods, convenience sampling provided this project with several advantages. The first is related to the goal of the focus group to learn about which components of programming have the most impact on RHY success. Because there was little information in the literature on this topic from the youth perspective, the project was designed to gain, “insights and in-depth understanding rather than empirical generalizations" (Patton, 2002, p. 230). Therefore, this method of sampling proved to be appropriate (Patton, 2002; Rubin \& Babbie, 2001).

Individual agencies facilitated recruitment of participants through purposive sampling methods. Youth were screened and recruited for participation in focus groups related to the programs from which they received services using the following protocol;

Basic Center Programs: For these programs, RHY ages $14-17$ years old were eligible for recruitment and afforded the ability to provide their own consent. This decision was based on Oregon Statute that allows youth ages 14 years and older to receive outpatient mental health and substance abuse treatment services without parental consent (Ore. Rev. Statute ch. 109, § 675, 2007). Furthermore, because youth may have 


\section{RUNAWAY AND HOMELESS YOUTH}

run away from home to escape abuse or neglect, it was determined that notification of their parents could potentially increase the risks of this project for the youth. Therefore, youth were afforded the right to provide their own consent to participate in this project.

Transitional Living Programs: For these programs, RHY ages 16 - 21 years old were eligible for recruitment and youth ages 16-17 were afforded the ability to provide their own consent. Again, this decision was based on Oregon Statute allowing youth ages 14 years and older to receive outpatient mental health and substance abuse treatment services without parental consent (Ore. Rev. Statute ch. 109, § 675, 2007). Additionally, Oregon Statute recognizes youth to be emancipated in certain circumstances if they have not been under the care of their parents for a period of 90 days or more (Ore. Rev. Statute ch. $109, \S 675,2007)$. Furthermore, many of these youth are not able to return home and have little, if any, contact with their parents. It was therefore determined that notification of the parents of youth under the age of 18 could potentially increase the risks of this project for the youth. Therefore, youth who were 16-17 years old were afforded the right to provide their own consent to participate in this project.

Street Outreach Programs: For these programs, all RHY ages 14 and older participating in a street outreach program were eligible for recruitment. Again, because youth living on the streets rarely have contact with their parents, it was determined that notification of the parents of youth under the age of 18 , even if it were possible, could potentially increase the risks of this project for the youth. Also, and as stated above, the decision was based on Oregon Statute that allows youth ages 14 years and older to 


\section{RUNAWAY AND HOMELESS YOUTH}

receive outpatient mental health and substance abuse treatment services without parental consent. Furthermore, Oregon Statute recognizes youth to be emancipated in certain circumstances if they have not been under the care of their parents for a period of 90 days or more (Ore. Rev. Statute ch. 109, $§ 675,2007)$. Therefore, any youth under the age of 18 were afforded the right to provide their own consent to participate in this project.

Program staff, who work with RHY on a daily basis, possess the professional expertise to determine the appropriateness of a youth to participate in a focus group. Consequently, program staff identified youth who demonstrated a level of maturity necessary for participation in a focus group of this type. Program staff explained the project and then invited identified youth to attend a pre-meeting of the focus group held prior to the focus group itself. Research team members who facilitated the focus groups met with the youth and their program staff to review expectations and the protocol. This pre-meeting served as a final screening by researchers to insure participant maturity and appropriateness for the focus group, answer any participant questions, and obtain a signed copy of the informed consent. Additionally, youth who participated in the focus group received a $\$ 25$ gift card to a local merchant.

\section{Recruitment of Youth Advisory Group}

With regards to the PAR principle of inclusion, Stringer (2007) conveys the need to involve as many affected individuals from as many affected groups as possible. Additionally, purposive sampling methods were employed to facilitate building a 


\section{RUNAWAY AND HOMELESS YOUTH}

research team of members with varying backgrounds and experiences aligned with the varying backgrounds and experiences of the runaway and homeless youth who served as the focus of this research. For this project, five youth, age 18 and older, who were currently participating or have participated in a Transitional Living Program (TLP) or Drop-in Center were recruited and paid \$15 per hour for membership in a Youth Advisory Group (YAG). Because youth participating in this type of program could possibly have personal histories that could potentially increase risk to them if they participated, agencies that work with RHY on a daily basis were asked to assist with recruitment. To support them with this process, they were provided with a Project Overview that introduced the project; described requirements for youth participation, plans for youth data analysis, and the researcher's analysis; and discussed plans for the focus group that would occur at the end of the project, and dissemination of the findings (see Appendix D, Project Overview).

Agency staff were instructed to include youth who may not be "doing well" in the program and to make efforts to recruit youth who reflect the diversity often found in the RHY population. Subsequently, program staff provided the researcher's contact information, youth contacted the researcher, and a meeting with each youth was scheduled. At that meeting, the researcher discussed the following:

- Informed consent and confidentiality

- The purpose of the project

- How the project came to be

- Stakeholders and partnerships 


\section{RUNAWAY AND HOMELESS YOUTH}

- How the agencies were chosen

- Focus group process

- How the youth for the focus groups were chosen

- How the questions were derived

- The plan for analysis

- The youth role in analysis

- The researcher's role

- Expectations around participation

- Payment

- The researcher's needs for publication.

The researcher also offered to answer youth questions.

During this meeting, youth received and reviewed, the Project Overview and the researcher asked a series of questions to insure they met the criteria for inclusion in the project; i.e., age, gender, sexual orientation, race and ethnicity, and their experience with homelessness (see Appendix E, Interview Checklist and Questions). Additionally, each youth was asked to read a one-page transcript and then discuss its content with the researcher to insure they met minimum literary requirements (see Appendix F, Transcript Example). This meeting also served as a final risk screening by the researcher to insure appropriateness for YAG participation. At the close of the meeting, if they expressed their wish to participate, the informed consent document was reviewed and signed. The informed consent afforded participants the ability to waive confidentiality in the event of publication of findings, presentation at a conference, or other forms of dissemination. Youth were told they could wait until the end of the project to sign the waiver section to 


\section{RUNAWAY AND HOMELESS YOUTH}

insure they were comfortable with the outcome of the project. At the conclusion of this

meeting, the youth were informed that the second meeting would be scheduled once all YAG members were recruited.

Meetings with prospective youth occurred over the course of two weeks and were scheduled at times and locations that were convenient for the youth. Two meetings occurred in office of the researcher, two others in a local coffee shop, and a third was completed by phone. This last one did not allow for a test reading of the transcript but because the youth was currently enrolled in high school, this requirement was waived. For those youth who were recruited early in the process, text messaging was used to stay connected and keep them updated on the progress of the project. When all the youth had been hired, a second meeting with all members was scheduled.

Of the five members recruited, the following socio-demographic information was gathered. Two participants were female and three male with two ages 18; one was 20, and the remaining two were 23 . Three participants were Caucasian, one was Native American, and one was multi-racial including African American, Caucasian, and Hispanic. One member was bi-sexual, with the remaining members identifying as heterosexual. Three of the members were currently participating in a Drop-in Center program, one in a TLP, and one was living independently in the community after receiving services from a TLP. 


\section{RUNAWAY AND HOMELESS YOUTH}

\section{YAG orientation and training meetings.}

The agenda for the first YAG meeting included introductions, a team building activity, a review of the project, an opportunity to withdraw from the project, and setting a time for the subsequent meeting (see Appendix G, Meeting \#1 Agenda). Additionally, YAG members were provided with supplies necessary to carry out their work, i.e. bags, binders to carry documents, highlighters, pens, post-it notes, etc.

A similar agenda was followed for the second meeting with a focus on instructions around content analysis and strategies to manage bias (see Appendix $\mathrm{H}$, Meeting \#2 Agenda). The last portion of this meeting was spent having the youth practice coding on sample transcripts. Additionally, to help youth remain informed between meetings, a short take-home document was provided that included key information about the project: the project to date, informed consent, and research bias (see Appendix I, Take-Home Document). Furthermore, youth were reminded about the role of the researcher and how that will affect analysis and dissemination needs. As advised by McIntyre (2008), this was repeated throughout the project.

These first two meetings were also used to insure the tenets and principles of PAR (McIntyre, 2008; Stringer, 2007) were being employed: engaging the youth in dialogue, establishing power sharing, getting to know participants, determining appropriate strategies to facilitate an empowering experience for participants, etc. At the end of the second meeting, youth were provided with the focus group transcripts for Question \#1 to take with them for individual analysis and a subsequent meeting was scheduled. 


\section{RUNAWAY AND HOMELESS YOUTH}

\section{YAG analysis meetings.}

YAG meetings were audio recorded to keep track of key decision points and areas of agreement and disagreement with respect to the analysis. Tapes were then transcribed for recordkeeping and assistance with organizing responses. Chart paper was hung throughout the meeting room to track responses and keep them visible to everyone as a reference throughout the discussion.

YAG members utilized content analysis to examine focus group transcripts. Although content analysis can be used as a tool to turn qualitative data into quantitative data (Rubin \& Babbie, 2001), Berg (2007) describes content analysis as the, "careful, detailed, systematic examination and interpretation of a particular body of material in an effort to identify patterns, themes, biases, and meaning” (p. 303-304). More to the point, Patton (2002) depicts content analysis as, "analyzing the core content...to determine what's significant" (p. 463).

There were two phases to content analysis, the descriptive phase and the interpretive phase. Descriptive analysis organizes the data into some manageable order that will assist the analytic processes that will occur during the interpretive phase such as, “an index for a book or labels for a file system" (Patton, 2002, p. 463). Miles and Huberman (1994), similar to Patton (2002), suggest developing some level of preliminary codes prior to beginning analyses of the data.

Upon completion of the descriptive phase, the interpretive phase of analysis began. It is in this phase where, "meanings are extracted..., comparisons are made, 


\section{RUNAWAY AND HOMELESS YOUTH}

creative frameworks for interpretation are constructed, conclusions are drawn, significance is determined, and, in some cases, theory is generated" (Patton, 2002, p. 465). Berg (2007) describes concepts as "symbolic or abstract elements representing objects, properties or features of objects, processes, or phenomenon" (p. 20). An example of this would be the concept of independence. To Americans, this concept may include the idea of the Declaration of Independence and/or the $4^{\text {th }}$ of July celebrations, it could also have more personal meaning as in the idea of client self-determination, or for someone in prison it could have an altogether different meaning. Additionally, concepts have two components, they are symbolic and yet there is a specific definitional component as well. Using the example above as the symbolic component of independence, it also has a specific definition separate from its symbolism. Yet as Miles and Huberman (1994) point out, "it is not the words themselves but their meaning that matters" (p. 56). This project hypothesized that by having youth who have similar experiences to those in the focus group interpret these meanings, a level of insight and understanding will be obtained that the researcher would have missed.

\section{Descriptive phase.}

For this study, this researcher performed the descriptive phase of the analysis was the only one with access to the complete focus group transcripts. Focus group transcripts were organized by question then by the type of program where the focus group occurred; e.g. basic center, street outreach, etc., and then by each specific agency. To insure 


\section{RUNAWAY AND HOMELESS YOUTH}

confidentiality, the researcher assigned identification numbers to each agency and blacked out names of programs, staff and/or youth. Additionally, any information that could potentially allow the reader to identify the program's location such as well-known landmark was also blacked out. At the end of each meeting, the researcher collected the selected portions for documentation. Transcripts are archived in a locked file and will be kept on file for a maximum of three (3) years.

\section{Coding for concepts.}

YAG members were provided focus group transcripts one question at a time to analyze individually and code for concepts. The analysts would then take those transcripts with them, analyze them, and then bring them back to the next meeting ready to present, and then discuss, what they had coded as significant. The first document they received was 53 pages in length and may have been a slightly overwhelming. It had initially been thought that YAG members would only need a day or two to analyze each question, but they felt they would need at least a week to properly review. Combined with the needs of individual schedules, the next meeting was scheduled nine days later. At that meeting, YAG members presented their findings first individually and then discussed those findings to determine consensus.

\section{Consensus and emergent findings.}

To this point, the goal of the analysis was to determine key concepts from individual analysis. Now, youth came back together and presented what they found to the 


\section{RUNAWAY AND HOMELESS YOUTH}

group and then, as a group, discussed the meaning of those findings. Similar to

Consensual Qualitative Research methods (Garrett, et al., 2008), YAG members used the "consensus process within a team of analysts to systematically examine patterns within and then across cases to generate themes that represent the sample" (p. 438). Miles and Huberman (1994) describe pattern coding as a way of distilling down the previous categories into "themes and constructs" (p. 69). During the process of coding, analysis involves a number of activities:

Attaching significance to what was found, making sense of findings, offering explanations, drawing conclusions, extrapolating lessons, making inferences, considering meanings, and otherwise imposing order on an unruly but surely patterned world (Patton, 2002, p. 480).

Youth began by presenting what they had discovered individually. It was decided that each member would have five minutes to present their individual analysis. During this time, other members could ask clarifying questions but could not comment on a finding. While each researcher presented, this researcher wrote down the findings on chart paper for the entire group to see. If subsequent members also had found a previously mentioned finding in their analysis, they would simply make note of that and move on to a new finding not yet reported. Each member was then given the option of an additional two minutes to use after each member had presented. Rarely was the additional two minutes ever requested. 


\section{RUNAWAY AND HOMELESS YOUTH}

After all group members presented their findings, the researcher facilitated a discussion to identify meaning and major themes that emerged from the individual analyses. It was envisioned that responses would be recorded as consensus or emergent. Consensus findings would be those findings for which agreement from all members was achieved, while emergent findings would be those responses for which consensus could not be obtained, yet the youth felt very strongly about. This would allow for individual experiences, viewpoints, etc. to be included and validated. Yet this did not occur. The discussion between YAG members never developed into the domain of "this finding is important and that one is not;" it focused on understanding the meaning behind the findings. After completing the process with this first transcript, YAG members became much more confident in what was expected of them and how much time it would take to complete. At the end of this meeting, youth were provided transcripts for the next question and a subsequent meeting was scheduled.

This process continued until all the questions had been analyzed with one exception. After the second question as analyzed, it became evident that the project did not have the resources to analyze all five questions. In consultation with the YAG, it was decided to skip the analysis of the third question (who is this program ideal for?). After the final analysis was completed, an additional meeting was scheduled that was more iterative in nature. Because the YAG received transcripts one question at a time, this final meeting was designed to review the themes that emerged over the course of the analysis and asked, "Now that you have read all the data, are there any changes or modifications 


\section{RUNAWAY AND HOMELESS YOUTH}

that should be made?" Responses were recorded as before. In all, there were four analysis meetings.

All but one of the YAG meetings were held on the campus of a local university. The room in which the meetings were held was in a newer, contemporary building and could easily accommodate $10-12$ individuals. Rectangular in shape, the room contained furnishings that were also new and included a large rectangular table in the center of the room, comfortable chairs, a large white board, and adequate wall space for hanging chart paper. Two walls of the room were constructed of glass that afforded views to any activity outside the room. At times the ability to see outside was a distraction yet it gave one the impression that the room was larger than it actually was and prevented the feeling of being confined. Because meetings were generally held during a mealtime, food was provided for each of them. This was most often pizza, but for the last meeting, feedback from the group indicated they were ready for something different. As a result, for the last meeting we met at a local deli, everyone ordered what they wanted, and then we walked back to the meeting room to eat and work.

Throughout the process of these meetings, YAG members were extremely conscientious about attendance. If they were going to be late or were having trouble with transportation, they called far enough in advance that meetings were never impacted. One youth called to say he had missed the bus and would have to wait for the next one. Instead, he located another stop, caught that bus, and made it to the meeting a few minutes early. Another youth was in a town 20 miles south of the meeting location and 


\section{RUNAWAY AND HOMELESS YOUTH}

his/her planned ride fell through. Yet the youth had called early enough that the researcher was able to drive down, pick him/her up, and still make the meeting on time. These are just two examples of the importance YAG members placed on this work.

Upon conclusion of the analysis of the focus group transcripts, a focus group was conducted with the youth analysts. The goal of this focus group was to evaluate the participatory methods that had been employed; determine specific features that had worked well and seek ways in which the process could be improved. The focus group lasted slightly longer than one hour and all five team members participated. Participants were asked to think about the work of analyzing the transcripts and were then asked each of the following questions;

1. What worked well,

2. What could have been done better,

3. What have you learned from all this, and

4. What advice would you give another researcher who wanted to do collaborative research with young people?

\section{Trustworthiness}

There are several strategies one may take to establish trustworthiness in qualitative research. Padgett (1998) lists triangulation, member checking, and leaving an audit trail as specific steps researchers can take to improve trustworthiness. As promoted 


\section{RUNAWAY AND HOMELESS YOUTH}

by Lietz, Langer, \& Furman (2006) this project employed several strategies to increase trustworthiness.

The method of triangulation refers to obtaining data from as many diverse sources as possible so as to obtain information around a phenomenon from various perspectives (Stringer, 2007). The project from which this data was obtained, the CEY project, incorporated triangulation into its data collection strategy. Agencies across Oregon, located in urban cities, rural communities and suburban settings were sources of data collection. Furthermore, the programs at each agency, i.e. SOP, BCP, or TLP, vary greatly according to the RHY they serve by age, length of homelessness, length of program services and other typologies used to describe RHY. The breadth of participants' experiences (triangulation) helped improve trustworthiness and resulted in findings that should be more applicable and relevant to wider population of RHY.

Another primary method proposed to insure trustworthiness is to provide an audit trail available for examination by a third party, if necessary, to insure the soundness of the results. Because of the unique flexibility of qualitative methods, countless decisions are made throughout analysis and researchers will often find themselves needing "to make unique research decisions not previously prescribed" (Lietz et al, 2006). Keeping track of those decisions is critical to insuring trustworthiness of findings. Therefore, notes, transcripts, decision journals, coding files from software, and recordings from YAG meetings were collected throughout this project and maintained for auditing purposes (Miles \& Huberman, 1994; Patton, 2002). 


\section{RUNAWAY AND HOMELESS YOUTH}

Perhaps the most essential method we used to insure trustworthiness was similar to that of member checking. This strategy entailed presenting findings to research participants to insure analysis accurately reflected the experiences members wished to communicate (Padgett, 1998; Stringer, 2007). Because of the data collection strategy, focus groups with RHY, direct member checking was not possible. However, to aid the prevention of researcher bias, young adults, with shared experiences, were hired for participation in the Youth Advisory Group (YAG), and their role was similar to that of member checkers. Member checking occurred at periodic intervals throughout the analysis phases of this project to insure that interpretations of the transcripts were congruent with RHY experiences.

\section{Ethical Issues with YAG}

There were no physical risks posed to the participants in the YAG. The subject matter (what works well) of their participation is not in an arena of human experience that would be considered emotionally traumatic or place them in a vulnerable position. However, as a precautionary method, a plan was in place. TLPs, from which YAG members were recruited, by the agreement to accept federal funds, provide some level of mental health services to the RHY they serve. Therefore, these youth had access to trained crisis counselors 24 hours a day. If a youth felt pained, upset, frightened, angry, etc. from the YAG sessions, the program staff would notified and the youth would be afforded access to a crisis counselor. For youth recruited from the Drop-in Center, 


\section{RUNAWAY AND HOMELESS YOUTH}

community emergency services would be contacted. These services were never needed throughout this project.

An additional, yet limited, risk is that someone might say something politically sensitive (in terms of intra-agency politics) that the researcher would not notice and might put in a written report so that it might be traceable back to the respondent. To minimize this risk, YAG members were provided access to the written document of their findings for review and approval. 


\section{RUNAWAY AND HOMELESS YOUTH}

\section{Chapter 4: Results}

\section{CEY Focus Group Findings}

Analysis of the focus group transcripts produced an array of patterns and themes. These were subsequently organized into two main categories, which included features associated with 'programs' and 'staff'. Within these categories were found further sub codes, or pattern codes (Miles \& Huberman, 1994) which are discussed below. The net result was a model of what youth find helpful in programming across various dimensions.

\section{A note on terminology.}

Because Youth Advisory Group (YAG) members who conducted this research were individuals who have shared experiences with those youth in the focus groups, the thoughts, ideas, and impressions of YAG members are also included in this section. Therefore, for the purposes of clarity, this section is laid out in the following manner. A finding is reported, a supporting exemplar is provided from the focus group youth, and then a statement from a YAG member is presented to reflect the importance of that finding. For added clarity, to recognize the level of work they performed, and to acknowledge the significance of their contributions to this project, YAG members are identified as 'team member(s)' or 'analyst(s)'. Conversely, youth who participated in the focus groups are referred to as 'focus group youth' when discussed collectively or, when individual exemplars are used, by the program were the focus group was held; i.e. 'TLP 


\section{RUNAWAY AND HOMELESS YOUTH}

youth', 'Drop-in Center youth', 'Street Outreach youth', or 'Basic Center youth'.

Furthermore, individual exemplars that may have been confusing or awkward to the reader were edited with care to insure the speaker's intent was not lost.

\section{CEY focus group sample.}

A total of 14 focus groups were conducted including 52 youth. The sample of focus group youth was drawn from eight agencies with one or more of the federally funded RHY programs. The focus groups occurred in Basic Centers programs (3), Dropin Centers (3), Street outreach programs (2), and TLPs (6). The programs were located in a range of city populations; small $(>25,000)$, medium $(70,000-150,000)$, and various programs distributed throughout a large metropolitan region ( $>2.2$ million). Table 7 below provides an overview of the sample of focus group participants. 


\section{RUNAWAY AND HOMELESS YOUTH}

Table 7

Overview of Focus Group Sample

\begin{tabular}{lccccc}
\hline & $\begin{array}{c}\text { \# of Focus } \\
\text { Groups }\end{array}$ & $\mathrm{n}$ & $\begin{array}{c}\text { Large } \\
\text { Sized City }\end{array}$ & $\begin{array}{c}\text { Medium } \\
\text { Sized City }\end{array}$ & $\begin{array}{c}\text { Small } \\
\text { Sized City }\end{array}$ \\
\cline { 2 - 6 } Basic Center & 3 & 9 & 1 & 2 & \\
Drop-in Center & 3 & 14 & 1 & 1 & 1 \\
Street Outreach & 2 & 5 & 1 & 1 & \\
TLP & 6 & 24 & 4 & 2 & 1 \\
\hline Total & 14 & 52 & 7 & 6 & \\
\hline
\end{tabular}

\section{Program features}

Focus group youth referenced an array of services they found to be beneficial to youth and important for programs to provide. In analyzing across all comments related to 'program', two distinct subcategories emerged. These were 1) specific services that youth felt were most helpful (the "what"); and 2) program attributes, specific traits or characteristics of the program that support the provision of those services (the "how").

\section{Program services - "what" was offered.}

Program services include skill-building and mental health services that encompassed counseling, substance abuse treatment and family mediation. Program services also include a range of services customized to meet individual needs, connecting youth to community supports, and activities. 


\section{RUNAWAY AND HOMELESS YOUTH}

Skill-building. Focus group youth described the significance of the instruction they received in basic skills required for daily living such as cooking, cleaning and paying bills.

Yeah, I didn't even know how to cook when I moved out. I had to buy all these cookbooks and it was bad the first few meals I cooked. But then the staff went through this cooking unit, nutrition unit with me and showed me stuff I should be eating and better things to buy and how to look for good deals in the stores (TLP youth).

Team members felt it was an important distinction that more effective programs, "teach youth how to provide for themselves" (analyst).

For those youth who were ready and able to find employment, assisting them in obtaining jobs was another critical service depicted by focus group youth. "We come to a life skills building group and we do different things like money management and the program did mock interviews where they show us how to interview and we do things like that" (TLP youth). Additionally, focus group youth felt it was critical for programs to not only help them find employment, but to also help them acquire the skills necessary to become more employable. One example given was computer skills, which analysts felt was a skill more frequently being required for entry level positions and absolutely essential for higher paying employment. 


\section{RUNAWAY AND HOMELESS YOUTH}

With jobs now especially if you want a better job, a lot of times, at least in my experience, they ask if you know how to use a computer. Like McDonalds has computers, so I mean a lot of things are based on computer (analyst).

Focus group youth who were presently employed spoke of the importance of financial management skill building provided by programs. One group of focus group youth described a savings plan designed by the program they were participating in that required them to turn over 30 percent of their paycheck to the program. This money was then placed into a savings account and given back to the youth when s/he moved out. 'I've never ever saved money in my life and I think now I've got at least a couple hundred dollars in my savings account" (TLP youth).

Mental Health / Counseling / Mediation/ Substance Abuse Counseling. Focus group youth spoke a considerable amount about the importance of programs providing mental health and counseling services for youth and, if appropriate, their families. One youth in particular detailed how her mother would come to the program and together the two of them would receive family counseling. Analysts felt providing some level of counseling was a critical service for programs to offer specifically with families and in the words of one team member, "Because if it is a program where the youth go back to the same environment something in that environment really has to change or else the conflict is going to stay the same way." Similarly, family mediation was a specific service listed by some of the focus group youth. "Mediation is wonderful, we spend a 


\section{RUNAWAY AND HOMELESS YOUTH}

lot of time talking. The first time we had mediation it was two hours to get us to calm down and be together and okay" (Basic center youth).

Additionally, drug and alcohol treatment, specifically groups and group work, was a service commonly mentioned throughout the focus groups as being an important service to the youth. "I like the groups that they do here. I'm not doing drugs anymore, which is good" (street outreach youth).

$\underline{\text { Services customized to meet individual needs. Alongside providing services }}$ and skill-building activities, focus group youth talked more explicitly about the impact of programs providing for the individual-specific needs of youth. Youth provided an assortment of personal examples of how programs assisted with individual-specific needs. One youth recalled how she needed a cap and gown for a high school graduation ceremony and the program staff purchased it because they were aware she couldn't afford it. Another youth described how a program helped him/her access a membership to a local health club while another reported how, "they helped me with bus tokens. They helped me with paperwork, like the other day they helped me with my taxes" (Drop-in center youth). One team member added, "And like food and stuff programs don't actually personally get food for the youth, but they help them get food stamps and other stuff like that. They go out of their way so things are covered for the youth." 


\section{RUNAWAY AND HOMELESS YOUTH}

Focus group youth described how some programs provided direct financial assistance. Sometimes these inducements were provided as rewards while other times they were provided as a regular allowance. At times money was used as the incentive and at other times non-cash items such as gas cards were provided. Moreover, as an incentive, some programs assisted with the purchase of specific health foods or the reimbursement of school supplies. "Yeah, so if you have a gym membership you can use it on that. Or healthy food like fruits or vegetables and stuff like that the program reimburses you on things like that (TLP youth). Team members felt these types of incentives were effective tools providing youth with, "something to look forward to" (analyst).

Focus group youth also indicated there is no "right way" or "one size fits all" type of service; supports must be tailored to the individual need. For some youth, navigating bureaucracies to obtain benefits such as Medicaid and/or food stamps might be the service required while for other youth locating resources for a housing subsidy is the pressing need. “An apartment right across from me is $\$ 761$ a month. And I was working a minimum wage job at the time. How am I going to afford that? And the program paid for that. I was only paying \$175" (TLP youth).

Community Supports. Connecting youth to community supports such as educational resources was also described as an important service for programs to provide youth. This could range from re-enrolling a youth in high school, enrolling 


\section{RUNAWAY AND HOMELESS YOUTH}

her/him in a GED program, or simply finding supports necessary for a youth to be successful in school.

If you are going to stay here for a while they have programs that help you transition back home. Or educational programs if you are a high school dropout, or if you need to keep attending school they have transportation or resources for you to go to school or get your GED (Basic center youth) Focus group youth seemed to recognize and appreciate the vast network of community connections that programs had developed. Analysts felt this was important not only so youth in the programs could access a variety of services and supports, but to provide opportunities for youth to build their own support networks as well as provide hope for youth who often feel there is no one in the community who can help them.

And that is one of the biggest things the program does for you is, you know, realizing for the most part that, you know, oh crap! I'm going to have to do all this on my own. And you begin to lose hope, and you begin to lose all your strength and you doubt yourself and you have no faith in anything, especially when you don't have a job. I mean you don't have the basic things needed to survive. It's like, what are you going to do? And that's what they do (TLP youth). 


\section{RUNAWAY AND HOMELESS YOUTH}

In the words of one analyst, "successful programs just get out there and they give you the resources to find and access needed items such as housing, food, and other personal needs."

Activities. Focus group youth described how programs provided them with opportunities to experience new and/or unfamiliar activities. These ranged from structured, planned recreation activities such as rock climbing, to more simple outings such as trips to the local swimming pool. Youth also described spontaneous activities such as playing games or engaging in pranks with each other and/or with staff. "They will just take you out to have fun" (TLP youth). Analysts felt these activities not only provided exposure to new experiences but also kept youth physically active.

There's always stuff to do. Recreation. Youth really like being busy. I heard a lot of that. Things to do. Like when you're not in the program you don't have things to look forward to each day. But when you're in the program you have different games you can play and different places you can go, and different things to do (Team member).

Additionally, focus group youth described how programs would expose them to new cultures or traditions. When exposed to these, youth spoke of how they gained new perspectives and an appreciation for others. Team members felt this was critical with helping youth connect to others in their community who are different from them. 


\section{RUNAWAY AND HOMELESS YOUTH}

And before the program the youth just were so closed-minded that they wouldn't even think to be nice enough to other people or think about other people's needs to do that kind of stuff for them. Then the program gave them knowledge about other people's areas of life, and even the youths' own areas of life and what they need to improve on, and it just opened their mind more to more knowledge (Team member).

Analysts felt it was important for programs to provide these types of 'fun' activities so youth had the opportunity to experience what team members referred to as 'childhood'. Analysts also felt it was important to note that staff did not merely set up and/or transport youth to an activity, they participated in the activity as well and interacted with the youth.

\section{Program attributes: “How" services were offered.}

"Program attributes" refer to the characteristics of service provision that youth find especially important. These include the ways in which programs engage and assess youth, insuring programs provide choices for youth, insuring an environment that is safe and stable while remaining flexible and patient. Youth clearly indicated they needed a sense of belonging similar to that one would expect from a family.

Engagement and Assessment. Focus group youth described and analysts noted it would be difficult for programs to assist with the individual needs of youth without 


\section{RUNAWAY AND HOMELESS YOUTH}

first adequately engaging and assessing the youths' specific situation. The way in which programs conduct this is critical. Some youth spoke of coming into the program needing more assistance with educational goals while others described the need to work on managing finances or other life skills. Youth felt it was critical that staff take

the time to thoroughly engage and assess and not simply assume they understood what was going on with each individual youth and their specific situation. Moreover, focus group youth reported that it took them time to begin to trust programs and their staff and it was important for youth workers to engage youth beyond formulary assessments or required program paperwork if they really wanted to understand the youth's situation.

The youth were okay with assessment forms or okay with this and that, but the case worker -- no, the youth didn't always go to the case worker and tell them they wanted to do this or that. So it was up to the case worker to pay attention to what the youth do (analyst).

Focus group youth also described how important it was for program staff, when interacting directly with youth, to be flexible and actively engage them. Upon entering a program, youth needed time to get know the program, begin to trust the staff, and become comfortable in the new environment. 


\section{RUNAWAY AND HOMELESS YOUTH}

If they see you're having a problem, the staff will take you aside and say, hey, what's going on? And if you don't want to open up, they don't push the issue. And that is not like a lot of other places I've been (Drop-in center youth).

Another youth described how staff allowed him to sleep in the lobby for several nights without requiring him to formally enter the program. Analysts felt programs that were willing to be more flexible with youth would be more successful engaging youth. "Like they take care of you, but they make it friendly and comfortable. Like you don't feel like you need to ask for it" (analyst).

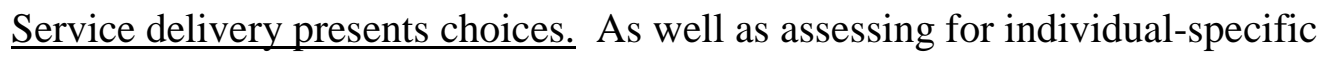
needs, focus group youth described how programs provided them with choices when it came to determining what those 'needs' should be. "In the house, it just seems like options instead of orders" (TLP youth). Along with providing choices to youth in determining specific personal goals, youth described a variety of options offered, from decisions about the daily functioning of the program to helping to plan activities. "And a lot of the youth seem to feel they have a lot of choices and responsibility. So a lot of things in the program are left up to them, it's their responsibility, it's their choice" (team member).

Findings also indicate that providing choices to youth is not only empowering, but youth also learn about the variety of options available to them and begin to use those skills to plan and make decisions for themselves. 


\section{RUNAWAY AND HOMELESS YOUTH}

Not only do the programs support you, but also give you, like, ideas to go for. Like, they help me set up my goals and help me decide what I wanted to do with my life when I had no idea what I wanted to do with my life. And now I am actually on track and I'm going somewhere and getting things done (Basic Center youth).

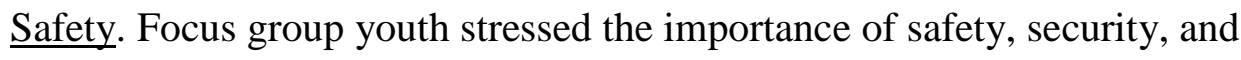
sense of stability that programs provide them. One youth recounted how, when he was living on the streets, he was continually afraid of being attacked or being told to leave certain locations by local police, making it difficult to find a safe place to sleep. Another youth described how the program they were involved with worked to afford everyone their individuality, yet, "it has to be a safe place for everyone" (TLP youth). Additionally, focus group youth described how programs provided a sense of safety. One of the ways was through program staff's interactions with youth as well as the monitoring of inter-youth interactions. 'It's safe because people are respectful. The program doesn't tolerate people being disrespectful or any other stuff like that" (Dropin center youth). Specifically youth mentioned, "no put-downs, no racism, sexism, nothing like that" (Basic center youth). Focus group youth described how acquiring a sense of safety was critical for them to be able to complete the tasks that programs expected of them. "Coming into this program I had this sounding board where I was in a safe place where I could be productive and do what I needed to do" (TLP youth). 


\section{RUNAWAY AND HOMELESS YOUTH}

Stability. Focus group youth repeatedly spoke about the need for programs to create a stable environment within the program. Meeting basic needs such as food and shelter was not enough to keep youth engaged and participating in a program. Youth described how they had left environments that were distressing and chaotic and they had no desire to dwell in a similar situation.

It's like your needs are met. You have your basic needs, shelter, a place to take a shower, and a place to wash your clothes. And the programs met that. And you can see all the time that people that were not in the program they were suffering so hard because they didn't have what we had. We had three meals a day. You know, we had programs like the something to do what was productive. But at the same time, in my situation, it wasn't like living with my mother where it was this oppressive environment (TLP youth).

A stable environment as well as consistency in programming was also extremely important to focus group youth. Youth disclosed they found changes in these areas to be especially distressing, particularly in the case of staff turnover. "There is evidence of that. Where they say they got different directors and it threw them off and they weren't happy about it and it became less of a stable place" (team member). Analysts felt the basis for the emphasis youth placed on stability was the personal histories of these youth and their desire for something they could rely on in some aspect of their life, "they need that" (team member). 


\section{RUNAWAY AND HOMELESS YOUTH}

The need for stability was also evident in the area of program rules and expectations. Several youth recalled a time when rules were modified by the program and changes were not adequately communicated to youth. On more than one occasion youth described that this resulted in receiving adverse consequences for a behavior they did not know violated a program rule. Analysts related to this and reflected that when they had encountered similar situations they found it to be extremely frustrating, "I used to hate this...the youth were like, 'Oh, you're not supposed to do that, that's against the rules?' But they didn't know it because they were never told the rules!' (team member).

Flexibility. Focus group youth stated they appreciated flexibility with regards to program rules. "It's kind of like if there is a different group of kids they don't change the rules, but they'll bend them just slightly. Little things like that make a difference" (Basic center youth). Some of the focus group youth reported how they had infringed on a rule and yet the program did not discharge them. Analysts felt this was important and that programs that understand the positive side of mistakes would help youth learn and grow far more than by simply discharging them.

I noticed that some of the programs groom the youth for mistakes like they don't just instantly kick them out and put them back in their same position. They leave room for mistakes, but also explain to the youth what they did and help them see like what they did was wrong (team member). 


\section{RUNAWAY AND HOMELESS YOUTH}

Focus group youth clearly affirmed that in addition to being discussed when entering the program, program rules should be written down and posted. And if these rules were 'broken', youth valued the ability to have choices with respect to consequences.

While there was general agreement among researchers that programs should be structured with regards to daily activities (set times when program events occur), expectations that youth participate in these activities, in an environment that is relaxed and flexible, "Youth want a place they can rely on that is the same and be somewhere that gives them responsibilities, but at the same time there is someone there to talk to" (analyst).

Family/sense of belonging. Focus group youth shared the significance of programs providing them with a sense of belonging and many referred to the program as their family. "I heard that over and over again, where they feel they belong. They get a sense of belonging and a family-type setting" (research team member). One way programs provided a sense of belonging was through a communal meal. "It's just everyone comes in this room, like all the residents and the staff that are working, and they all get together and have dinner and talk about what's going on" (Street outreach youth).

Analysts commented that this feeling of connection was extremely important to the youth in the programs because, "they come from places where they don't have 


\section{RUNAWAY AND HOMELESS YOUTH}

anyone who really cares and here they have someone who cares about what they think and what they want."

I feel like there are people I can count on to like listen to me and not judge me. And be there for me when things get bad and help figure out what I should do and they won't be biased in any way (TLP youth).

Yet youth did not necessarily want another set of 'parents', "which I think goes back to them saying, they already failed the first time having parents. They are not here to live with parents for a second time" (research team member).

Like when you get home from school parents keep doing what they're doing and they say, 'how long have you been home?' You're like, 'I walked in right in front of you made a peanut butter and jelly sandwich right in front of you!' Here, the program staff are actually like, 'how's your day? Where are you going? Did you have fun hanging out with your friends or doing whatever you're doing?' (team member).

Youth also described how, because they know other youth in the program have similar backgrounds, they feel comfortable opening up to each other. Again, analysts felt this was an important feature for programs to encourage. "I've met some of my most best friends here" (drop-in Center youth).

Patience. Focus group youth described how youth entering runaway and homeless youth programs often experience a sense of being overwhelmed and asked 


\section{RUNAWAY AND HOMELESS YOUTH}

for programs to be patient with them. Youth talked about the need to take a break from the daily grind of survival and take time to focus on longer-term goals such as education. While in the program, youth felt that time to interact with staff, counselors, and case workers to establish realistic personal goals was extremely valuable. Analysts felt that youth often enter these programs only after they have attempted to remedy their situation through all means available. It should not be surprising that the youth need some time to give, "them a little breathing space so they can stop and think about what they want to do as opposed to being all stressed out with what is going on in the real world right now" (team member).

Additionally, findings indicate that youth entering these programs need time to further develop or acquire life skills, find employment, save money, etc. "And the right programs did it without pushing and when youth were ready to learn this stuff in their life and when they needed to learn this stuff" (analyst).

The one main thing about this place is that they never give up on you, which is awesome. I mean, I've made quite a few mistakes and they keep helping me out. They always look toward the future. They don't look at the past. They want to make what's best for your future (street outreach youth).

Analysts felt programs that can exhibit patience with youth and afford them time to make mistakes and then learn from those mistakes will be more successful. 


\section{RUNAWAY AND HOMELESS YOUTH}

\section{Summary.}

Providing services to this population of youth, with their array of backgrounds, developmental needs, and cultural differences is a challenging endeavor for programs. Findings indicate programs should be prepared to provide or assist with the acquisition of daily needs such as transportation, healthcare, counseling, childcare, and legal issues. Yet, "how" those services and supports are provided is as important as "what" those services and supports are. It is critical that services and supports be customized to the individual youth, youth should be offered as an array of choices, and services provided in ways that teach youth how to utilize these skills in a milieu suitable for young people.

Focus group youth described specific program attributes that seemed critical when working with runaway and homeless youth. Programs should have a relaxed atmosphere, provide a sense of protection and stability, and be flexible. Additionally, youth should feel a sense of belonging, patience, and expect to make mistakes. "I'd just like to say I don't think any of these are more important than the other. I think they are all [important] qualities" (team member).

I would have to say the main thing that sticks in my mind is the key to success for these programs is becoming structured friends with the youth. It's like this, they need to find that medium in between making them comfortable and becoming their friends and making them feel trusted and trustworthy or 


\section{RUNAWAY AND HOMELESS YOUTH}

whatever. And getting things done. And they need to find that in between instead of being too hard on them in certain rules or being too lenient on things. And that's really, a really big key to success (team member).

\section{Staff.}

Characteristics of individual staff also emerged as an important contributor to success when working with RHY. These included being resourceful, being accessible to youth, and skill in modeling healthy behaviors. Furthermore, youth want to work with staff who develop a personal connection, are nonjudgmental, and are knowledgeable about youth in general as well as the specific needs of RHY.

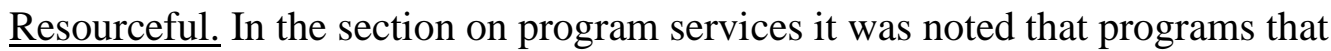
find concrete resources were favored. Focus group youth indicated they rely heavily on staff to support them with locating and acquiring resources essential for safety as well as successful independent living. This indicates that individual staff who are 'resourceful' are highly valued. These resources could include a range of items from housing, food, medical or mental health services to more unexpected yet equally important items such as gym memberships or special dietary assistance. Because of the uniqueness of needs that each youth brings, staff must demonstrate a high level of resourcefulness. 


\section{RUNAWAY AND HOMELESS YOUTH}

The skill of resourcefulness includes a number of qualities. First, staff must be knowledgeable of the services currently available in their community. In combination with this, they must possess a network of community connections and relationships with those services, "If your program doesn't offer it, the staff knows a program that does" (analyst). Secondly, if the connection to a particular resource is missing, staff must exhibit inquisitiveness and an enthusiasm to seek out new options in the community, "if they can't do it, they find other programs that can help you" (analyst). Finally, being resourceful implies staff are persistent in the pursuit of matching the right resource for the individual youth. "Staff will give you a whole bunch of options. If one option doesn't work, they go for the next option. If that one doesn't work they keep going until they find one that does" (drop-in center youth).

How the resourcefulness was carried out was important as well. Youth indicated that obtaining resources was important not only for the resource itself, but that in the process of obtaining it, staff modeled for youth the self-advocacy skills necessary for independent living. "They are not just telling you to do something, they are instructing you on how to do something, they help you understand and they teach you" (TLP youth). Analysts agreed it is critical that youth workers use these opportunities to teach youth how to navigate bureaucracies and access necessary resources on their own, "as opposed to giving youth a whole booklet of numbers, the staff actually help you" (analyst). Findings indicate that merely telling youth about a 


\section{RUNAWAY AND HOMELESS YOUTH}

particular resource would not only be a missed opportunity to teach a valuable life skill, but also increased the likelihood of failure:

Staff want to go out of their way and they want to go look for a program that can help you with this, and other times you have a staff that just gives you the number and they say, call them. And you get the run around (analyst).

Accessible. Focus group youth described the need for staff to be accessible when youth needed them even though it may not be convenient for the staff. "She drops a whole days worth of meetings because I went into her office and I had done some stuff I shouldn't have done and she was there for me, and that meant a lot to me" (TLP youth). Analysts agreed with the importance of accessibility to help resolve immediate needs, which perhaps prevented an escalation into a crisis and also had a lasting, positive impact on the youth.

The youth seem to say that staff go out of their way in certain situations for them. Like if a youth wakes up in the morning and things are bad and the staff is in a meeting or something, the staff drops everything they're doing to come help them out, and I think that was a pretty big deal for staff to just drop everything they're doing and come accommodate to the youth and their situation (analyst).

Model healthy behavior. Youth, at times, have come to rely on skills necessary to survive in a chaotic (and sometimes even dangerous) environment. Because of this, 


\section{RUNAWAY AND HOMELESS YOUTH}

focus group youth discussed the importance of staff modeling healthy behaviors and prosocial interactions. "Like the staff are teaching the youth to be in good relationships with maybe their family and other people around them, but they are also showing that example of good relationships while they're trying to teach them" (analyst).

Youth from the focus groups seemed well aware when staff modeled healthy behavior and understood how staff used these skills to help teach youth new, healthier ways to respond when troubled or upset. Focus group youth described how staff modeled healthy behavior, especially in times of high anxiety.

And I just went off. But afterwards I realized how stupid I was because I yelled at her and the whole time she was like, 'I know, I know.' And I thought, 'I'm yelling at you, respond! Yell back at me, something.' They don't hold grudges (TLP youth).

Analysts felt from own their experiences that youth in the programs often resorted to yelling simply because that had been how they were taught by their families or peers, or it was the only way they felt they could be heard. Because of this, it was especially important that staff not respond in a similar fashion.

Just like with the yelling thing. I think a lot of youth when they get angry they resort to yelling because that is all they see in their families and maybe their friends yell when they get angry. But when someone doesn't yell back and you 


\section{RUNAWAY AND HOMELESS YOUTH}

expect it, you kind of quiet yourself. When you're sitting there and yelling and yelling and they are just calm and talking to you, you start to calm yourself because you realize you don't need to get your message across like that. Because they are getting their message across just fine without yelling (analyst).

One team member summed it up by stating, "staff should lead by example." Personal connection. Focus group youth stressed the importance of staff developing a personal connection, becoming familiar with youth on a personal as well as professional level. "If they don't really know you they can't really help you" (Dropin center youth). A personal connection entails the interpersonal skill of emotional intelligence or compassion - being thoroughly familiar with each individual youth's likes and dislikes, goals and aspirations, as well as who they are in relationships with and how those relationships might be impacting them in the program or other areas of their life. As one team member stated, "staff took the time to find out who the youth were, like each individual person, each individual youth.”

The staff said, 'I remember when you sat on the steps and cried when he went to jail. That was a sad day.' I was like, wow, they remember stuff like that. Stuff you wouldn't even think they care about, you know what I mean? My boyfriend went to jail on their property. Do you think they really care about that? And he was like, 'that was a sad day' (TLP youth). 


\section{RUNAWAY AND HOMELESS YOUTH}

Additionally, because youth are often not aware of the full range of possibilities with regards to goal setting, the skill of developing a personal connection allows staff to recognize each individual youth's strengths and abilities. This will afford youth workers the ability to help connect youth to areas and activities where the youth will naturally excel. Moreover, youth workers need to be proactive in assessing these skill areas because, "the youth didn't always go to the case worker and tell them they wanted to do" (analyst). Youth analysts knew from their own experience the importance of the staff skill of proactive assessment. As one analyst remarked, "It is up to the case worker to pay attention to what youth do. And it is up to them to help try to find youths' talents and point them in the right direction."

A personal connection also means that staff are familiar enough with each individual youth that they can recognize when a youth is experiencing a particularly difficult day. Awareness of these changes in youths' behavior and/or affect will help the youth worker modify their own behaviors and actions so they can appropriately interact with youth and again, possibly prevent escalation into a crisis.

And usually by the look on your face they know if you are in a good mood or bad mood. If you're in a bad mood, half the time they'll walk up to you, take you outside and be like, 'What's going on? Do we need to go get some eggs? Or a coffee dog walking?' you got to love the Sunday coffee dog walking (TLP youth). 


\section{RUNAWAY AND HOMELESS YOUTH}

A personal connection also insures staff do not miss an opportunity to celebrate when a youth is having an especially good day.

I think the way the youth feel cared about is the staff show excitement and expression where say a girl comes from a background where she's an only child and her dad only has one expression. Like when someone else shows you that, it's more, I don't know, it makes more of a point (Team member).

A personal connection also means staff recognize that because of the individuality of each youth and their distinctive needs, one skill set or staff attribute may work particularly well for one youth and not another. "You have to test the water and get to know the youth before you can do this right. And it's about being able to try different approaches. You have to have different skills" (analyst). A personal connection means staff understand the nuances of each particular youth, are flexible, and understand that although there may be a particular style of youth interaction staff are more comfortable employing, at times, individual youth may require a different style. "The staff understand the different youth, different personalities and they adapt to help different youth in different ways. Staff might help me and help her in totally different ways but we could get the same outcome" (TLP youth).

Focus group youth were clear it was not enough for staff to merely have a set of professional skills; they needed to have a personal connection with youth so they 


\section{RUNAWAY AND HOMELESS YOUTH}

can be aware and understand what is happening in the lives of the youth outside the program and how those happenings could potentially affect youth and their ability to succeed inside the program. "Staff know your basic needs and they know your more personal needs whether it is your mental ability, physical abilities, they literally look to see what they can do (drop-in center youth).

Nonjudgmental. Holding a nonjudgmental view of youth was a highly valued staff quality brought up in the focus groups. Focus group youth described how they felt when they sensed they were being judged by others as recounted by two youth from a TLP;

Youth \#1: And you get those looks from people when you go into a grocery store or some other place and they just know. You get that old biddy of a grandma who just looks at your clothes and is like, 'you're one of those troubled kids.'

Youth \#2: They make you take off your backpack and they follow you around the store.

Youth \#1: Yeah, you have to love that one.

Analysts were also reminded of their own similar incidents in the community, "I remember when I was homeless I would go into a store and I hadn't shaved in a while or my clothes were dirty and they kind of look at you like they're better than you or something." 


\section{RUNAWAY AND HOMELESS YOUTH}

Because of this response by the community, it was essential that staff have a nonjudgmental perspective. This helped youth workers effectively engage youth, have ongoing working relationships with them, and create an environment where youth were comfortable and felt good about themselves.

Like when you're out there in the world people are judging you constantly, and you constantly have to put up with that, you know, how people are looking at you, you know, and what you've done, and all that. It is a lot of pressure you know, but then you come here and staff doesn't judge you, no one really judges you (basic center youth).

Youth analysts quickly spotted this theme. From their own experience they knew it was important. They themselves were keenly aware of "the transition of people looking down at you like you're trash, to people actually looking at you like you're an individual instead of a dog on the side of the street" (analyst).

One way analysts felt youth experience nonjudgmentalism is when they are adequately supported as they learn and grow. "Doing the things you're supposed to be doing, whatever that is, staff support those things and help out with that" (analyst). Focus group youth not only discussed how important it was for staff to be nonjudgmental toward them, but how youth respected staff who would not judge youth especially when the youth had made a mistake. 


\section{RUNAWAY AND HOMELESS YOUTH}

But I love knowing no matter what I do, it doesn't matter how bad I mess up, the end of the day I can come here and be like, 'I fucked up so bad! How do I fix this? This is not what I wanted to do!' And I'll still get that help. The staff don't judge me for that fuck up (TLP youth).

Knowledge. Focus group youth noted that understanding - both that gained from life experience and from formal education or training - was important.

A shared experience with the youth was noted as a major contributor for many staff getting into youth work. "One of my staff used to live here. She was in the same situation, pregnant and everything" (street outreach youth). Analysts agreed that many staff they had encountered, "used to be in the same situation and now they want to help people because they used to be like that" (analyst).

However, analysts felt that acquiring specific training to work with runaway and homeless youth was extremely important and necessary, "to understand the youth better" (analyst). Specifically, it was essential for staff to be empathic and, "trained to understand the youths' basic needs and how to assess for their personal needs" (analyst). Acquiring these skills was not only important for the staff themselves to work effectively with youth, but also because, "the more understanding the staff has, the more successful the program is going to be" (analyst). Yet findings were mixed about whether that training should come from a more formal education or a shared experience of having been previously homelessness. On the one hand, team members 


\section{RUNAWAY AND HOMELESS YOUTH}

noted that focus group youth attributed staff success to some level of higher education and was necessary to insure specific skill sets were acquired such as understanding specific needs of youth transitioning to adulthood as well as, "all the paper pushing stuff” (TLP youth). Additionally analysts felt that some type of certification would help improve staff skills regardless of staff’s shared experiences. However, “just because staff might have a bachelors, masters or doctorate or whatever, that doesn't mean they have the street smarts of someone that hasn't been to school" (research team member).

In the end, the research team agreed that an ideal situation would be a staff member who had a shared experience with youth yet also obtained some sort of degree, special training, or certification. "I think that the employees of the program should be, they should qualify. They should have proper knowledge or training, you

know, well-rounded, that will eliminate a lot of the problems that the staff might have with youth" (analyst). Analysts felt it was important that this finding not be used in a manner that would exclude hiring or retaining staff.

\section{Summary.}

The overall success of a runaway and homeless youth program will depend heavily on the individual interactions between the youth and the program's staff. Findings from this study indicate that staff who are resourceful, model healthy 


\section{RUNAWAY AND HOMELESS YOUTH}

behavior, develop personal connections with the youth, are non-judgmental, and have knowledge (both experiential and from formal education) of youth issues will provide programs and youth with the best possible chances at success.

\section{PAR Findings}

Upon conclusion of the analysis of the CEY focus group transcripts, a focus group was conducted with the youth analysts. The goal of this focus group was to evaluate the participatory methods and determine specific features that worked well and ways in which it could be improved. As with the previous findings section, individual exemplars that may have been confusing or awkward to the reader were edited with care to insure the speaker's intent was not lost. Also, unless otherwise noted, any exemplars used in this section are from research team members.

\section{What went well.}

Overall, team members felt the project was successful and referenced several key features they felt were critical to that success. These included 1) the recruitment process; 2) the meeting environment; 3) the individual analysis; and 4) the collective work.

The recruitment process. During the recruitment of youth analysts, purposive sampling methods were employed to facilitate building a research team of members with varying backgrounds and experiences. Team members were informed of this 


\section{RUNAWAY AND HOMELESS YOUTH}

objective during the interview process and stated over the course of the project they clearly saw why it was important to obtain varying perspectives. Additionally, they acknowledged they saw how it added to the overall process of analysis.

I think it was a good idea that you didn't just hire the first five people that came along. You had your criteria. You wanted someone from different ethnicities. You wanted them from different everything. You wanted your salad bowl, I guess is the way to say it. A salad bowl that turned into a melting pot. Everyone here is all different, but we all came together to agree, and at times to disagree.

Moreover, they understood how, "If you brought people that are all the same, they end up perceiving the same things in a lot of situations, doing it this way just gives it less chance of being biased." Team members also appreciated how having multiple perspectives improved the validity of the findings, helping to highlight information that might otherwise have been overlooked.

I noticed that those two would say something and I was always like, 'why didn't I think of that?' Because sometimes it was the obvious things, it was just too obvious. And sometimes the little things are the things I tend to skip over. The meeting environment. Team members stated that meeting at a university became an important factor in the process. One member felt it had a positive impact precisely, "because it was at a school." Other comments included, "I like the academic 


\section{RUNAWAY AND HOMELESS YOUTH}

environment. It helped a lot," and "it kind of makes me feel important, you know." The physical environment (i.e. the layout of the room, the building where it was located, etc.) was important to team members "Because when you're in a classroom you tend to feel more closed in, and the windows gave you a sense of open space and freedom."

Providing food was also acknowledged as an important feature to the success of the project. Team members stated, "I think the food actually helped a lot. When you're hungry and trying to do work, you think about your hunger more so than work." Another remarked how they "never really thought about how food can help a group and focus attention. It gets you more comfortable."

Individual analysis. As described in the methods section, team members were provided with the transcripts from the youth focus groups - one question at a time. The analysts would then take those transcripts with them, analyze them, and then bring them back to the next meeting ready to present, and then discuss, what they had coded as significant. Analysts stated that reading each transcript individually was an important aspect of the process. Pragmatically, team members noted this afforded them time to read the document thoroughly, make notes, and mark up the text with highlighters, which they stated "worked really, really well to find a small detail later on." They also noted that reading the text individually helped them provide "voice" to the transcript. 


\section{RUNAWAY AND HOMELESS YOUTH}

It's kind of like when someone sends you a text message 'LOL'. Are they really laughing out loud or are they just saying that? It's kind of like on here, all you know is what they say. We don't know their emotion or how they said it, just what they said. So you have to decide that.

Team members were particularly sensitive to the need to control bias as much as possible, a topic covered in the initial training. Throughout the project, and again during the focus group, there were several discussions about whether or not it would have been better for the research team to have been able to actually hear the focus group recordings versus only reading the text. Yet the theoretical constructs supporting this method relied on them adding their "voice" through their own experiences, again, resulting in improved validity. In the end the team concluded it was better that they had not had access to the audio recordings.

Just like with the whole unbiased thing, the direction we went with that, everything we did to make it as unbiased as possible. Like the individual work and the fact that you blank out the names. Also, I liked the fact that we couldn't hear their voices. It could have made me want to agree with them more just because you think you know them.

Collective work. The collective work provided a forum for achieving two objectives, 1) presenting individual analysis, and 2) establishing consensus as to the importance of those findings. The group meetings allowed analysts, one by one, to 


\section{RUNAWAY AND HOMELESS YOUTH}

share with the group what they had determined as important themes in the transcripts. "I think what worked good is how we each individually gave our own opinion, our own individual thought." Analysts noted that a critical feature of this working well was cultivating an environment where "there are no wrong answers" when presenting individual work to the group. "Like right now we're laid back and it's easy to joke with each other, which is good because you're not afraid to shoot-out your ideas." Team members specifically stated the significance of an environment that provided for the, "safety and comfort of expressing our opinions." This feature was important for team members to freely to share their ideas, experiences and hypotheses, but also to encourage deeper discussions. "I like how we didn't discourage topics that weren't precisely on topic. Rather than it being a straight line of constant chatter, ideas, and opinions, it was more like a web of expanding ideas."

Secondly, through the collective work, synergistic discussions transpired where a shared understanding was built from the individual insight of each team member.

I would say something and then would elaborate on that and come up with a new idea from that idea. And from there would think of something else, and it would just go back and forth like that.

It happened so much, we would be talking about something along the lines of, 


\section{RUNAWAY AND HOMELESS YOUTH}

like one of the questions that was asked, what we found as far as answers, but we wouldn't stop there. We wouldn't stop with just the answers. We then expanded to other ideas, other thoughts that we all had, and it wasn't discouraged. That's what I liked about it.

Team members also observed that these discussions exposed them to new ideas and understanding. "Maybe we don't get the big things, but you end up seeing everything with all the different perspectives."

\section{Summary.}

With regards to what went well with the process, team members highlighted the importance of the recruiting methods and striving to build a team that encompasses a variety of personal experiences. The environment where group meetings take place is also an important feature and should offer furnishings that accommodate space for a project such as this; e.g. laying out a variety of documents, notes, tape recording, etc. as well as providing food and comfort. Additionally, the room should provide an environment of professionalism while at the same time it should not feel, “claustrophobic.” Finally, allowing youth to first work individually and then collectively is especially critical to this process.

\section{What could have gone better.}

There were two major elements of the process that team members felt could 


\section{RUNAWAY AND HOMELESS YOUTH}

have been improved upon; 1) the initial training, and 2) the way in which the meetings were scheduled.

The goal of the initial training was to introduce team members to qualitative analysis and strategies to manage bias. As part of that training, members practiced coding on a one-page sample transcript. Upon reflection, analysts felt there was too much information provided too quickly and the training should have provided more time to practice the coding process.

We found our way to do it on our own, but a lot of us had to do it from scratch on our own because this is completely new to all of us. We did do it. But a little more preparation could have gone a long way and made it more efficient. To help improve future projects, team members provided suggestions of what they felt would be a more effective way to provide the training.

You could have given us something more than that just one page. You could have given us something that would have taken an hour, and then we could have come back. And given us a little more practice time. You could have even wrote up your own questions and answers just like homework or a practice test.

As an additional technical note, team members felt the transcripts should have been double spaced and had wider margins to provide more space for note taking right on the document. 


\section{RUNAWAY AND HOMELESS YOUTH}

The way in which meetings were scheduled was also noted as an area that needed to be improved upon. At the end of the second of the two initial meetings (orientation and training meetings), and the end of each subsequent meeting, team members were provided with the set of transcripts from one of the focus group questions that were referred to as "the packet". Based on the size of the packet (i.e. how long they felt it would take them to read and analyze) and the personal schedule of each analyst, the group would schedule a subsequent meeting. Although all but one of the meetings were held in the same location, it was unclear if that room would be available when the next meeting was scheduled and could not be confirmed until university staff could be contacted the following work day. If we met on a Friday night or Saturday, authorization could not be obtained until Monday, generally receiving confirmation later in the day. Although it occurred only once, the room was not available at the date/time the team had specified for the next meeting, which required finding and securing a room at an alternate location. In addition, there was one other time when a meeting had to be rescheduled because a group member had a personal need arise, this too added to the challenge of securing a room location.

On the one hand, members saw the advantages of flexibility and allowing team members to schedule the meetings. "Instead of saying, 'hey, we're going to meet every Tuesday each week,' I liked how flexible the meeting time was because then you could be like, 'hey, this packet is big or this week is really busy for me."' Yet on the 


\section{RUNAWAY AND HOMELESS YOUTH}

other hand, the flexibility, at times, led to frustration when, "in the middle of the group we have to sit and figure out when our next meeting should be and whatnot." Although members agreed it would have been difficult to pre-schedule each meeting, they felt, "a little more structure" would be helpful.

\section{Summary.}

Regardless of the ages of research analysts, caution must be taken when providing training on new concepts, especially if the individuals have little experience on the topic. Team members pointed out that providing adequate time to understand and, perhaps more importantly, practice new skills will not only help members feel more comfortable, but will result in higher levels of efficiency for the project. Also, obtaining access to meeting locations that offer flexibility for scheduling needs will help alleviate confusion and or frustrations.

\section{What team members learned.}

Team members described various ways in which new learning took place throughout this project, particularly through the teamwork aspect of working on the project. They described this teamwork as understanding the differences each member brought to the group and while, at times, those differences resulted in, "a tiny bit of butting heads," they learned how those differences allowed for a deeper understanding of the data to emerge. 


\section{RUNAWAY AND HOMELESS YOUTH}

You learn to agree. Not agree necessarily, but see their side. Like I never think metaphorically or to compare to other situation, which is exactly what he does all the time. You see that side of it. And it's really cool.

Members also learned that working as a team not only had a positive effect on the analysis, but on the team members themselves, which, in turn, improved the overall project.

You know, just the different views that people have about things. Kind of what

was saying. Just the learning experience of just being a research analyst and working with a team and for a good cause. It was positive and that will make a difference.

Team members also described how they learned from one another and from the youth who spoke to them through the focus group transcripts.

I love seeing other angles on things because, first of all, your life is your life, you're not going to see it from another's perspective. But I love actually trying to see other people's perspective and capturing that on paper. And when I heard this is like the programs I've been through, and a lot of them had the lifestyle I've had. And you go back and look at theirs you go, 'whoa, that's what they saw, I never saw that.'

Members also stated they learned how much they enjoyed this type of work. They enjoyed the experience, learning from one another, observing others' excitement 


\section{RUNAWAY AND HOMELESS YOUTH}

over a specific finding, the discussions that emerged around the individual findings, and the feeling of achievement.

It's not like, oh, it's finally over. It was like, oh, we're scheduling for the new one and I can't wait to say my ideas for the next one. It was something to look forward to. And afterward you feel accomplished. Not like a negative air in here.

\section{Advice for researchers.}

For this section, the term "researcher(s)" refers to professional investigators applying scientific methods. Yet the advice given from this team would be beneficial to a broader definition of researcher that includes youth and adults, experienced and novice, as well as those with a degree from an institute of higher education and those without.

Advice for researchers working with participant analysts focused on the level of researcher involvement with the research team. Although participatory methods propose the researcher's role is to stand clear of the analysis and be more of a catalyst for the project, the research team stated it would be unrealistic, if not impossible, for the researcher to completely remove himself from the process. Team members stated they understood that simply by being in the room, the researcher is part of the process. Moreover, team members felt that researchers attempting to completely remove 


\section{RUNAWAY AND HOMELESS YOUTH}

themselves from the process could potentially have a negative effect.

You mentioned at beginning of the program that you didn't want to take too much of a big part in this but let's face it, you did take a few parts in it. And I don't think there's anything wrong with that. I don't think researchers should shy away from getting involved, at least to some extent. Getting completely removed from it kind of takes something away from the group.

Yet there should be a balance. Members described how early on in the process they needed more involvement from the researcher through prompts, questions and by, "coaxing and talking us through the conversation." However, researchers should be cautious about offering too many prompts as members stated it can actually result in analysts, "losing the train of their thought." Researchers need to look for an opportunity to transition from more involvement to backing away as the team begins to settle into their roles and take over the process. Team members stated very directly that, "involvement is too much when you [the researcher] try to carry things. That's where it ends."

\section{Researcher analysis.}

Analysis of the final focus group with YAG members also resulted in the researcher noting several additional themes that emerged; pride, educational aspirations, and the importance of youth voice. 


\section{RUNAWAY AND HOMELESS YOUTH}

Team members exhibited an immense amount of pride throughout the performance of this project. "It kind of makes me feel important, you know. Sitting here at University Medical building and the leader of our group is a teacher." Members took this work very seriously and on more than one occasion made statements such as, “It's a job, we're doing something important.” Moreover, they were not satisfied with doing the minimum requirement; they were excited about doing more.

It was a lot of useful information from all of us that will hopefully benefit other attempts to do something like this again. And hopefully get more use out of this particular group than if we would have just focused on the questions, the 'right answer'.

Team members remarked how, "inspired you get once you begin to understand the work." As the work progressed, they began referring to themselves as "research analysts" and as a "research team". These remarks corresponded with a rising sense of accomplishment, for example,

I love how accomplished people felt in this group. You feel like you're getting a lot of stuff done. And just by getting your opinion out there and listening to other people. You just feel better after the group.

YAG members were paid \$15 per hour for work on this project, not to exceed 47 hours, which was determined to be a fair wage given the level of work that was to 


\section{RUNAWAY AND HOMELESS YOUTH}

be performed. This was undoubtedly a motivating factor, initially, for participation in the project, although it did not appear to be an unreasonably high amount as the project still struggled to recruit an adequate number of youth. While the wage may have engaged the youth with the project, it certainly is not what kept them there.

Through the environment, the group structure, the type of work, etc., participants stated they felt as if they were back in school, yet it was different. "It always seems like we're more in class and taking homework home and doing homework. Like we're studying." To which another member responded, "I wish school could come to you like this." This prompted participants to exhibit aspirations regarding higher education, "It inspires me to go further." Toward the end of the focus group, the discussion turned toward how they might be able to access higher education with members wondering if this researcher "could be like a connection into the college world?"

Finally, participants felt very strongly that utilizing youth to evaluate programs should be expanded, perhaps even mandated.

I really, really like the idea that this can be expanded into any project now that we've done it. Like bringing young people in that have not only been through the things, and are more understanding, but they have recently been through the things. Not like adults where it happened years and years ago. It's much easier to relate, and much easier to think about how you felt in the same 


\section{RUNAWAY AND HOMELESS YOUTH}

situation that these young people are going through.

Strongly supporting the tenets of participatory action research, analysts were also clear that youth should have been involved in this project from the beginning, not only the analysis portion. "It's good work, but we should have all been in it from the beginning. We would have met the youth and talked to people. We should have been involved with the whole thing." 


\section{RUNAWAY AND HOMELESS YOUTH}

\section{Chapter 5: Discussion}

In light of the limited research on runaway and homeless youth and poor service utilization rates, this study sought to understand the aspects of RHY programs that youth feel are most important. As such, this study asked the question; according to youth, what are programs doing right in regards to services being provided to RHY? To accomplish this, youth who were currently being served in federally funded RHY programs were recruited to participate in focus groups. The programs included Basic Centers, Transitional Living Programs (TLPs), street outreach programs, and drop-in centers. The focus groups were audio recorded and then transcribed. Subsequently, youth who were currently being served or had been previously served by a RHY program were hired to conduct the analysis of the focus group transcripts.

Above all, findings from this project highlight the importance of including youth in all aspects of programming, e.g. development, evaluation, etc. However, before presenting a discussion on their significance and implications for the field of social work, the study limitations will be presented.

\section{Limitations}

\section{Focus groups.}

A major strength of this project was that it incorporated youth voice. Other 


\section{RUNAWAY AND HOMELESS YOUTH}

studies have conducted similar projects with both street youth and those being served in RHY programs, yet this study collected data from RHY and then employed RHY to analyze it. Additionally the study included a large and varied sample. Moreover, there are many advantages to collecting data via focus groups. They are generally economical, the quality of data can be improved from participant interaction, and they are particularly effective at distinguishing between collective versus individual perspectives (Patton, 2002). Freeman and Mathison (2009) add that focus groups can be especially beneficial with youth, "because they diminish the effects of adult power, reduce the pressure on individuals to answer questions, and provide support from others in the group" (p. 104).

Yet there are several key limitations with focus groups that could affect reliability and validity. The chief limitations of the sampling method for the focus groups are selection bias and timing (Patton, 2002). In relation to timing, only those youth who were currently receiving services in one of these programs were generally recruited to participate in the focus groups. Consequently, the experiences of youth who participated in services outside this timeframe were excluded. Another limitation specific to this project is that focus groups were made up of youth for which the program was working. In regards to selection bias, the first criterion for selection was that a youth had to be receiving services from one of the RHY programs. This would exclude RHY who were not receiving services. Because this project hoped to 


\section{RUNAWAY AND HOMELESS YOUTH}

determine key elements of programming and service philosophy that facilitated youth engagement and success, understanding why those non-served RHY were unwilling to enter a program or receive services could provide essential information and facilitate changes needed in RHY service delivery models. Additionally, for youth to be selected, they would have to be engaged at a level where staff would be familiar enough with them to feel they were appropriate to participate in a focus group. Again, youth who did not meet this criterion according to staff could very well be the type of youth for whom agencies need to modify their programs. These youth could potentially provide the critical details around programming and service philosophy that could revolutionize RHY services. Although this project was not an evaluation of programs or services, the impact of "researchers" from a university conducting a site visit could lead staff to select youth they felt certain would reflect positively on the program. Again, those youth who might provide unflattering reflections could in fact provide critical information needed to help programs be more engaging of all RHY (Mangione, 1998; Patton, 2002: Singleton \& Straits, 2005).

Specific limitations with focus groups include individual participants discovering that their viewpoint does not align with the majority of group members and not speaking up. Youth may be especially susceptible to this type of group pressure. Additionally, comments that might be perceived as negative may be difficult for participants out of fear, because they currently need the program's services, or they 


\section{RUNAWAY AND HOMELESS YOUTH}

have a sense of loyalty to the program (Flores, 2008; Patton, 2002). Moreover, it is possible, “that an individual's expressed opinion may be influenced by a desire to fit in with other group members" (Freeman \& Mathison, 2009, p. 105).

Many of the findings from the CEY portion of this project are supported in the literature. Federally funded RHY programs are required to provide many of the services focus group youth described as important. Because focus group youth were asked what programs are doing right, it stands to reason that youth responses would be limited to what they were currently experiencing in those programs. If youth had been asked, what programs should be doing, responses could have been distinctly different. However, utilizing youth voice provided additional depth and understanding.

Another key limitation is that this project grouped all responses into a single "RHY" response. This is problematic for several reasons, foremost, the significant variations across youth within the RHY population (Slesnick et al., 2009). In this study, there appeared to be differences in the emphasis on certain findings between groups of youth (e.g. those in Basic Center programs versus those in TLP's), but this project lacked the resources to adequately explore those differences. As such, this project combined findings from a population that is known to have distinct differences. However, care was taken to compensate for this by only focusing on those themes that the research team felt were useful in all types of youth service models. 


\section{RUNAWAY AND HOMELESS YOUTH}

\section{Participatory action research.}

Participatory action research (PAR) collaborates with the communities to be investigated and provides them with the tools to carry out research. The literature on PAR methods prescribes that the research includes members of those communities at each step of the process. A chief limitation of this project was that it failed to do that. Another key challenge to participatory research is, "to make sure that participation is genuine and authentic, not just token or rhetorical" (Patton, 2002, p. 184). Although YAG members participated in a final focus group to assess the PAR process, this project had no formal mechanism to evaluate the level of participation outside of this feedback and the personal observation of this researcher.

However, a key strength of this project was that the focus group transcripts were analyzed by RHY, drawing upon their experiences to create meaning and assign importance. Strauss and Corbin (1990) discuss theoretical sensitivity and the ways in which it affects the analysis of qualitative data, "Theoretical sensitivity refers to the attribute of having insight, the ability to give meaning to data, the capacity to understand, and capability to separate the pertinent from that which isn't” (p. 42). Referring to professional researchers, they list the sources of theoretical sensitivity as the literature, professional and personal experiences, as well as "the analytic process itself' (p. 43). This supports the idea that the researcher conducting analysis will be more likely to pick out patterns in the data that confirm her/his theoretical 


\section{RUNAWAY AND HOMELESS YOUTH}

suppositions. Theoretical sensitivity is always at play, therefore the question becomes whose sensitivity should be at play? Based on the tenets of theoretical sensitivity, youth will provide depth and understanding to the interpretation of other youth's responses not possible for the researcher. This supports the importance of utilizing youth to analyze data and privileging their theoretical sensitivity.

As the researcher bringing my own set of experiences and biases to this project, it is difficult to ascertain how much I influenced outcomes. It is quite possible that I could have pushed, nudged or otherwise unknowingly influenced the formulation of the ideas and topics of discussion throughout this project. At times, I became aware of being challenged to stay neutral in discussions, the analysis, and the writing portions of the project. My experience in the field along with the time spent in the literature made it difficult to NOT "connect the dots" that I was seeing unfold and continually had to constrain myself. Yet it is difficult to determine how successful I was at that. Conversely, it would seem that if staying neutral was challenging for me, while explicitly focusing on participatory methods, it would have been even more so if I had actually been the one solely responsible for the analysis. I believe this helps validate using PAR methods. 


\section{RUNAWAY AND HOMELESS YOUTH}

\section{Race.}

The implications of race did not come up in this study; there are several explanations as to why this may have occurred. First, demographic data was not gathered on focus group youth. This was done as an extra level of precaution to insure confidentiality and anonymity because youth as young as 14 years old were afforded the right to provide their own consent to participate. Because of this, it impossible to understand how different program services and attributes and staff characteristics might actually be adding to racial disparity. With the awareness of racial disparities in other youth-serving systems, there is reason to believe it is in the RHY system as well. Secondly, based on the tenets of critical race theory, this researcher's position as a white male would make it challenging to recognize nuances within this project that may have been affected by race. For example, although every attempt was made to share power with the YAG members, did the hiring process or the way in which meetings were facilitated create a hierarchical relationship that could have pressured youth of color to conform?

Despite these limitations, this study provides valuable information about the services and attributes RHY programs should focus on as well as important skills and behaviors staff should exhibit when working with RHY. Moreover, this project supports collaborating with youth in planning and evaluating services and provides additional details to the current body of literature on how to best do that. 


\section{RUNAWAY AND HOMELESS YOUTH}

\section{CEY}

\section{Summary of key themes.}

Conducting focus groups with RHY participating in Basic Centers, TLPs, and Street Outreach/Drop-in Centers the CEY portion of this project asked: what are programs doing right in regards to services provided to RHY? Findings from the analysis indicates there are three key components to successful RHY service provision; 1) program services - what is offered, 2) program attributes - how it is offered, and 3) staff characteristics and skills.

With regards to program services, youth described important services programs should be prepared to directly offer youth or assist them with accessing in the community. These include skill building, counseling, services customized to meet individual needs, connection to concrete supports, and activities.

Findings from this study suggest that youth place a high value on the acquisition of life skills. Focus group youth described the importance of skill building as those skills necessary for daily living such as cooking, cleaning, and managing money. Skill building also includes assistance with skills to improve the employability of youth such as resume writing, practice interviewing, and providing opportunities within the program for youth to acquire and practice new skill sets. This contrasts with 


\section{RUNAWAY AND HOMELESS YOUTH}

the literature that discusses the teaching of skills to RHY were the focus is generally on social skills (Teare et al., 1994; Thompson, Pollio, \& Bitner, 2000).

Findings also stressed the importance of counseling for mental health and substance abuse issues for individual youth as well as family counseling. When providing these services, the literature suggests ecologically based family therapy (EBFT) may be most effective, especially in the case of substance abuse treatment (Slesnick \& Prestopnik, 2005). If program goals include family reunification, as in the case of Basic Centers, counseling services should also include mediation for youth and their family to help facilitate the youth returning home and preventing future runaway events. A search of the literature found one study that looked at the effectiveness of mediation between youth in shelters and their families. Working specifically with at risk parents and youth, Stahler, DuCette, and Povich (1990) found that using a formal mediation model, extremely high success rates were reached in mediation agreements between youth and their parents. However, similar to other intervention studies with RHY, further research with more rigorous methods needs to be performed.

Services customized to meet individual needs are those items that afford youth full participation educationally, vocationally, socially and in other areas of health and wellness. Examples provided by youth ranged from simple every day needs that one could expect for most RHY such as bus tokens to get around to more personal items such as supplying caps and gowns for high school graduation ceremonies or a health 


\section{RUNAWAY AND HOMELESS YOUTH}

club membership. Services customized to meet individual needs also included providing assistance with navigation through social service bureaucracies, underscoring how complicated these systems can be, and offering youth incentives to reward their successes. The finding of connecting to concrete supports highlights the importance of RHY programs building extensive networks of community collaborations to assist youth' access to these services as well as help youth build their own support networks to sustain independent living.

The finding of activities emphasizes the importance of offering recreation and is essential to help youth stay active physically as well as experientially. This confirms the findings of several recent studies that support the importance of providing youth with recreational opportunities. For example, in an effort to understand low participation rates in after-school programs, Sanderson and Richards (2010) found that "In order to fulfill student needs and simultaneously meet parent expectations, a blend of academic, recreational, and communal (or social) activities appears to be an important mix for after-school programs to achieve" (p. 437). Additionally, Akers, Muhammad and Corbie-Smith (2011) found that a lack of recreational opportunities can lead to a higher incidence of adolescent pregnancies. According to CEY focus group youth, activities should include a range from planned as well as spontaneous outings. The findings from this study also highlight the importance of staff participation in those activities with youth. 


\section{RUNAWAY AND HOMELESS YOUTH}

\section{"How" services are provided.}

This study found, as did others (Garrett et al., 2008; Raleigh-DuRoff, 2004) that "how" services and supports are provided (program attributes) is equally, if not more, important than "what" those services and supports are. CEY focus group youth articulated program attributes that are key to successful services. These include the manner in which engagement and assessment is performed, providing choices to youth, creating a youth focused milieu that includes safety and stability while simultaneously cultivating in youth a sense of belonging, and being flexible with rules and patient with youth. Yet, continued involvement in current RHY interventions is often contingent upon some type of behavior change tied to continued participation (Hurley et al., 2006; Pollio et al., 2006; Teare et al., 1994; \& Thompson et al., 2002). Because of this, programs can easily become a means of social control, doing little to resolve the underlying causes of homelessness and even be exacerbating poor utilization rates (Gil, 1998; Trattner, 1999).

This study also found that how a program conducts engagement and assessment is critical, confirming findings from Raleigh-DuRoff (2004), which also highlight the significance of effective engagement. Moreover, findings from this study provide additional details on how a program should conduct engagement and assessment. Focus group youth felt it was vital that staff have, and take, time to thoroughly engage and assess youth. This provides staff the opportunity to obtain a 


\section{RUNAWAY AND HOMELESS YOUTH}

comprehensive understanding of youth needs so they are able to identify services customized to individual needs, i.e. educational, vocational, social, etc. This time also provides youth with the time needed to feel comfortable and develop trust of programs and their staff. Conversely, rushing through this stage will have dire consequences such as staff imposing inappropriate or incompatible goals onto youth. Other researchers have found that coercing youth into goals that conflict with their selfinterest will actually create more barriers for youth transitioning off the streets than they remove (Garrett et al., 2008; ORHWG, 2005; Raleigh-DuRoff, 2004). Slesnick and colleagues (2009) explain that when policies define youth goals, "the likelihood of youth rejecting services increases" (p. 2). For example, RHY are often fearful of being compelled to return home or to the foster care system. The League of Women Voters (LWV) (2006) also found that, "having treatment forced on them" (p. 17) would result in youths' rejection of services. The life cycle model of youth homelessness (Auerswald \& Eyre, 2002) suggests that when youth first run away they find themselves at a critical crossroads. If they encounter programs and services that are providing services inappropriately, they may be more likely to engage with the street culture to have their needs met, increasing their exposure to variety of serious risks.

The finding of services customized to individual needs confirms that youth autonomy is a necessary feature of program services. Whitbeck and colleagues (2001) theorize running away from home to be an attempt by youth to gain independence 


\section{RUNAWAY AND HOMELESS YOUTH}

from parents and other forms of social control. Interrelated with this was the importance youth placed on the value of independence/self-reliance (Garrett et al., 2008). Garrett and colleagues (2008) found that skills acquired by youth to survive on the streets provided them with a sense of pride and garnered respect from others. Their findings also indicated youth felt they would have to give this up in order to access services and, just as anyone would resist giving up their autonomy, youth were reluctant to do so. This helps explain the importance of programs providing choices and including youth when determining youths' needs and goals. Doing so creates an environment of empowerment, youth learn about the variety of options available to them, and they begin to use those skills to plan and make decisions for themselves.

This study also found that simply meeting basic needs of youth is not enough to keep them engaged and participating in a program; programs must provide an environment that youth find appealing. Yet, Moses and Kopplin (1992) suggest that because of entrenched American ideas that youth need to be "controlled" and the myth that the family is the most appropriate environment for adolescents, programs are challenged to construct youth appropriate environments. Nonetheless, findings from this study suggest many programs had been successful in creating a youth friendly milieu. Focus group youth described an environment suitable for young people as one that includes providing a relaxed atmosphere, a sense of safety and stability, and flexibility concerning the implementation of policies and procedures. 


\section{RUNAWAY AND HOMELESS YOUTH}

This study finds that key components of the environment include being safe and stable. Having run away or being homeless can be a frightening experience at best and programs must insure youth feel safe when they are participating in services. Garrett and colleagues (2008) found this to be even more important in a shelter model where programs have added responsibility to provide for "the safety of the people, their health, and their belongings" (p. 438). Additionally, perhaps because family conflict is consistently identified by youth as the primary reason for running away from home (Toro et al., 2007), CEY focus group youth were clear that they would not be willing to remain in a program where chaos and conflict exists. The inability of programs to provide safety and stability will certainly influence youths' willingness to engage in the services.

This study also found that flexibility around rules is a critical program feature and confirms that its absence could directly inhibit service utilization (Garrett et al., 2008). This finding also corroborates the LWV (2006) study that found consistent rules and structure are essential elements of the program environment but also that "living with rigid rules" (p. 17) would reduce utilization rates. The CEY focus group youth also identified consistent rules as essential for service provision yet they also stressed the need for flexibility. It is important that programs understand that when rules are infringed upon, there is an opportunity for youth to learn and grow far more than by simply disciplining or discharging them. 


\section{RUNAWAY AND HOMELESS YOUTH}

Findings from CEY focus group youth also indicate there is a striking significance to programs providing youth with a sense of belonging and many youth referred to the program as their 'family'. However, it is important to note that youth are not looking for new 'parents'. These findings confirm findings from RaleighDuRoff (2004) that indicate youth need to feel connected to a supportive group in order to transition off the streets.

This study also highlights the importance of patience when working with RHY. The daily struggle to survive as well as the time it takes youth to accomplish longer-term goals such as education, employment, life skills, etc. requires programs to be patient when expecting change. Patience is also required for youth to effectively interact with staff, counselors, caseworker, etc. so they can establish realistic personal goals.

\section{Staff.}

Findings from this study indicate that staff who are resourceful, model healthy behavior, develop personal connections with the youth, are non-judgmental, and have knowledge of youth (both experiential and from formal education) will provide youth and programs with the best possible chance at success.

The CEY focus group youth identified resourceful staff as important. The ecological-development perspective explains that homelessness, "results from 


\section{RUNAWAY AND HOMELESS YOUTH}

inadequate resources [and] recognizes the importance of the family system in mediating the resource losses that result or manifest as homelessness" (Haber \& Toro, 2004, p. 145). Therefore, it makes sense that when youth are separated from a family system, they rely heavily on staff to support them with accessing resources essential for health, safety, and successful independent living. This confirms Garrett's (2008) finding that youth need staff who offer, "practical help" (p. 438) while adding detail to the specifics of what a resourceful staff looks like. CEY focus group youth stressed that to be resourceful staff must be knowledgeable about the community services, possess a network of community connections and relationships with those services, exhibit inquisitiveness and an enthusiasm to seek out new services, and be persistent in the pursuit of matching the right resource with the individual youth. "How" resourcefulness is carried out is essential as well. Obtaining a vital resource is important, but through the process of acquiring it, staff make use of the opportunity to teach and model self advocacy skills necessary for independent living. Conversely, simply telling youth about a particular resource is not only a missed opportunity to teach a valuable life skill, it also increases the likelihood of failure.

Moreover, this study highlights the importance of staff developing a personal connection with youth. According to CEY focus group youth, a personal connection includes interpersonal skills, the ability to recognize each individual youth's strengths, be proactive in assessing skill areas, and be familiar enough with each individual 


\section{RUNAWAY AND HOMELESS YOUTH}

youth to recognize when they are experiencing a particularly difficult day as well as an especially good one. These findings confirm Raleigh-DuRoff's (2004) finding of the need to, "celebrate each small success" and, "help [youth] identify their passions and interests" (p. 571). Additionally, a personal connection means that staff understand the nuances of each particular youth, are flexible, understand that youth may require different styles of interaction, and have the ability to adapt their own behavior to appropriately interact with youth. A personal connection also means staff are aware of and understand what is happening in the lives of the youth outside the program and how those external events could potentially affect youth and their ability to succeed inside the program.

It is important to note that this depth of personal connection may be at odds with the concept of professional boundaries. Professional social work emphasizes boundaries in order to prevent the harming of clients. The NASW Code of Ethics provides requirements for the ethical provision of services to clients and specifically warns about developing dual relationships. Code 1.06, subsection (c) states, "Dual or multiple relationships occur when social workers relate to clients in more than one relationship, whether professional, social, or business" (National Association of Social Workers, 2008). Yet findings from this study suggest those boundaries could actually diminish the ability of a social worker to effectively engage and work with RHY. 


\section{RUNAWAY AND HOMELESS YOUTH}

Findings from this study also indicate that youth are watching, and learning from, staff and how they conduct themselves. Bandura (1973) describes social learning theory as, "human behavior is to a large extent socially transmitted, either deliberately or inadvertently, through the behavioral examples provided by influential models" (p. 68). Modeling behavior, according to Bandura, has the ability to generate three types of effects on those observing: 1) acquisition of new behaviors, 2) already learned yet inhibited behaviors are moderated, and, 3) modeling behavior can, "serve as social prompts that facilitate similar behavior in observers" (p. 69). RHY program staff must understand the importance of this dynamic and pay particular attention to what they are teaching youth through their behaviors. Because of prior social learning, youth in programs may resort to yelling or other similar behaviors in times of high stress or anxiety. Therefore, it was especially important that staff not respond in a similar fashion.

The overall success of a runaway and homeless youth program will depend heavily on the individual interactions between the youth and the program's staff. Highlighting this importance, Raleigh-DuRoff (2004) found that for every participant in her study with youth who had transitioned from the streets, "there were at least one adult and one organization that helped each of the participants leave the streets" (p. 571). Studies on resiliency also demonstrate the importance of caring and supportive relationships with, "adults who encourage [youth] to aim high and [provide] 


\section{RUNAWAY AND HOMELESS YOUTH}

opportunities to contribute through participation in meaningful activities" (USDHHS, 2007, p. 21). Additionally, the most common statements made by youth in focus groups with the LWV (2006) centered on the importance of having one relationship with an adult role model for the provision of advocacy, mentoring, and guidance.

Historically RHY have been viewed through the lens of delinquency, resulting in theories that focused on the criminal behavior of youth (Moses \& Kopplin, 1992; Schweitzer, Hier \& Terry, 1994). Findings from this study suggest this paradigm is still active today and youth are well aware of it. Because of this, it is essential that staff practice with a nonjudgmental perspective. This allows staff to effectively engage and assess youth, develop a personal connection and an ongoing working relationship with them, as well as create an environment where youth feel comfortable. One way staff can exhibit nonjudgmentalism is to support youth as they learn and grow, understanding that "mistakes" are a normal part of the learning and growing process. Conversely, Garrett and colleagues (2008) found, "staff whom young people perceive as judgmental or as having ulterior motives for helping them may prevent them from accessing services" (p. 438). Additionally, the LWV (2006) found that "preaching and condescending approaches" (p. 17) were described as specifically problematic for youth. Furthermore, in their report on research findings and interventions with RHY, Toro and colleagues (2007) found that many of the examples of family conflict, the chief reason given for running away, were in areas where youth may feel they are 


\section{RUNAWAY AND HOMELESS YOUTH}

being negatively judged on their behavior choices, "sexual activity,... sexual orientation,... and alcohol or drug use" (p. 6), all behaviors that, for the most part, are socially acceptable for "adults". It could be that family conflict results from this judgment thereby making youth especially sensitive to it.

\section{Summary.}

The chief critique of intervention studies is the limited information about specifics of program services. Those that do provide detail seem to focus on the behavioral changes that RHY "need" to make, so they will be "able" to return home or other safe housing. The key voice missing from the development and oversight of RHY programs is that of the youth who utilize these programs. In light of this, it is imperative that youth voice be the centerpiece of program development, improvement and evaluation.

Many of the findings reported from this study confirm previous research. Yet, because youth analyzed the focus group data, there is added validity to these findings. Findings from this study suggest there are key elements that programs and staff should be focusing on to improve service utilization rates. Additionally, findings from this study begin to provide some of the details of the behaviors staff should be trained and evaluated on to improve utilization rates. 


\section{RUNAWAY AND HOMELESS YOUTH}

Findings suggest that skill building should emphasize life skills and be less focused on social skills. Counseling should include mental health and substance abuse treatments but should also incorporate family mediation services. Programs must focus on developing extensive community networks in order to provide customized services. These services should be concrete, useful, and customized to meet the individual needs of youth. Additionally, activities should be an integral part of any RHY program model.

Yet, how these services are provided are, perhaps, even more critical than the actual service being provided. Because of this, current policies and models that dictate youth goals and/or focus on changes in youth behavior are resulting lower utilization rates among RHY. A program's environment and the manner in which staff enforce program rules and regulations will also influence utilization rates. Additionally, program attributes must include services delivered in ways that support youth autonomy; doing otherwise has been shown to be rejected by youth and demonstrated in lower utilization rates.

Finally, the findings from this study propose that staff who are resourceful, model healthy behavior, develop personal connections with the youth, are nonjudgmental, and have knowledge (both experiential and from formal education) of youth issues will provide youth with the best possible chance at success. Moreover, 


\section{RUNAWAY AND HOMELESS YOUTH}

youth reported their preference for staff who offer what youth perceive as useful help while at the same time respecting youths' autonomy.

\section{PAR}

\section{Importance of PAR with youth.}

Participatory action research (PAR) provides researchers with an approach from which to construct research methodology. McIntyre (2008) depicts the tenets PAR as a commitment to engage, investigate, and disseminate findings in partnership with those populations involved. Stringer (2007) describes the key elements of PAR as democratic, equitable, liberating, and life enhancing. There are distinct advantages associated with the use of PAR methods, which include increased likelihood of community utilization of the findings, improved viability, and enhanced rigor (Turnbull, Friesen, \& Ramirez, 1998). Youth, too, are valuable partners when conducting PAR. Freeman and Mathison (2009) list five reasons why youth-led research should be supported; 1) youth have abilities that can be tapped in developing and implementing a research project, 2) youth bring to a research project a unique perspective or voice that cannot but help the process of answering questions about youth, 3) youth are vital stakeholders in the process and outcome of research, 4) the knowledge and skills youth acquire through active participation in research can transfer to other aspects of their lives, and 5) youth-led research can help broaden and 


\section{RUNAWAY AND HOMELESS YOUTH}

revitalize an activity that has a reputation as being boring, inconsequential, and of interest to only a small select group of adults. (p. 171).

Constructivist researchers are routinely called upon to address objectivity in their research, yet objectivity is not a goal. As in the case of PAR, the aim is to represent the perspectives of participants from their own standpoint. The dual role of co-researchers is embraced on the assumption that findings will be more valid when interpreted through the lenses of people who have experienced the phenomenon of study. As Stringer (2007) points out, "the meaning or significance of any... information, however, can be determined only by the people who live the culture of the setting, who have the profound understanding that comes from extended immersion in the social and cultural life of that context" (p 203). For this study, members of the YAG played multiple roles. They were simultaneously research analysts, research participants and they had shared experiences with the focus group youth. This unquestionably had effects on their findings. Analysts were being asked to assess the responses of the focus group youth, while simultaneously acknowledging their own experiences, and then responding to the understanding presented by other team members. Management of researcher bias is still necessary and in this study, this was addressed through the initial training sessions, recurring discussions with team members, and an audit trail of documents and audio recordings. PAR recognizes that there are a variety of ways of "knowing", all with strengths and limitations. Therefore, 


\section{RUNAWAY AND HOMELESS YOUTH}

the question is not necessarily which way of knowing is better, but whose knowing provides the best understanding. This study privileges the knowledge and understanding of runaway and homeless youth. It is now up to the reader to determine if these findings make sense in their local context.

\section{Summary of key themes.}

Upon conclusion of the analysis of the focus group transcripts, a focus group was conducted with the youth analysts to evaluate the participatory methods that had been employed. Participants were asked to think about the work of analyzing the transcripts and were then asked each of the following questions; 1) what worked well, 2) what could have been done better, 3) what have you learned from all this, and 4) what advice would you give another researcher who wanted to do collaborative research with young people?

There was little in the research literature to guide the specific steps used in this study. Findings from this study highlight several key features when working with young people on a project such as this. These include the recruitment process, the meeting environment, the individual analysis, and the collective work.

Findings indicate that youth understand and appreciate the importance of the recruitment process in building a research team with individuals from varying backgrounds and experiences. A variety of perspectives improved validity of the 


\section{RUNAWAY AND HOMELESS YOUTH}

findings and helped control for bias. As conveyed by Freeman and Mathison (2009), a project such as this provides multiple learning opportunities for participants. This study found that teamwork is a significant component of that learning. Explicitly, youth came to understand how individual differences allowed for a deeper understanding of the data to emerge. They also learned that working as a team improved the analysis and enhanced their own personal growth, which, in turn, improved the overall project. Moreover, as noted by Freeman and Mathison (2009), through the learning from one another and the feelings of achievement, youth also learned to enjoy the experience of research.

Findings from this study also highlighted the importance of the meeting environment. The meeting environment needs to offer comfort as well as provide for the needs of this type of work, i.e. adequate table space, white boards, etc. Supplying food is also key to a successful meeting environment helping analysts feel at ease, which improved their ability to focus on the work at hand.

This study also found that breaking the work up into individual analysis (first analyzing each transcript individually) and collective work (presenting, then discussing with the team) was an important process. Individual analysis provided team members time to thoroughly read each document, make notes, and code the data all at their own pace. Individual analysis also provided time for analysts to provide "voice" to the transcript. The decision on what type of format to provide the CEY 


\section{RUNAWAY AND HOMELESS YOUTH}

focus group data to the analysts also provided interesting results. There was a concern that if the only option of providing that data was transcripts, it might create a barrier to who was able to participate in the analysis, i.e. they would have to know how to read and read well. The idea of providing audio recordings of the focus groups was also discussed, but youth who had hearing challenges or lacked access to playing devices might be excluded. In addition, analysis of focus group data is traditionally conducted as soon after possible after the completion of the group and by the facilitator to insure context and circumstances are accounted for. This seems to have placed these youth analysts as a distinct disadvantage. It was decided to provide written transcripts only, which had effects on the outcome. Doing this removed the "voice" of the actual focus group youth and interjected the "voice" of the youth analysts, which provided the theoretical sensitivity this project sought. Because individual socio-demographic information was not gathered on the original focus group participants, this allowed the project to reintroduce "known" experiences. Additionally, this reflects the range of possibilities when implementing PAR methods.

The collective work provided a forum for achieving two objectives, 1) presenting individual analysis, and 2) establishing consensus as to the importance of those findings. The collective work allows analysts to share with the group what they have determined as important. The meeting environment plays a critical role in the collective work. For the group process to work well, the facilitator must cultivate an 


\section{RUNAWAY AND HOMELESS YOUTH}

environment where analysts feel free to share their ideas, experiences and hypotheses as well as encourage deeper discussions that build a shared understanding from the individual insight of each team member. These discussions not only add to the project but also expose members to new ideas and understanding thereby broadening their own personal perspectives.

Although team members felt that the project was a success, findings indicate there were portions that could have gone better, namely the initial training and the way in which the meetings were scheduled. The goal of the initial training was to introduce team members to qualitative analysis and strategies to manage bias. This study underscores the care researchers must use when providing training on new concepts to inexperienced research team members. Additionally, there must be adequate time allowed for all participants to understand and practice new skills. This will help team members feel more comfortable with the process and result in higher levels of efficiency throughout the project.

With regards to the scheduling of meetings, there are two key factors that impact the length of time required between group meetings and must be taken into account; the amount of data to be analyzed and the personal schedules of individual team members. While flexibility in scheduling can be advantageous, it also brought challenges and at times frustration. Although it may extend the project timeline, prescheduling meetings at the same location would provide a level of constancy, which in 


\section{RUNAWAY AND HOMELESS YOUTH}

turn would diminish frustrations. The alternative resulted in some instability, which, at times, felt chaotic, an unhealthy feeling for any individual and be especially troubling to RHY. Additionally, a fixed time and location will help team members keep track of when/where the next meeting is. One concern during the planning stage for this project was trying to get it done as quickly as possible before youth began to drop out. This study clearly demonstrated that to be an unfounded concern.

Youth analysts also offered guidance for adult researchers who are contemplating similar methodology. This advice focused on the level of researcher involvement with the research team. Although prescribed by PAR methodology, it may be unrealistic the adult researcher to completely remove themselves from the process. Team members stated they understood that by simply being in the room, the researcher becomes part of the process and should not attempt to completely remove her/himself from the process. Adult researchers should expect youth to need more involvement from the researcher and then look for an opportunity to transition to less involvement as the team begins to settle into their roles and take more control over the process. This researcher found that finding the appropriate balance between support and interference to be exceeding difficult. Because of this, as well as traditional adultyouth relationships and stereotypes, researchers should expect this to be challenging and be diligent in observation and make adjustments accordingly. 


\section{RUNAWAY AND HOMELESS YOUTH}

\section{Additional findings beyond the research question.}

Through personal observation and the analysis of the final focus group, additional themes emerged that shed light on this dynamic, these included pride, educational aspirations, and the importance of youth voice. Team members exhibited an immense amount of pride throughout the performance of this project. Analysts repeated stated how important they felt this work was to the field and took personal ownership of this responsibility, were not satisfied with doing the minimum requirement and took on the title "research analyst." While team members felt as if they were back in school, they stated it was different, prompting them to inquire about opportunities for higher education. Improvement in these areas suggests an enhancement in social capital, which is critical for successful transition to adulthood for all youth (Laser \& Leibowitz, 2009; Markward, McMillian, \& Markward, 2003) and has been specifically shown to reduce a variety of maladies in homeless youth (Bantchevska, Bratle-Haring, Dashora, Glebova, \& Slesnick, 2008).

Finally, findings strongly support expanding, and perhaps even mandating, the utilization of youth to evaluate programs. A major premise underlying PAR is that participants are involved in every aspect of the project: identification of the problem, data gathering plan, development of questions, sampling requirements, etc. However, research has traditionally dismissed youth outside of the role of being objectified through observation. Stringer (2007) cautions that care must be taken so that one does 


\section{RUNAWAY AND HOMELESS YOUTH}

not perform PAR with youth to "merely train kids to formulate themselves and their problems in our terms to answer our questions" (p. 170). He also emphasizes the importance of power-sharing in the researcher-participant relationship "Titles such facilitator, associate, and consultant are more appropriate in community-based action research than director, chief, or head" (p. 24-25). Yet others remind us that the quantity of participation does necessarily equal quality of participation (Hart, 2008; McIntyre, 2008). According to Hart's (2008) ladder of participation, the level of youth involvement in a program can range from being manipulated to actually sharing decision-making responsibilities. Findings from this study clearly exhibit the advantages attained when young people are given the power to share in decisionmaking aspects of, and participation in, research. It does not seem to be a stretch to infer from these findings that youth would be just as valuable a resource in all aspects of program development. The ladder of participation could prove to be a useful tool for helping those working with youth determine if youth are truly partners or merely tokens.

A review of the literature discovered that although participation of service users in service development has been encouraged in the U.S. for several decades, its development has been very limited in most fields of practice including RHY services. In contrast, in England participation of consumers in services, referred to as user involvement, has been codified in, "both childcare and community care government 


\section{RUNAWAY AND HOMELESS YOUTH}

guidance and legislation... [and] established as a formal component at levels of both collective policy and individual practice" (Beresford, 2000, p. 491-492; Pilgrim \& Waldron, 1998).

However, legislation alone provides limited affects. In a critique of the user involvement system in the U.K., Beresford and Croft (2001) point out that while many service systems attempt to include service users to help shape practice, policy and research, "control [often] remains with the service system" (p. 296). A mistake is made when service users are brought in only to help a service system improve on what has already been designed rather than allowing the service users to actually design the service. The authors go on to describe how doing "participation" this way has detrimental effects on the service users, as indicated by limited participation, and, consequently, "most involvement in such service system-led initiatives for participation has achieved little for much effort" (p. 297). When discussing the appropriate level of participation in research, Beresford (2000) suggest that control is the key and, although generally presumed otherwise, recognizing that "academic knowledge claims have no greater validity than service users ones" (p. 497). According to Pilgrim and Waldron (1998) the root of this conflict stems from the competing goals of the two groups. Service providers are concerned with providing personal choices to existing services while service users are concerned with issues of citizenship and civil and human rights. Moreover, the authors state that when service 


\section{RUNAWAY AND HOMELESS YOUTH}

systems, or researchers, have all the power in these partnerships, service users are wary of collaboration, "voluntarism and coercion are [as] incompatible, as partnership and paternalism" (p. 100). Consequently, for meaningful participation to occur, service users must be given formal power within organizations.

Beresford (2000) indicates there is much to be gained from user involvement. When service users are given control of knowledge development it, "makes it possible for the debate to identify, reflect and advance their needs, concerns and interests more accurately and closely and can enable more relevant and participatory research and analysis" (p. 489-499). Moreover, participation in this manner implies that service user knowledge is valued and respected and, additionally, "is likely to have more political weight" (p. 499). Specific to RHY, youth alone are the ones who have directly experienced the impact of the policies and practices developed for them, yet there is a nagging tendency from "professionals" to devalue their understanding and insight; knowledge that is desperately needed to move the field forward.

This, along with the findings of this study, strongly supports Stringer's (2007) claim that that the level of participation directly affects a participant's willingness to engage with the project. The opportunity to accomplish tasks that feel important is critical to effective participation. Although PAR methods imply that participants must be involved throughout the entire process, this study demonstrated that there may be multiple ways to conduct PAR that will still provide benefit to projects. Although 


\section{RUNAWAY AND HOMELESS YOUTH}

youth joined this study during the analysis of the CEY transcripts, they were able to identify and provide a level of analysis that would have been difficult, if not impossible, for this researcher working alone. Similar outcomes could be expected if youth were allowed to participate in other areas of program development and research.

\section{Theoretical implications.}

Because the central RHY program models and services have been created absent youth voice, PAR methods were drawn upon for this project to restore equity. Although RHY were not included in the steps leading up to and including gathering data the tenets of theoretical sensitivity (Strauss \& Corbin, 1990) and PAR (McIntyre , 2008; Stringer, 2007) suggest youth will provide depth and understanding to the interpretation of focus group youths' responses not possible for adult researchers. This methodology privileges the theoretical sensitivity of youth analysts over the theoretical sensitivity of adult or academic views.

This study appears to challenge the concept of control theory (Empey, 1982) in relation to RHY. Control theory suggests youth run away because they lack of the internal controls necessary to cope with their environment. Findings from this study suggest that when youth are provided with appropriate external motivation (treated equally, a fair wage for work, etc.) they exhibit behavior that indicates they do in fact have internal controls and can modify their behaviors accordingly. From this, it would 


\section{RUNAWAY AND HOMELESS YOUTH}

seem that it is not the youth, but society, that is simply not providing adequate external motivation, as noted by Garrett et al. (2008). This would also suggest that Stringer's (2007) supposition that the characteristics of PAR are that it is, "democratic... equitable... liberating... [and] life enhancing" (p. 11) may be understood that if a program/project is democratic and equitable, then it will be liberating and life enhancing.

The risk amplification model (RAM) suggests that disadvantages, e.g. maltreatment, poverty, etc., have a cumulative effect on individuals (Whitbeck et al., 2001). Findings from this study indicate that although the RAM may help explain how homeless youth end up driven to the fringe of our society, it is not final. The PAR methods employed in this project suggest youth can, want to and will overcome the challenges suggested with RAM if given the proper supports.

Finally, this study wholly supports Velazquez and Garin-Jones’ (2003) statement,

There is a portrait of youth that is not only misleading, but harmful. We ought to correct the record out of a sense offairness, as well as accuracy. These young people desperately need a chance to get started in responsible careers. Instead, they are frequently saddled with the image of being uninterested and unwilling to assume responsibility. Complaining about youth is all too common (Adultism and cultural competence section, para. 1) 


\section{RUNAWAY AND HOMELESS YOUTH}

\section{Challenges encountered.}

Implementing these methods was not without its challenges. At the outset, researchers employing PAR should schedule a longer period of time to conduct the project. Just as this study found when working with RHY, at the foundation of PAR are the relationships between the researcher and the participants. Time is needed to cultivate these relationships in ways that empower participants. In addition;

Time is needed for many additional tasks including locating [participants] ... arranging the logistics of communication, carrying out the communication, allowing sufficient time in advance of the communication for preparation by [participants], and allowing sufficient time after the communication for adequate reflection and feedback (Turnbull, Friesen, \& Ramirez, 1998, p. 180).

Moreover, researchers should account for the increased funding needs associated with paying all members of the research team, i.e. the participants.

\section{Summary.}

Many of the findings from the PAR portion of this project align with the findings from the CEY focus groups. The services and supports offered are important (i.e. training, room, food, etc.), yet how they are offered is just as critical (the environment, nonjudgmental interactions, etc.). Projects such as this not only provide 


\section{RUNAWAY AND HOMELESS YOUTH}

valuable information for programs, services, interventions, etc., but when young people are afforded opportunities for meaningful participation, they learn from others and about themselves. What possible reason can there be for not providing this opportunity for learning and growth?

Dismissing the value of youth and their potential impact on policies, programs, and practices lead to missed opportunities for youth accomplishments, blaming the youth for challenges they meet, and continues the discomfort youth and adults feel when they are in each other's company. Together, these mistakes continue a cycle of youth oppression that has severe consequences for RHY, and even more so for RHY of color or LGBT. When youth are included in programming and research, one not only realizes improved benefits with projects, but there are latent outcomes that benefit the youth as much, if not more, than any planned intervention (e.g. pride of work, educational aspiration, and youth voice). Just as with programming, one must make the project work for the youth; the alternative is to continue oppressive service provision that youth reject.

\section{What do these Findings Mean for Policy, Practice, Programming}

Based on the findings of this study, a comprehensive systemic change in the way RHY services are carried out are critically needed. While well meaning advocates have developed practices, program models and policies they feel best serve this 


\section{RUNAWAY AND HOMELESS YOUTH}

vulnerable population, utilization rates suggest these models may not be the most effective. Additionally, researchers from both the U.S. and the U.K. suggest that to develop a useful service system the views of RHY are vital (Beresford, 2000; Beresford \& Croft, 2001; Pilgrim \& Waldron, 1998; Stringer, 2007). Moreover, the voices of youth are available and staff, as well as researchers, need to create opportunities for RHY to give input to improve services. YAG members are still exploring the breadth of options available to them for distributing this work, yet there are several key recommendations for RHY practice, programming, and policy. Discussed in more detail below, Table 8 provides an overview of those recommendations.

Table 8

Recommendations

\begin{tabular}{lll}
\hline \multicolumn{1}{c}{ RHY practice } & \multicolumn{1}{c}{ RHY Programs } & \multicolumn{1}{c}{ RHY Policy } \\
\hline $\begin{array}{l}\text { Continuing education \& training } \\
\text { in service models that emphasize } \\
\text { relationship building }\end{array}$ & $\begin{array}{l}\text { Provide opportunities for } \\
\text { meaningful youth inclusion } \\
\text { for program development and } \\
\text { evaluation }\end{array}$ & $\begin{array}{l}\text { National Conference on } \\
\text { Runaway and Homeless Youth }\end{array}$ \\
$\begin{array}{lll}\text { Move away from pathology } \\
\text { oriented service models }\end{array}$ & $\begin{array}{l}\text { Review program policies for } \\
\text { barriers to services }\end{array}$ & $\begin{array}{l}\text { Support expanded research in } \\
\text { area of RHY }\end{array}$ \\
$\begin{array}{l}\text { NASW evaluate ethical policies } \\
\text { that inhibit youth work }\end{array}$ & $\begin{array}{l}\text { Provide employment within } \\
\text { programs for skill } \\
\text { development }\end{array}$ & $\begin{array}{l}\text { Require youth inclusion in } \\
\text { research \& evaluation }\end{array}$ \\
$\begin{array}{l}\text { Provide opportunities for } \\
\text { meaningful youth participation } \\
\text { in evaluation/research projects }\end{array}$ & $\begin{array}{l}\text { Ensure staff autonomy to } \\
\text { utilize appropriate methods }\end{array}$ & \\
\hline
\end{tabular}




\section{RUNAWAY AND HOMELESS YOUTH}

\section{RHY practice.}

Staff need to insure they are providing the right services using the appropriate methods. Doing one without the other will likely result in significant negative impacts on the youth they are attempting to serve. This study found that how practices are conducted is as important as what is provided. Because of this, training modules on effective relationship building and power sharing with RHY need to be developed and emphasized. For example, the Runaway and Homeless Youth Training and Technical Assistance Center should ensure there is an emphasis on the importance of relationship in any training they develop or sanction. Moreover, and at a minimum, formerly homeless young people should be included in the development of these training modules as well as compensated for their work. Additionally, any youth worker certification should emphasize training on structural barriers that RHY must deal with and move away from the pathology of RHY. Additionally, partnering with youth in meaningful ways and privileging their voice holds potential to be valid across other youth serving systems.

Specific to social work practice, findings from this study suggest there is incongruity between the professionalism of social work and the needs of youth. CEY focus group youth were explicit in stating the importance of establishing personal connections with staff to the degree that, at times, youth felt were on par with those of family members. Yet the field of social work has specified ethical codes and practice 


\section{RUNAWAY AND HOMELESS YOUTH}

models that inhibit this level of relationship from forming. The National Association of Social Workers needs to reexamine this dynamic and provide guidance to the field.

\section{RHY programs.}

Programs also need to ensure the right service using the appropriate method is being used with youth. The primary way programs can ensure this is by incorporating RHY in every aspect of programming. For example, youth should be sitting on agency boards of directors to help insure that agency wide decisions do not negatively affect

youth. Additionally, with training and support youth should be actively engaged in the process of program evaluation and compensated for their work. Youth are exceptionally capable to carry out interviews or focus groups with current or past program participants including question development, strategies for sampling, and data analysis. Moreover, youth are best suited to evaluate why other youth are not utilizing available services, which is critical information for useful program changes or the development of new services/programs. Youth participation needs to be meaningful, which means programs and staff will have to share power. If programs are contracting with outside evaluators/researchers, they should insure that youth are utilized in those processes as well. Because this study suggests benefits can be realized along the continuum of PAR methods, programs have the latitude to collaborate with 


\section{RUNAWAY AND HOMELESS YOUTH}

youth even on current or ongoing projects though youth may not have been involved with their creation.

Additionally, partnering with youth, programs should conduct a review of their internal policies and procedures to identify those that are creating barriers. Those that are found to create barriers must be modified. For example, because of the conflict between, "institutional and developmental transitions" (Davis, 2003, p. 496), because, “adolescence and adulthood are not tidy developmental categories" (Scott \&

Steinberg, 2008, p. 237), because of study participants recommendation for patience in service delivery, any policy that dictates service time limits should be reviewed. Also, findings from this study suggest that programs deemphasize the teaching of social skills and emphasized life skills building. Moreover, the activity of policy review should be repeated at regular intervals.

Regardless of size, all RHY programs have the same basic needs for staffing. Whether that is interfacing with the public by answering phones or participating in community meetings, writing up reports, or data entry and analysis programs offer a variety of opportunities for youth to acquire valuable job skills. If employment is the means to independent living, then youth need obtain those skills. Who better to provide an environment of learning, where the individual needs of the youth are the goal, than RHY programs? Therefore, programs should actively seek out ways to put youth into employment roles and adequately compensate them for their work. 


\section{RUNAWAY AND HOMELESS YOUTH}

One last important note, although programs may establish what services can be offered (e.g. skill-building, mental health services, activities, etc.), they need to provide staff the autonomy to decide how those services are carried out (e.g. engagement and assessment, provision of choices, flexible, etc.).

\section{RHY policy.}

Critical to the issues of RHY is that policy, practice, and research are not well linked. Currently, it appears that federal policy dictates practice and then relies on research methods to "prove" their effectiveness. To successfully create programs that engage and work for RHY, this relationship needs to be fundamentally modified.

With the confusion surrounding definitions, inaccuracies in census data, limitations around intervention effectiveness studies, and poor utilization rates, it seems prudent to call for a White House Conference on Better Futures for Homeless Youth. With a focus on bottom-up system redesign, this conference would invite youth, researchers, and practitioners to develop new ways of thinking about and responding to the needs of RHY. For example, as other scholars have advocated for, the populations of youth who are "runaway" and "homeless" should be separated in policy as well as programs and practices, and new federal policy should be detached from Juvenile Delinquency policy (Glassman, Karno, \& Erdem, 2010). The outcome, along with required changes needed at the national level, would then be presented to 


\section{RUNAWAY AND HOMELESS YOUTH}

the federal departments currently active in youth services; Housing and Urban

Development, Health and Human Services (including Administration for Children and Families and the Family and Youth Services Bureau), Department of Education, Department of Labor, and the Department of Justice (including the Office of Juvenile Justice and Delinquency Prevention).

Primarily, federal research policy needs to support expanded research in the area of RHY. Concurrently both private (philanthropic foundations, United Way, etc.) and public (federal, state, and local government) funding for RHY services and research should require the inclusion of youth.

\section{Next Steps for Research}

Foremost, the methods utilized in this project strongly support collaborating with RHY in all aspects of research and evaluation that could have an effect on them. Recognizing the impact theoretical sensitivity has on research is vital. RHY researchers and advocates must remove themselves from this position of power and support RHY participation. Not only will this improve the outcome of research, it will also insure that findings are useful to the youth and the field. Ignoring this not only continues to disempower RHY, it will undoubtedly continue the rift between youth and communities and subsequently the underutilization of services that further marginalizes this population. 


\section{RUNAWAY AND HOMELESS YOUTH}

Moreover, there is an urgent need to explore the impact of race in the RHY service system. Based on the literature review for this project, there is every reason to believe that racial disparities exist in RHY services and yet there seems to be no determined effort to respond to it. There are indications that youth of color are running away at higher rates and that those who do access RHY services achieve diminished outcomes when compared to youth who are White. Federally funded RHY programs are currently required to collect racial data on the youth they serve, but it is unclear if that information is being used to determine effectiveness of interventions or being used to modify services to the specific needs of youth of color. Because current census methods are problematic, future research must develop census methods that incorporate the breadth of the RHY population. This information is essential for the field to identify and address issues of disparity within the system. Including youth of color and/or members of other oppressed communities (e.g. LGBTQ, young people with severe mental illness, physical disability, etc.) in the development of these methods will unquestionably provide insight and understanding necessary to move the field of RHY services beyond its current limited impact. Concurrently, RHY policy should be analyzed for its impact on racial disparity.

Future research should replicate this study and work with youth to disaggregate responses by program, an idea that is supported by other researchers (Slesnick et al., 2009). That work should also seek out ways to understand the impact of various 


\section{RUNAWAY AND HOMELESS YOUTH}

pathways into homelessness. For example, how do these findings support or conflict with the typologies presented by Orten \& Soll (1980) (first, second, and third degree runners)? Does the intensity of the intervention differ with members of these groups? Family mediation holds some promise as an effective intervention for shelter youth who are able to return home. Which group is this practice most effective with and why?

Researchers should also collaborate with youth to create evaluations that measure the program attributes found in this study (how programs engage and assess, deliver services, demonstrate flexibility, etc.) and then determine if and how they predict longer-term outcomes in youth such as stable education, employment, housing, etc. Additionally, findings from this study propose that program environment is critical. Rigorous research needs to be done to understand program environments. How are the programs from this study creating a youth environment? What are these programs doing specifically? How is it working for the youth who are in the program?

In an effort to understand poor service utilization rates among RHY services, this project privileged the voice of youth who were engaged in those services. Future research must also privilege the voice of those youth for whom RHY services did not work, including youth who either refused to engage in the services or did engage but then left because their needs were not being met. These youth can provide critical 


\section{RUNAWAY AND HOMELESS YOUTH}

data. Where the CEY focus groups were essentially asked, what are programs doing right, future research needs to ask, what are programs doing wrong?

The PAR methods utilized in this study hold promise in that they suggest involving youth at any step along a project timeline will be advantageous. Yet more research is needed. Additional research questions could include, are there other means of incorporating PAR methods that should be explored? Are there ways to utilize PAR methods that would be more valuable to researched communities? Are there other ways to include youth in research projects?

\section{Reflections}

I imagine dissertations often feel more like arduous journeys to those who embark on them. This project was no different for me. When first conceptualized, I had anticipated conducting the analysis myself and then recruiting RHY to be surrogate member checkers. I was eager to analyze the focus group transcripts, write up the findings and then disseminate what I felt I had been hearing in those CEY focus groups. Moreover, having my own experiences working in the field of RHY, I felt I understood both the practical abilities of program staff and the need for change in the way services are being provided to RHY. However, as the project developed, I realized I was simply repeating the mistakes of those before me; a well-meaning advocate wanting to develop programs the way I thought was best. 


\section{RUNAWAY AND HOMELESS YOUTH}

While in the field working with youth, I had always attempted to work from a positive youth development perspective and yet it seemed that now, when it really mattered, I was getting cold feet. Could youth really do this level of work? Was I really prepared to turn over control of the focus group data to them? After much selfreflection on what working with youth really meant for me, I came to the conclusion it would have been better for this study to have utterly "failed" with youth, than to have "succeeded" without them. However, the challenges I faced did not end there.

As I sought out methods to guide this process, I landed on PAR, but was this even a valid approach to employ PAR methods? I felt I was in a "damned if you do, damned if you don't" scenario. PAR seemed to suggest that the project begins with developing partnerships with the communities. Yet this project had already designed the focus groups, the recruitment process, and the questions, and even collected the data. I was proposing stepping in and injecting a new method from a different theoretical perspective. More than once, I felt I had bitten off more than I could chew and wondered if the entire project should all be thrown out and started over with youth from the very beginning. But then there were the youth who had participated in the CEY focus groups and their belief that the information they offered was going to be used to help make programs better and, hopefully, help more RHY. To start this project over would mean that their responses would likely end up collecting dust at the bottom of file cabinet. 


\section{RUNAWAY AND HOMELESS YOUTH}

This was challenging work. At any given moment I felt I could negatively impact the dynamics and, subsequently, the outcome of the project. Furthermore, although I have significant experience in organizing large undertakings, the logistics for this project were hard. I was able to secure funding to pay youth for their work but there were time constraints involved. Completing the recruitment process, getting the University's paperwork filled out, getting the project started, etc. were much more complicated than I had anticipated. Concurrent with the coordination of other logistics, securing a room, providing transportation, etc. at times felt overwhelming.

However, what I learned from this project is that youth are far more capable than I had ever imagined. I learned that when given meaningful opportunities to participate, in an environment that is supportive, young people will eagerly rise to the challenge.

I also learned that the specific RHY service is not as important as how the service is provided. When I first started, I imagined inventorying the services, codifying them, manualizing them, and then distributing them to the field for implementation. In the end, I realize it has less to do with what is being offered and more to do with how it is offered. Specifically, how youth are treated, respected, and valued.

There were two chief things that surprised me. No youth ever missed a meeting and their taking on the title researcher. The meeting/room scheduling did not go as 


\section{RUNAWAY AND HOMELESS YOUTH}

smoothly as I had hoped. However, not once did any youth miss a meeting. In fact, if they merely thought they were going to be late, they called me ahead of time. One YAG member was in her first trimester of pregnancy and there was one meeting in particular where she was feeling quite ill. In fact, twice she got up and went to the restroom to throw up. Yet she always returned and actively participated in the discussions. I cannot believe I simply got lucky recruiting these five youth. I believe it is indicative of the level of professionalism youth are capable of when given the chance to participate in meaningful ways.

This project has certainly changed the way I see young people. The foremost is the attention I pay to the language I use when talking to, or about, young people. When I first conceptualized this project I had come up with the title Youth Advisory Group and detailed how the "youth" were going to complete this or that step. Yet almost immediately, I became embarrassed referring to them as "youth". I was interviewing them for employment, they were part of a research team, and they were conducting detailed analysis of qualitative data. It felt no more appropriate to refer them as "youth" as it would be for me to refer to an older team member as "senior".

One last point I want to note, is how my status may have affected my relationship with the YAG. As a middle-aged, white male, youth worker who is married with children of my own, I am situated with my own level of privilege. In what ways could this have affected the findings? It is quite possible that an 


\section{RUNAWAY AND HOMELESS YOUTH}

unrecognized paternal relationship developed. What impact would this have on the way I responded to them, or conversely, how they responded to me? How might my race have impacted the willingness of the participants of color to voice concerns? Questions such as this should be centered at the forefront of new research projects that collaborate with youth. This model of research should be replicated with RHY and other populations of youth in other locations, programs, and service models. When the research literature is replete with studies developed and conducted by youth, regardless of whether or not it will support or contradict these findings, youth will have been given their rightful place of power. 


\section{RUNAWAY AND HOMELESS YOUTH}

\section{Chapter 6: Conclusion}

Although difficult to confirm, researchers in the field of RHY are consistent in their conviction that the vast majority of runaway and homeless youth never access social services, leaving them at high risk for a multitude of diseases and infections, mental health conditions, as well as victimization both physically and sexually (Garrett et al., 2008; Slesnick et al., 2009). Because RHY program models and services have been created absent youth voice, participatory action research (PAR) methods were drawn upon for this project. This study sought to understand what programs are doing well from the perspectives of youth who utilize those services, which is critical to improving services and/or developing new interventions for this particularly vulnerable population. This project contributes to a knowledge base that can inform direct service providers, program administrators, and policy makers.

This study took data collected from focus groups with runaway and homeless youth participating in a variety of RHY programs (i.e. street outreach, drop-in centers, Basic Centers, and Transition Living Programs). Then, employing the principles of PAR, current and previously homeless youth were hired to create a research team to analyze the data, privileging youth voice over that of the researcher. A final focus group was performed with the young people who made up the research team to evaluate the PAR process. 


\section{RUNAWAY AND HOMELESS YOUTH}

Findings from this study indicate there are key services that are important to youth who access them. These include skill-building needed for daily living such as cooking and managing their finances as well as mental health services, which include substance abuse treatment and family mediation. Youth also described the importance of services that are customized to meet their individual needs, which could range from bus tokens to assistance with navigating confusing bureaucracies when accessing government services such as food stamps. Additionally, youth described the importance of services that help them build their own social support networks and the significance of providing recreational activities.

However, findings also indicate that RHY services should focus on how services are being provided as much as what they are providing. Focus group youth stressed the importance of thoroughly engaging and assessing youth, ensuring that trust was established and that staff thoroughly understood the needs of each individual youth, before attempting to help them. Moreover, youth stated that autonomy and being provided choices was extremely important to them. Focus group youth also described the importance of a program environment that provides safety, security and a sense of stability and how this was critical for youth to be able to complete the tasks program expected of them. Additionally, youth described how they needed flexibility with regards to program rules and the need for programs to be patient with them while 


\section{RUNAWAY AND HOMELESS YOUTH}

they are learning new skills. Furthermore, youth explained the significance of programs providing them with a place where they feel they belong, as with a family.

Focus group youth also described characteristics of individual staff that were important contributors to success when working with RHY. These included being resourceful, which youth described as staff who are knowledgeable of current services, possess a network of community connections, exhibit inquisitiveness and an enthusiasm to seek out new options in the community, and are persistent in the pursuit of matching the right resource with the individual youth. Youth elaborated on the need for staff to be accessible to them and model healthy behavior, especially in times of high stress. They described the necessity for staff to develop a personal connection with youth; becoming familiar with the youth on a personal as well as a professional level. Moreover, youth described the importance of staff being nonjudgmental and how this helped effective engagement with youth, develop ongoing working relationships and create an environment where youth were comfortable and felt good about themselves.

With regards to the PAR focus group, the research team described several specific aspects of the process they felt went well. These included recruiting youth from various backgrounds and experiences, the environment in which team meetings took place (including providing food), and affording youth time to analyze the data individually and then collectively. Research team members also noted items that could 


\section{RUNAWAY AND HOMELESS YOUTH}

have been improved, which included providing more time in the initial training sessions for youth to practice new skills and devising better ways to schedule meetings. Research team members also described how through participation in this project they learned about the importance of teamwork and how varying backgrounds and experiences resulted in a deeper understanding of the data. Team members also described how they learned from others in the group and described how they came to enjoy this type of work.

Additional themes emerged from the analysis of this focus group. These included pride in the work the young people exhibited and the development among them for future educational aspirations. Moreover, findings indicate that PAR methods can be employed along a continuum of participation and that RHY are well suited and capable to complete this level of research, validating the importance of youth voice and refuting the dominate discourse related to RHY.

Findings from this study indicate that RHY programs and staff must insure they are providing the right service using the appropriate method. Programs should also actively seek out ways to create opportunities for youth to develop a range of employment skills within their program. Additionally, programs should partner with youth and review policies that create barriers for youth. Findings also indicate that policies and service models that dictate youth goals and/or focus on changes in youth behavior are likely resulting in lower utilization rates among RHY. Because of this, 


\section{RUNAWAY AND HOMELESS YOUTH}

RHY training modules that focus on effective relationship building and power sharing with youth, and deemphasize the pathology of RHY, need to be developed and emphasized. Furthermore, and at a minimum, formerly homeless young people should be included in, and compensated for, the development of these training modules. Findings from this study indicate that youth are exceptionally capable to carry out every aspect of research and evaluation. Additionally, these findings suggest there is incongruity between the social work ethical code around professional boundaries and what the youth say they need in staff relationships. The National Association of Social Workers (NASW) needs to review its ethical code of conduct and provide guidance to the field.

In light of these findings, future research must collaborate with runaway and homeless youth on research projects and create evaluations of RHY services. Because current census methods are problematic, future research must develop methods that incorporate the breadth of the RHY population. This information is critical for the field to identify and address issues within the system such as racial disparity, youth who identify as LGBTQ, young people with severe mental illness, and those with a physical disability. Providing youth with meaningful opportunities to participate in the development of these methods will unquestionably provide the insight necessary to move the field of RHY services beyond its current limited impact. 


\section{RUNAWAY AND HOMELESS YOUTH}

Additionally, the field of RHY must move away from one-size-fits-all service models. Foremost, RHY federal policy should be detached from Juvenile Delinquency policy. Concurrently, as other researchers have called for, the populations of youth who are identified as "runaway" and "homeless" should be disentangled in policy, programs and practices. Alongside these changes, future research should differentiate youth based on their various pathways into homelessness (e.g. runaway, homeless, thrownaway, etc.) and develop specific interventions based on those needs. In addition, while this project privileged the voice of youth for whom RHY programs were working, future research must privilege the voice of those youth for whom these services did not work. These youth hold the potential to provide the most critical data.

Critical to the issues of RHY is that the relationship between policy, practice, and research is not well linked and needs to be fundamentally modified. With the confusion surrounding definitions, inaccuracies in census data, limitations around intervention effectiveness studies, and poor utilization rates, it seems prudent for a national call for youth, researchers and practitioners to gather and redesign that RHY system.

Finally, the importance of the inclusion of youth voice must not be understated. It is vital that youth be included and given the power to influence programs and policies that impact their well-being. Only then can we expect runaway 
RUNAWAY AND HOMELESS YOUTH

and homeless youth to feel they are respected and take their rightful place as valued members of our communities. 


\section{RUNAWAY AND HOMELESS YOUTH}

\section{References}

Aarons, G.A.; Brown, S.A., Garland, A.F. \& Hough, R.L. (2004). Race/ethnic disparity and correlates of substance abuse service utilization and juvenile justice involvement among adolescents with substance use disorders. Journal of Ethnicity in Substance Abuse, 3(1), 47-64.

Administration for Children and Families. (2008a), Fact sheet: Basic center program. Retrieved from http://www.acf.hhs.gov/programs/fysb/content/youthdivision/programs/bcpfactsh $\underline{\text { eet.htm }}$

Administration for Children and Families. (2008b), Fact sheet: Positive youth development. Retrieved from http://www.acf.hhs.gov/programs/fysb/content/positiveyouth/factsheet.htm

Administration for Children and Families. (2008c), Fact sheet: Transitional living program for older homeless youth. Retrieved from http://www.acf.hhs.gov/programs/fysb/content/youthdivision/programs/tlpfactshe $\underline{\text { et.htm }}$

Administration for Children and Families. (2008d), Fact sheet: Street outreach program. Retrieved from http://www.acf.hhs.gov/programs/fysb/content/youthdivision/programs/sopfactsh eet.htm 


\section{RUNAWAY AND HOMELESS YOUTH}

Akers, A.Y., Muhammad, M.R., \& Corbie-Smith, G. (2011). "When you got nothing to do, you do somebody": A community's perceptions of neighborhood effects on adolescent sexual behaviors. Social Science and Medicine, 72, 91-99.

American Psychiatric Association (2000). Diagnostic and Statistical Manual of Mental Disorders. $4^{\text {th }}$ Ed. Arlington, VA. American Psychiatric Association.

Arnstein, S.R. (1969). A ladder of citizen participation. Journal of the American Institute of Planners, 35(4), p. 216-224.

Auerswald, C. L., \& Eyre, S. L. (2002). Youth homelessness in San Francisco: A life cycle approach. Social Science \& Medicine, 54(10), 1497-1512.

Baer, J. S., Peterson, P. L., \& Wells, E. A. (2004). Rationale and design of a brief substance use intervention for homeless adolescents. Addiction Research \& Theory, 12(4), 317-334.

Bandura, A. (1973). Aggression: A social learning process. Englewood Cliffs, N.J.: Prentice-Hall Inc.

Bantchevska, D., Bratle-Haring, S., Dashora, P., Glebova, T. \& Slesnick, N. (2008). Problem behaviors of homeless youth: A social capital perspective. Journal of Human Ecology. 23(4), 285-293.

Barth, R. P. (1986). Social and cognitive treatment of children and adolescents. San Francisco: Jossey-Bass. 


\section{RUNAWAY AND HOMELESS YOUTH}

Bass-Rubenstein, D. (2008). Youth at risk. Encyclopedia of Social Work. Terry Mizrahi and Larry E. Davis. Encyclopedia of Social Work: (e-reference edition). Oxford University Press. Retrieved from http://www.oxfordnaswsocialwork.com/entry?entry=t203.e421.

Beresford, P. (2000). Service users' knowledges and social work theory: Conflict or collaboration? British Journal of Social Work, 30, 489-503.

Beresford, P. \& Croft, S. (2001). Services users' knowledges and the social construction of social work. Journal of Social Work, 1(3), 295-316.

Berg, B.L. (2007). Qualitative research methods for social sciences $\left(6^{\text {th }}\right.$ ed.). Boston: Allyn and Bacon.

Bickman, L., \& Rog, D.J. (Eds.). (1998). Handbook of applied social research methods. Thousand Oaks, CA: Sage Publications, Inc.

Bohman, J. (2005). Critical theory. Retrieved October 19, 2006 from http://plato.stanford.edu/entries/critical-theory/

Bronfrenbrenner, U. (1979). The ecology of human development. Cambridge, MA. Harvard University Press.

Bronfenbrenner, U. (1986). Ecology of the Family as a Context for Human Development: Research Perspectives. Developmental Psychology, 22(6), p 723-742. 


\section{RUNAWAY AND HOMELESS YOUTH}

Burt, M., Aron, L.Y., Lee, E. \& Valente, J. (2001). Helping America's homeless: Emergency shelter or affordable housing. Washington D.C.: The Urban Institute Press.

Cheung, C. K., Liu, S. C., \& Lee, T. Y. (2005). Parents, teachers, and peers and early adolescent runaway in Hong Kong. Adolescence, 40(158), 403-424.

Cohen, A. (1955). Delinquent boys. New York. Free Press

Cohen, M. A. (1998). The monetary value of saving a high-risk youth. Journal of Quantitative Criminology, 14(1), 5-33.

Courtney, M.E. \& Zinn, A. (2009). Predictors of running away from out-of-home care. Children and Youth Services Review, 31, 1298-1306.

Crespi, T. D., \& Sabatelli, R. M. (1993). Adolescent runaways and family strife: A conflict-induced differentiation framework. Adolescence, 28(112), 867.

Davis, M. (2003). Addressing the needs of youth in transition to adulthood. Administration and Policy in Mental Health, 30(6), 495-509.

Delgado, R. \& Stefancic, J. (2001). Critical race theory: An introduction. New York University Press. New York.

Elder, G. (1998). The life course as developmental theory. Child Development. 69 (1), 112.

Empey, L. T. (1982). American delinquency. Homewood, IL: Dorsey. 


\section{RUNAWAY AND HOMELESS YOUTH}

Fairman-Cooper, E. (2006). The runaway and homeless youth program: Administration, funding, and legislative actions, No. RL31933, Congressional Research Service.

Farson, R. (1974). Birthrights, New York: Macmillan Publishing. Retrieved from http://www.youthrights.org/quotes.php .

Fernandes, A.L. (2007), Runaway and homeless youth: Demographics, programs, and emerging issues, No. RL33785, Congressional Research Service.

Fisher, D. G., \& Wilson, P. J.. (1995). Sexual and drug-taking experiences reported by runaway youth. Journal of Alcohol and Drug Education, 40(2), 88.

Florida State University (n.d.) David Matza. Retrieved from http://www.criminology.fsu.edu/crimtheory/matza.htm .

Flores, K.S. (2008). Youth participatory evaluation: Strategies for engaging young people. San Francisco: Jossey-Bass.

Freeman, M., \& Mathison, S. (2009). Researching children's experiences. New York, NY: The Guildford Press.

Garrett, S.B., Higa, D.H., Phares, M.M., Peterson, P.L., Wells, E.A., \& Baer, J.S. (2008). Homeless youths' perception of services and transitions to stable housing. Evaluation and Program Planning, 31, 436-444.

Gil, D. G. (1998). Confronting injustice and oppression: Concepts and strategies for social workers. New York: Columbia University Press. 


\section{RUNAWAY AND HOMELESS YOUTH}

Giroux, H.A. (2003). Racial injustice and disposable youth in the age of zero tolerance. Qualitative Studies in Education. 16(4), 553-565.

Glassman, M. \& Karno, D. (2009). On establishing a housing right of contract for homeless youth in America. Seattle Journal for Social Justice. 7(2), 437-465.

Glassman, M., Karno, D. \& Erdem, G. (2010). The problems and barriers of the RHYA as social policy. Children and Youth Services Review, 32, 798-806.

Haber, M. G., \& Toro, P. A. (2004). Homelessness among families, children, and adolescents: An ecological-developmental perspective. Clinical Child and Family Psychology Review, 7(3), 123-164.

Hammer, H., Finkelhor, D., Sedlak, A.J. (October 2002). Runaway/thrownaway children: National estimates and characteristics. National Incidence Studies of Missing, Abducted, Runaway, and Thrownaway Children (NISMART). Retrieved http://www.ncjrs.gov/html/ojjdp/nismart/04/.

Harris, M.S., Jackson, L.J., O’Brien, K. \& Pecora, P. (2009). Disproportionality in education and employment outcomes of adult foster care alumni. Children and Youth Services Review, 31(11), 1150-1159.

Hart, R.A. (2008). Ladder of participation. The FreeChild Project. Retrieved on May, 24, 2009 from http://www.freechild.org/ladder.htm

Hurley, K.D., Ingram, S., Czyz, J.D., Juliano, N., \& Wilson, E. (2006). Treatment for youth in short-term care facilities: The impact of a comprehensive behavior 


\section{RUNAWAY AND HOMELESS YOUTH}

management intervention. Journal of Child and Family Studies. 15(5), 1062-1024 (Print), 1573-2843 (Online).

Jozefowicz-Simbeni, D.M. H. \& Israel, N. (2006). Services to homeless students and families: The McKinney-Vento act and its implications for school social work practice. Children \& Schools. 28(1), 37-44.

Kamberelis, G. \& Dimitriadis, G. (2008). Collecting and interpreting qualitative materials, (3ed), N.K. Denzin \& Y.S. Lincoln (Eds). Thousand Oaks, CA: Sage Publications.

Kidd, S.A. (2003). Street youth: Coping and intervention. Child and Adolescent Social Work Journal. 20(4), 235-261.

Kurtz, P. D., Kurtz, G.L., \& Jarvis, S.V. (1991). Problems of Maltreated Runaway Youth. Adolescence, 26(103), 543.

Laser, J.A., \& Leibowitz, G.S. (2009). Promoting positive outcomes for healthy youth development: Utilizing social capital theory. Journal of Sociology \& Social Welfare. 36(1), 87-102.

League of Women Voters of Oregon Educational Fund (LWV). (2006). Oregon's Homeless Youth. Retrieved from http://www.lwvrv.org/pdf_docs/homelessyouth\%202006.pdf .

Lietz, C.A., Langer, C.L., \& Furman, R. (2006). Establishing trustworthiness in qualitative research in social work. Qualitative Social Work, 5(4), 441-458. 


\section{RUNAWAY AND HOMELESS YOUTH}

Livesey, C. (n.d.). Deviance and social control. Unit M6: Subcultural theories. Retrieved from http://www.sociology.org.uk/devtsubc.doc

Mangione, T.W. (1998). Mail surveys. In L. Bickman \& D.J. Rog (Eds.), Handbook of Applied Social Research Methods (pp. 399-427). Thousand Oaks: CA: Sage.

Markward, M., McMillian, L., \& Markward, N. (2003). Social support among youth. Children and Youth Services Review. 25(7), 571-587.

Matza, D. (1964). Delinquency and drift. New York, Wiley.

McIntyre, A. (2008). Participatory action research. Qualitative Research Methods Series 52. Los Angeles: Sage.

McRee, N. (2008). Child abuse in blended households: Reports from runaway and homeless youth. Child abuse \& neglect, 32(4), 5.

Miles, M. B., \& Huberman, M.A. (1994). Qualitative data analysis: An expanded sourcebook. Thousand Oaks, CA: Sage Publications.

Miller, A. T. (1990). Patterns of runaway behavior within a larger systems context: The road to empowerment. Adolescence, 25 (98), 271-289.

Moffitt, T. (1997). Adolescence-limited and life-course-persistent offending: A complementary pair of developmental theories. In Thornberry, T. (Ed)., Developmental Theories of Crime and Delinquency. Vol. 7. 11-54. New Brunswick, NJ: Transaction Publishers. 


\section{RUNAWAY AND HOMELESS YOUTH}

Moore, J. (2006). Unaccompanied and homeless youth: Review of literature 1995-2005. National Center for Homeless Education. Retrieved from www.serve.org/nche.

Moses, C.E., \& Kopplin (1992). Applying humanistic principles to the treatment of runaway and throwaway adolescents. Paper presented at Annual Convention of the Southwestern Psychological Association, Austin, Tx.

Interviewing, (2011). An overview of motivational interviewing. Retrieved from http://www.motivationalinterview.org/Documents/1\%20A\%20MI\%20Definition \%20Principles\%20\&\%20Approach\%20V4\%20012911.pdf

National Alliance to End Homelessness (n.d.a). Policy focus area: Youth. Retrieved from http://www.endhomelessness.org/section/policy/focusareas/youth

National Alliance to End Homelessness (n.d.b). Policy focus area: Youth. Retrieved from http://www.endhomelessness.org/section/policy/legislature/rhya

National Alliance to End Homelessness (2006a). Fundamental issues to prevent and end youth homelessness. Retrieved from http://www.endhomelessness.org/content/article/detail/1058

National Alliance to End Homelessness (2006b). Explainer: Questions and answers on homelessness policy and research. Retrieved from http://www.crossroadsri.org/pdf/NAEH-Federal_Spending_Homeless_2007.pdf

National Alliance to End Homelessness (2007). Fact checker: Accurate statistics on homelessness. Retrieved from 


\section{RUNAWAY AND HOMELESS YOUTH}

http://www.endhomelessness.org/files/1659_file_10606_NAEH_YouthHomeless ness_4_.pdf. .

National Association of Social Workers. (2008). Code of Ethics of the National Association of Social Workers. Retrieved from http://www.socialworkers.org/pubs/code/code.asp.

National Coalition for the Homeless (2008). Homeless youth. NCH fact sheet \#13 Retrieved from http://www.nationalhomeless.org/publications/facts/youth.html

National Collaboration for Youth. (2006). Runaway and homeless youth act programsfact sheet. Retrieved from http://www.nassembly.org/nydic/policy/breifs/documents/06CollabRHYA.pdf

National Crime Justice Reference Service (October, 2002). National incidence studies of missing, abducted, runaway, and throwaway children (NISMART). Retrieved from http://www.ncjrs.gov/html/ojjdp/nismart/04/ns2.html

National Gay and Lesbian Task Force. (2006). Lesbian, gay, bisexual, and transgender youth: An epidemic of homelessness. Retrieved from http://www.thetaskforce.org/downloads/HomelessYouth.pdf

National Runaway Switchboard (2006). 2005 call statistics. Retrieved from http://www.nrscrisisline.org/news_events/call_stats.html

Nesmith, A. (2006). Predictors of running away from family foster care. Child Welfare, 85(3), 585. 


\section{RUNAWAY AND HOMELESS YOUTH}

Ore. Rev. Statute ch. 109, § 675. (2009). Right to diagnosis or treatment for mental or emotional disorder or chemical dependency without parental consent. Retrieved from http://www.leg.state.or.us/ors/109.html.

Oregon Runaway and Homeless Work Group [ORHWG] (2005). From Out of the Shadows: Shedding Light on Oregon's Runaway and homeless Youth. Report to the Interim Committee on Health and Human Services February 2005

Orten, J. D., \& Soll, S. K. (1980). Runaway children and their families: A treatment typology. Journal of Family Issues, 1(2), 249-261.

Osgood, D.W., Foster, E.M., Flanagan, C. \& Ruth, G.R. (2005). On your own without a net: The transition to adulthood for vulnerable Populations. London: University of Chicago Press.

Padgett, D.K. (1998), Qualitative methods in social work research: Challenges and rewards. Thousand Oaks, CA: Sage Publications

Patton, M.Q. (2002). Qualitative research \& evolution methods $\left(3^{\text {rd }}\right.$ ed.). Thousand Oaks, CA: Sage Publications.

Pavkov, T.W., Travis, L., Fox, K.A., King, C.B. \& Cross, T. (2010) Tribal youth victimization and delinquency: Analysis of youth risk behavior surveillance survey data. Cultural Diversity \& Ethnic Minority Psychology, 16(2), 123-134. 


\section{RUNAWAY AND HOMELESS YOUTH}

Peled, E., Spiro, S., \& Dekel, R. (August 2005). My home is not my castle: Follow-up of residents of shelters for homeless youth. Child and Adolescent Social Work Journal. 22(3-4), 257-279.

Pilgram, D. \& Waldron, L. (1998). User involvement in mental health service development: How far can it go? Journal of Mental Health, 7(1), 95-104

Piquero, A. (2008). Disproportionate minority contact. The Future of Children, 18(2), 5980.

Pollio, D.E., Thompson, S.J., Tobias, L., Reid, D. \& Spitznagel, E. (2006). Longitudinal outcomes for youth receiving runaway/homeless shelter services. Journal of Youth and Adolescence. 35(5), 859-866.

Prochaska, J.O., DiClemente, C.D., \& Norcross, J.C. (1992). In search of how people change. American Psychologist. 47(9), 1102-1114.

Raleigh-DuRoff, C. (2004), Factors that influence homeless adolescents to leave or stay living on the street. Child and Adolescent Social Work Journal. 21(6), 561- 572.

Rew, L. (2008). Caring for and connecting with homeless adolescents. Family \& Community Health, 31(1), S42-S51.

Rogers, A.T. (2010). Human behavior in the social environment (2ed). New York, NY. Routledge. 


\section{RUNAWAY AND HOMELESS YOUTH}

Rosenheck, R. (2000). Cost-effectiveness of services for mentally ill homeless people: the application of research to policy and practice. The American Journal of Psychiatry, 157(10), 1563-1570.

Roy, E., Haley, N., Leclerc, P., Sochanski, B., Boudreau, J. F., \& Boivin, J. F. (2004). Mortality in a cohort of street youth in Montreal. Jama-Journal of the American Medical Association, 292(5), 569-574.

Rubin, A. \& Babbie, E. (2001). Research methods for social work (4 ${ }^{\text {th }}$ ed.). Blemont, CA. Wadsworth.

Runaway and Homeless Youth Act of 2008, Pub. L. 110-378.

Saleebey, D. (2009). The strengths perspective in social work practice ( $\left.5^{\text {th }} \mathrm{ed}\right)$. Boston, MA. Allyn \& Bacon.

Sampson, R.J. \& Laub, J.H. (1997). A life-course theory of cumulative disadvantage and stability of delinquency. Advances in Criminological Theory, 7. 133-161.

Sanchez, R.P., Waller, M.W., \& Greene, J.M. (2006). Who runs? A demographic profile of runaway youth in the United States. Journal of Adolescent Health. 39. 778-781.

Sanderson, R.C. \& Richards, M.H. (2010). The after-school needs and resources of a low-income urban community: Surveying youth and parents for community change. American Journal of Community Psychology. 45(3-4), 430-440. 


\section{RUNAWAY AND HOMELESS YOUTH}

Scales, P.C., Benson, P.L., Mannes, M. (2006). The contribution to adolescent well-being made by nonfamily adults: An examination of developmental assets as contexts and processes. Journal of Community Psychology. 34(4), 401-413.

Schweitzer, R., Hier, S.J., \& Terry, D. (1994). Parental bonding, family systems, and environmental predictors of adolescent homelessness. Journal of Emotional \& Behavioral Disorders, 2 (1), 39-45.

Scott, E.S. \& Steinberg, L. (2008). Rethinking juvenile justice. Cambridge, MA: Harvard University Press.

Seita, J.R. \& Brendtro, L.K. (2003). Adversarial contests or respectful alliances. Reclaiming Children and Youth. 12(1), 58-60.

Singleton, Jr., R.A., \& Straits, B.C. (2005). Approaches to social research (4 ${ }^{\text {th }}$ ed.). New York. Oxford University Press.

Slesnick, N., Dashora, P., Letcher, A., Erdem, G., \& Serovich, J. (2009). A review of services and interventions for runaway and homeless youth: Moving forward, Children and Youth Services Review, doi:10.1016/j.childyouth.2009.01.006

Slesnick, N. \& Prestopnik, J.L. (2005). Ecologically based family therapy outcome with substance abusing runaway adolescents. Journal of Adolescence. 28(2), 277-298.

Snow, K. (2008). Disposable lives. Children and Youth Services Review. 30, 1289-1298. 


\section{RUNAWAY AND HOMELESS YOUTH}

Snowden, L.R.; Masland, M.C.; Fawley, K. \& Wallace, N. (2009). Ethnic differences in children's entry into public mental health care via emergency mental health services. Journal of Child and Family Studies, 18(5), 512-519.

Stahler, G.J., DuCette, J.P., \& Povich, E. (1990). Using mediation to prevent child maltreatment: An exploratory study. Family Relations. 39(3), 317-322.

Staller, K.M. (2006), Runaways. New York: Columbia University Press.

State Public Welfare Commission (SPWC) (1951). The History of Child Welfare in Oregon. Portland Oregon

Stiffman, A. R. (1989a). Physical and sexual abuse in runaway youths. Child Abuse and Neglect: The International Journal, 13(3), 417.

Stiffman, A. R. (1989b). Suicide attempts in runaway youths. Suicide and LifeThreatening Behavior, 19(2), 147.

Stringer, E.T. (2007). Action research ( $3^{\text {rd }}$ ed.). Los Angeles: Sage Publications

Strauss, A. \& Corbin, J. (1990). Basics of qualitative research: Grounded theory procedures and techniques. Newbury Park, CA: Sage Publications

Teare, J. P., Peterson, R. W., Furst, D., Authier, K., Baker, G., \& Daly, D. L. (1994). Treatment implementation in a short-term emergency shelter program. Child Welfare, 73, 271-281.

Theriot, M.T. (2009). School resource officers and the criminalization of student behavior. Journal of Criminal Justice. 37, 280-287. 


\section{RUNAWAY AND HOMELESS YOUTH}

Thompson, S.J., Pollio, D.E., \& Bitner, L. (2000). Outcomes for adolescents using runaway and homeless youth services. Journal of Human Behavior in the Social Environment. 3(1), 79-97.

Thompson, S. J., Safyer, A. W., \& Pollio, D. E. (2001). Differences and predictors of family reunification among subgroups of runaway youths using shelter services. Social Work Research, 25(3), 163-172.

Thompson, S. J., Pollio, D. E., Constantine, J., Reid, D., \& Nebbitt, V. (2002). Short-term outcomes for youth receiving runaway and homeless shelter services. Research on Social Work Practice, 12(5), 589-603.

Thompson, S.J., Kost, K.A., \& Pollio, D.E. (2003). Examining risk factors associated with family reunification for runaway youth: Does ethnicity matter? Family Relations, 52(3), 296-304.

Thompson, S. J., Zittel-Palamara, K. M., \& Forehand, G. (2005). Risk factors for cigarette, alcohol, and marijuana use among runaway youth utilizing two services sectors. Journal of Child \& Adolescent Substance Abuse, 15(1), 17-36.

Toro, P. A., Dworsky, A., Fowler, P.J. (2007). Homeless youth in the United States: Recent research findings and intervention approaches. Paper presented at the Toward Understanding Homelessness: The 2007 National Symposium on Homelessness Research. Retrieved from http://aspe.hhs.gov/hsp/homelessness/symposium07/toro/index.htm . 


\section{RUNAWAY AND HOMELESS YOUTH}

Trattner, W. I. (1999). From poor law to welfare state: A history of social welfare in America (6th ed.). New York: The Free Press.

Turnbull, A.P., Friesen, B.J., \& Ramirez, C. (1998). Participatory action research as a model for conducting family research. Research and Practices for Persons with Disabilities, 23(3), 178-188

Tyler, K. A., Cauce, A. M., \& Whitbeck, L. (2004). Family risk factors and prevalence of dissociative symptoms among homeless and runaway youth. Child Abuse \& Neglect, 28(3), 355-366.

Tyler, K. A., Whitbeck, L. B., Hoyt, D. R., \& Cauce, A. M. (2004). Risk Factors for sexual victimization among male and female homeless and runaway youth. Journal of Interpersonal Violence, 19(5), 503.

U.S. Department of Health and Human Services (n.d.). Description of program, service, function or activity. Retrieved from http://aspe.hhs.gov/SelfGovernance/inventory/ACF/557.htm.

U.S. Department of Health and Human Services (2007). Promising strategies to end youth homelessness: Report to congress. Retrieved from http://www.acf.hhs.gov/programs/fysb/content/docs/reporttocongress_youthhome lessness.pdf . 


\section{RUNAWAY AND HOMELESS YOUTH}

Van Leeuwen, J. M., Boyle, S., Salomonsen-Sautel, S., Baker, D. N., Garcia, J. T., Hoffman, A., Hopfer, C.J.(2006). Lesbian, gay, and bisexual homeless youth: An eight-city public health perspective. Child Welfare. 85(2), 151-170.

Velazquez, Jr., J. \& Garin-Jones, M. (January/February, 2003). Adultism and cultural competence. Children's Voice. Child Welfare League of America. Retrieved from http://www.cwla.org/articles/cv0301adultism.htm

Whitbeck, L., Hoyt, D., Yoder, K., Cauce, A., Paradise, M., (2001). Deviant behavior and victimization among homeless and runaway adolescents. Journal of Interpersonal Violence. 16 (11), 1175-1204.

Yoder, K. A., Whitbeck, L. B., \& Hoyt, D. R. (2003). Gang involvement and membership among homeless and runaway youth. Youth \& Society, 34(4), 441. 


\section{RUNAWAY AND HOMELESS YOUTH}

Appendices 


\section{RUNAWAY AND HOMELESS YOUTH}

\section{Appendix A: Evolution of Federal RHY Policy, 1912-2003}

Source: Created by the Congressional Research Service

1912: Children's Bureau established to investigate and report on all matters related to children's welfare.

1933: Federal Transient Bureau assists states in developing aid for homeless children and adults. Civilian Conservation Corps establishes camps for more than one million older youth.

1935: Social Security Act is passed and for the first time, the federal government provide (sic) grants to states for child welfare.

1950: Social Security Act is amended to permit use of federal child welfare funds for the return of a runaway child under the age of 16.

1954: Division of Juvenile Delinquency is established in the Children's Bureau.

1955: Senate Subcommittee to Investigate Juvenile Delinquency first examines problem of RHY.

1958: Social Security Act is amended to provide federal funds for the return of a runaway child under the age of 18

1961: Congress enacts the Juvenile Delinquency and Youth Offenses Control Act drawing on the recommendations of the President's Committee on Juvenile 


\section{RUNAWAY AND HOMELESS YOUTH}

Delinquency and Youth Crime regarding the economic and social underpinnings of delinquency.

1968: Congress passes the Juvenile Delinquency Prevention and Control Act which provides funding to four RHY.

1970: The Youth Development and Delinquency Prevention Administration (the predecessor organization to the Family and Youth Services Bureau) is created within HHS to provide leadership in youth issues.

1972: Senate Subcommittee to Investigate Juvenile Delinquency holds two-day hearings on problems facing RHY. Senate passes runaway youth legislation, but House does not act.

1974: Congress enacts the Runaway Youth Act as Title III of the Juvenile Justice and Delinquency Prevention Act. The legislation establishes what is now referred to as the Basic Center Program

1977: Congress reauthorizes the Runaway Youth Act and broadens its scope to include "otherwise homeless youth."

1988: Runaway and Homeless Youth Act is reauthorized. A provision is added to establish the Transitional Living Program.

1994: Street Outreach Program is established by the Violent Crime and Law Enforcement Act. 


\section{RUNAWAY AND HOMELESS YOUTH}

1999: The Runaway and Homeless Youth Act is reauthorized. Funding and administration or the Basic Center Program and Transitional Living Program are merged under the Consolidated Runaway and Homeless Youth Program.

2003: Runaway, Homeless, and Missing Children Protection Act reauthorizes the Runaway and Homeless Youth Act for FY2004 through 2008. 


\section{RUNAWAY AND HOMELESS YOUTH}

\section{Appendix B: Federal Funding for Runaway and Homeless Programs}

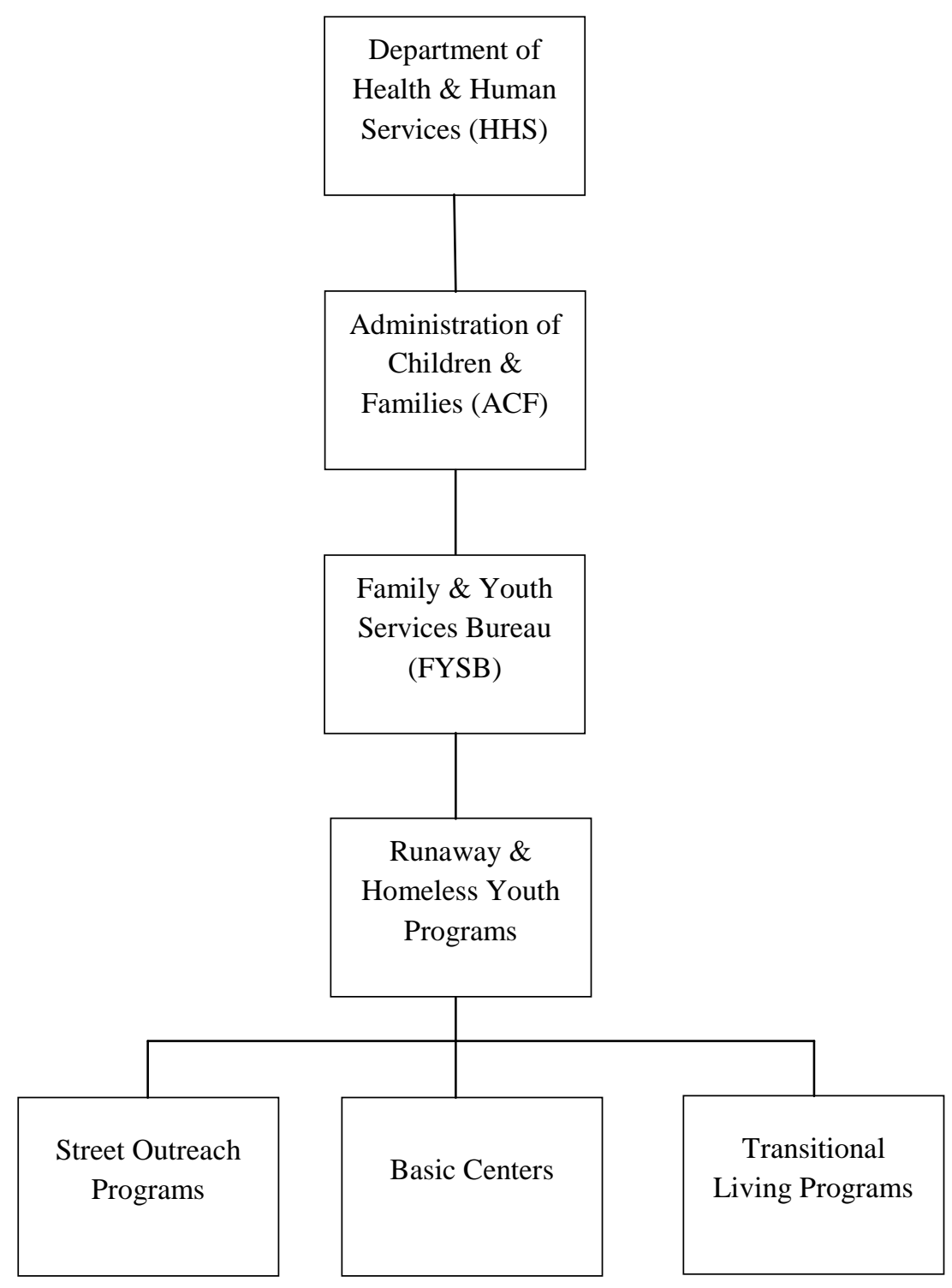




\section{RUNAWAY AND HOMELESS YOUTH}

\section{Appendix C: RHY Intervention Studies}

\begin{tabular}{|c|c|c|c|c|c|}
\hline Author/Date & $\begin{array}{l}\text { Population or } \\
\text { Sample }\end{array}$ & Intervention & Measures & Results & Conclusion \\
\hline $\begin{array}{l}\text { Hurley, } \\
\text { Ingram, Czyz, } \\
\text { Juliano, \& } \\
\text { Wilson, (2006) }\end{array}$ & $\begin{array}{l}\text { Runaway and } \\
\text { homeless } \\
\text { youth referred } \\
\text { to shelter } \\
\text { services }\end{array}$ & $\begin{array}{l}\text { Managing } \\
\text { Youth in Short } \\
\text { Term Care } \\
\text { (MYSTC), an } \\
\text { adaptation of } \\
\text { the Boys Town } \\
\text { Family Home } \\
\text { Program. }\end{array}$ & $\begin{array}{l}\text { Staff } \\
\text { implementation } \\
\text { of tx, critical } \\
\text { youth } \\
\text { incidents, and } \\
\text { staff opinion } \\
\text { surveys. }\end{array}$ & $\begin{array}{l}\text { Majority of } \\
\text { staff excelled } \\
\text { rated at } 89- \\
93 \% \text {. } \\
\text { Critical } \\
\text { incidents } \\
\text { declined from } \\
1.81 \text { incidents } \\
\text { per youth per } \\
\text { month to } 1.25 \text {. }\end{array}$ & $\begin{array}{l}\text { Findings indicate } \\
\text { it is possible to } \\
\text { implement a } \\
\text { shelter-wide tx } \\
\text { approach and see } \\
\text { significant } \\
\text { improvements. } \\
\text { Also, there is a } \\
\text { need for } \\
\text { extensive staff } \\
\text { training. }\end{array}$ \\
\hline Kidd, (2003) & $\begin{array}{l}\text { Street youth } 24 \\
\text { years old and } \\
\text { younger who } \\
\text { had spent a } \\
\text { significant } \\
\text { amount of time } \\
\text { homeless or } \\
\text { with no fixed } \\
\text { address. }\end{array}$ & $\begin{array}{l}\text { Qualitative } \\
\text { analysis of } \\
\text { youth's } \\
\text { perception of, } \\
\text { and experiences } \\
\text { with, coping } \\
\text { and what has } \\
\text { and has not } \\
\text { been helpful for } \\
\text { them in their } \\
\text { struggle to } \\
\text { survive on the } \\
\text { streets. }\end{array}$ & $\begin{array}{l}\text { Grounded } \\
\text { theory } \\
\text { development of } \\
\text { individual } \\
\text { interviews. }\end{array}$ & $\begin{array}{l}\text { Coping } \\
\text { strategies }{ }^{7} \text { and } \\
\text { youth's } \\
\text { evaluation of } \\
\text { mental health } \\
\text { professionals } \\
\text { were } \\
\text { inventoried. }\end{array}$ & $\begin{array}{l}\text { Among others, a } \\
\text { key finding of } \\
\text { this study is the } \\
\text { need to work } \\
\text { with and develop } \\
\text { the existing } \\
\text { strengths of } \\
\text { street youth. }\end{array}$ \\
\hline
\end{tabular}

\footnotetext{
${ }^{7}$ Coping strategies included hanging out w/friends, using "softer" drugs such as marijuana and/or alcohol, being alone, drawing or writing, making themselves laugh, and sleeping. Youth's evaluation of mental health professionals included negative interactions was the precipitating event that lead youth to the street, welfare paperwork was too cumbersome, delays in services made it difficult to get off the streets, and several youth felt mental professionals were pill pushers or ineffectual due to the harsh realities of street life.
} 


\section{RUNAWAY AND HOMELESS YOUTH}

\begin{tabular}{|c|c|c|c|c|c|}
\hline Author/Date & $\begin{array}{l}\text { Population or } \\
\text { Sample }\end{array}$ & Intervention & Measures & Results & Conclusion \\
\hline $\begin{array}{l}\text { Pollio, } \\
\text { Thompson, } \\
\text { Tobias, Reid, } \\
\text { \& Spitznagel, } \\
(2006)\end{array}$ & $\begin{array}{l}\text { Runaway and } \\
\text { homeless } \\
\text { youth. }\end{array}$ & Shelter services & $\begin{array}{l}\text { Runaway } \\
\text { behavior, } \\
\text { family } \\
\text { relationship, } \\
\text { substance use, } \\
\text { school } \\
\text { behavior, } \\
\text { employment, } \\
\text { sexual activity, } \\
\text { and self-esteem } \\
\text { were collected } \\
\text { at intake, } 6 \\
\text { weeks, } 3 \\
\text { months, and } 6 \\
\text { months posttx. }\end{array}$ & $\begin{array}{l}\text { Positive } \\
\text { outcomes for } \\
\text { runaway } \\
\text { behavior, } \\
\text { family } \\
\text { interactions, } \\
\text { and substance } \\
\text { use. } \\
\text { Sexual activity } \\
\text { did not improve } \\
\text { over time. } \\
\text { Employment } \\
\text { and self-esteem } \\
\text { improved } \\
\text { initially but } \\
\text { diminished over } \\
\text { time. }\end{array}$ & $\begin{array}{l}\text { While the impact } \\
\text { of shelter } \\
\text { services appear } \\
\text { to improve youth } \\
\text { in a variety of } \\
\text { domains, those } \\
\text { improvements } \\
\text { can be short } \\
\text { lived and require } \\
\text { follow-up } \\
\text { services to } \\
\text { maintain gains. }\end{array}$ \\
\hline $\begin{array}{l}\text { Peled, Spiro, \& } \\
\text { Dekel, (2005) }\end{array}$ & $\begin{array}{l}\text { Israel's first } 2 \\
\text { shelters for } \\
\text { homeless } \\
\text { youth }\end{array}$ & $\begin{array}{l}\text { Evaluation of } \\
\text { program }\end{array}$ & $\begin{array}{l}\text { Exit location of } \\
\text { youth and their } \\
\text { desire to go } \\
\text { there. Youth's } \\
\text { evaluation of } \\
\text { shelter stay. }\end{array}$ & $\begin{array}{l}\text { There were } \\
\text { notable } \\
\text { differences } \\
\text { between the } \\
\text { places the youth } \\
\text { had stated they } \\
\text { wanted to go } \\
\text { and where they } \\
\text { ended up after } \\
\text { the shelter. } \\
\text { Majority of } \\
\text { youth rated the } \\
\text { shelter stay as } \\
\text { positive ( } 75 \%) \\
\text { and thought the } \\
\text { stay changed } \\
\text { them for the } \\
\text { better (60\%). }\end{array}$ & $\begin{array}{l}\text { Findings suggest } \\
\text { the shelter is } \\
\text { successful in } \\
\text { placing youth in } \\
\text { a normative } \\
\text { residence, yet } \\
\text { there are } \\
\text { concerns about } \\
\text { options for youth } \\
\text { besides their } \\
\text { parent's home } \\
\text { which may not } \\
\text { be the healthiest } \\
\text { place for youth } \\
\text { to be living. }\end{array}$ \\
\hline
\end{tabular}

${ }^{8}$ Normative is the term used by the authors to describe a safe living environment. 


\section{RUNAWAY AND HOMELESS YOUTH}

\begin{tabular}{|c|c|c|c|c|c|}
\hline Author/Date & $\begin{array}{l}\text { Population or } \\
\text { Sample }\end{array}$ & Intervention & Measures & Results & Conclusion \\
\hline $\begin{array}{l}\text { Slesnick, \& } \\
\text { Prestopnik, } \\
\text { (2005) }\end{array}$ & $\begin{array}{l}124 \text { runaway } \\
\text { youth from } 2 \\
\text { shelters in } \\
\text { New Mexico. }\end{array}$ & $\begin{array}{l}\text { Ecologically } \\
\text { based family } \\
\text { therapy (EBFT) } \\
\text { (treatment } \\
\text { group) and } \\
\text { services as } \\
\text { usual (SAU) } \\
\text { from a local } \\
\text { shelter program } \\
\text { (control group). }\end{array}$ & $\begin{array}{l}\text { Substance use, } \\
\text { adolescent } \\
\text { psychological } \\
\text { functioning, } \\
\text { family } \\
\text { functioning, } \\
\text { HIV risk } \\
\text { behaviors, and } \\
\text { diagnostic } \\
\text { status were } \\
\text { measured } \\
\text { pretx, posttx, } 6 \\
\text { months posttx, } \\
\text { and } 12 \text { months } \\
\text { posttx. }\end{array}$ & $\begin{array}{l}\text { Overall, youth } \\
\text { in EBFT group } \\
\text { showed greater } \\
\text { reduction in } \\
\text { substance use. } \\
\text { Among youth } \\
\text { who reported } \\
\text { abuse, those in } \\
\text { EBFT reported } \\
\text { fewer problem } \\
\text { consequences. }\end{array}$ & $\begin{array}{l}\text { Findings suggest } \\
\text { that EBFT with } \\
\text { this population } \\
\text { who are } \\
\text { substance users } \\
\text { is effective. } \\
\text { Youth involved } \\
\text { in shelter } \\
\text { programs have } \\
\text { positive impacts } \\
\text { on behaviors } \\
\text { across a variety } \\
\text { of domains even } \\
1 \text { yr posttx. }\end{array}$ \\
\hline $\begin{array}{l}\text { Teare, } \\
\text { Peterson, } \\
\text { Furst, Authier, } \\
\text { Baker, \& Daly, } \\
\text { (1994) }\end{array}$ & $\begin{array}{l}\text { Runaway and } \\
\text { homeless } \\
\text { youth who had } \\
\text { been admitted } \\
\text { to youth } \\
\text { emergency } \\
\text { shelters }\end{array}$ & $\begin{array}{l}\text { The Boys Town } \\
\text { Emergency } \\
\text { Shelter Program } \\
\text { (BTESP). }\end{array}$ & $\begin{array}{l}\text { Frequency of } \\
\text { social skills } \\
\text { taught to } \\
\text { youth, youth } \\
\text { satisfaction } \\
\text { with program } \\
\text { post- } \\
\text { intervention, } \\
\text { and frequency } \\
\text { of negative } \\
\text { behavioral } \\
\text { events } \\
\text { (incidents). }\end{array}$ & $\begin{array}{l}\text { Mean frequency } \\
\text { of teaching } \\
\text { social skills = } \\
24 \text { per } \\
\text { youth/per day. } \\
\text { Ratio of } \\
\text { positive } \\
\text { interactions to } \\
\text { negative }=15.4 \\
\text { to } 1 . \text { Youth } \\
\text { satisfaction } \\
\text { ranged from } \\
5.78 \text { to } 6.23 \text {. }\end{array}$ & $\begin{array}{l}\text { It is possible to } \\
\text { provide safe, } \\
\text { harm-free, } \\
\text { treatment } \\
\text { oriented } \\
\text { environment for } \\
\text { youth in } \\
\text { emergency } \\
\text { shelters in which } \\
\text { youth are } \\
\text { satisfied with } \\
\text { their stay. }\end{array}$ \\
\hline
\end{tabular}




\section{RUNAWAY AND HOMELESS YOUTH}

\begin{tabular}{|c|c|c|c|c|c|}
\hline Author/Date & $\begin{array}{l}\text { Population or } \\
\text { Sample }\end{array}$ & Intervention & Measures & Results & Conclusion \\
\hline $\begin{array}{l}\text { Thompson, } \\
\text { Pollio, \& } \\
\text { Bitner, (2000) }\end{array}$ & $\begin{array}{l}\text { Runaway and } \\
\text { homeless } \\
\text { youth who had } \\
\text { utilized } \\
\text { emergency } \\
\text { shelter } \\
\text { services. }\end{array}$ & $\begin{array}{l}\text { Emergency } \\
\text { shelter program. } \\
\text { Programs that } \\
\text { provide crisis } \\
\text { intervention } \\
\text { then incorporate } \\
\text { some } \\
\text { combination of } \\
\text { family } \\
\text { (counseling or } \\
\text { parent training) } \\
\text { and youth } \\
\text { (social-skills } \\
\text { training or } \\
\text { academic } \\
\text { remediation) } \\
\text { interventions } \\
\text { were identified } \\
\text { as most } \\
\text { effective. }\end{array}$ & $\begin{array}{l}\text { An instrument } \\
\text { was } \\
\text { constructed for } \\
\text { this study test- } \\
\text { retest } \\
\text { correlation } \\
\text { alpha range for } \\
\text { each item = .56 } \\
-1.00 \text { with an } \\
\text { overall } .78^{9} .\end{array}$ & $\begin{array}{l}\text { Youth who } \\
\text { were living at } \\
\text { home at time of } \\
\text { follow-up were } \\
\text { significantly } \\
\text { related to } \\
\text { currently being } \\
\text { in school } \\
\text { ( } \mathrm{r}=.51, \\
\mathrm{p}=.0001) \text {, and } \\
\text { not running } \\
\text { away after } \\
\text { discharge } \\
\text { ( } \mathrm{r}=.87, \mathrm{p}=- \\
.005) . \text { Youth } \\
\text { who had not } \\
\text { runaway were } \\
\text { more likely to } \\
\text { be in school } \\
\text { ( } \mathrm{r}=.28, \mathrm{p}=.02 \text { ) } \\
\text { and not having } \\
\text { sexual relations } \\
\text { ( } \mathrm{r}=.32 \text {, } \mathrm{p}=.009 \text { ) } \\
\text { during the post } \\
\text { discharge } \\
\text { period. }\end{array}$ & $\begin{array}{l}\text { Among other } \\
\text { findings the most } \\
\text { notable is that } \\
\text { youth returning } \\
\text { home to live } \\
\text { with parents } \\
\text { have a broad } \\
\text { range of positive } \\
\text { outcomes } \\
\text { relative to youth } \\
\text { discharged to } \\
\text { other locations. }\end{array}$ \\
\hline $\begin{array}{l}\text { Thompson, } \\
\text { Pollio, } \\
\text { Constantine, } \\
\text { Reid, \& } \\
\text { Nebbitt, (2002) }\end{array}$ & $\begin{array}{l}\text { Runaway and } \\
\text { homeless } \\
\text { youth }\end{array}$ & $\begin{array}{l}\text { Youth } \\
\text { participating in } \\
\text { youth shelter } \\
\text { program (tx } \\
\text { group) and in } \\
\text { day tx programs } \\
\text { (control group). }\end{array}$ & $\begin{array}{l}\text { Collected at } \\
\text { baseline and } 6 \\
\text { weeks posttx, } \\
\text { runaway } \\
\text { behavior, } \\
\text { family } \\
\text { relationships, } \\
\text { school } \\
\text { behavior, } \\
\text { employment, } \\
\text { sexual } \\
\text { behavior, and } \\
\text { self-esteem. }\end{array}$ & $\begin{array}{l}\text { Every outcome } \\
\text { variable } \\
\text { demonstrated } \\
\text { significant } \\
\text { improvement } \\
\text { postx. No } \\
\text { difference } \\
\text { between tx } \\
\text { group and } \\
\text { control group. }\end{array}$ & $\begin{array}{l}\text { Study suggests } \\
\text { short-term } \\
\text { effectiveness of } \\
\text { crisis shelter } \\
\text { services. }\end{array}$ \\
\hline
\end{tabular}

\footnotetext{
${ }^{9}$ The instrument measured primary outcome variables and secondary outcome variables (behaviors identified as potentially related to primary outcomes). Primary outcome variables included: clinical status (number of times used substances post discharge), functional status (in school [yes/no], employed [yes/no]), life satisfaction and fulfillment (discharge location and participation in school activities [yes/no]), and welfare and safety (ran away after discharge [yes/no] and had sex since discharge [yes/no]).
} 


\section{RUNAWAY AND HOMELESS YOUTH}

\section{Appendix D: Project Overview}

\section{Introduction}

Four to six youth, age 18-24, will be recruited to take part in a Youth Advisory Group (YAG). These youth must be current or past participants in a Transitional Living Program or a Street Outreach Program. For the data analysis portion of the project, youth will be paid $\$ 600^{10}$.

\section{Part 1: Youth Recruitment}

Recruitment will occur in collaboration with RHY programs. After programs have designated which youth are interested, I will conduct interviews and assess the following criteria:

- Level of literacy (there will be quite a bit of reading)

- Ability to reflect and talk about experience with the analysis

- Willingness to work collaboratively with other youth

- Ability to work independent of direct supervision

- Demographics (wanting to recruit youth who reflect diversity of the RHY population)

- Their schedule is compatible

- They able to accept payment by check (they have a SS Card, government issued ID, and can get to PSU to fill out paperwork)

\section{Part 2: Data Analysis}

Our first meeting ( $\underline{1 \text { hour }})$ will review the project in more detail. A second meeting ( $\underline{2}$ hours) will include training on participatory action research methods. Subsequent meetings ( $\underline{2 \text { hours }})$ will be scheduled and youth will be provided transcripts for analysis. Youth will analyze this material on their own and prior to the next meeting where discussions around interpretation, coding, and directions for next steps will be discussed. Meetings will be tape recorded to keep track of key decision points and areas of agreement and disagreement with respect to the analysis.

\section{Part 3: Researcher Analysis}

Tape recordings will be analyzed by the researcher to assess how the process of conducting participatory research might be improved.

\footnotetext{
${ }^{10} \$ 600$ is based $\$ 15 / \mathrm{hr}$ for 40 hours. If the project runs over the 40 hours, youth will be paid $\$ 15 / \mathrm{hr}$.
} 


\section{RUNAWAY AND HOMELESS YOUTH}

\section{Part 4: Focus Group}

At the conclusion of the analysis portion of the project, youth will participate in a focus group and asked about the process and how it might be improved.

\section{Part 5: Dissemination of Findings}

Youth will have the final decision on how the findings will be disseminated. If they choose, they may be listed as an author on any report or paper that may come from this work. Additionally, the researcher will support youth in creating presentations for conferences, community groups, legislators, etc. that the youth feel could benefit from the findings. 


\section{RUNAWAY AND HOMELESS YOUTH}

\section{Appendix E: Interview Checklist and Questions}

\section{Checklist}

Go over Project Overview document

Interview questions

Ask for questions
Informed consent

Exchange contact information

(phone, email, business card, etc.)

Next meeting details

\section{Interview Questions}

1. Initials:

2. Age

3. Current or past TLP/SOP program participant) Yes

4. Ability to cash a check (SS Card, ID) Yes

No

5. How do you feel about reading? Ask youth to read portion of a transcript and explain (level of literacy). Concerns?

6. Tell me about your RHY experience (ability to reflect). Concerns?

7. How do you feel about working with other youth? Can you give me an example? How would you handle a disagreement? (willingness to work collaboratively) Concerns?

8. How do you feel about working independently? Can you give me an example? (ability to work independent of supervision) Concerns?

9. How flexible is your schedule (Hillsboro meetings)? How long do you feel this project will take? Concerns?

10. I'm trying to recruit youth who represent the broad spectrum of the RHY population in Oregon.
a. Gender
b. Sexual Orientation
c. Race/Ethnicity 


\title{
RUNAWAY AND HOMELESS YOUTH
}

\section{Appendix F: Transcript Example}

\author{
My name is _ , I'm eighteen years old. I'm pleased to have the opportunity
} today to share my story with you. On January 7, 2007, my life changed for the better because that was the day that I was committed to the

in . Although I will speak from my own experience, I am also here to represent the experiences of the other youth whose lives have been positively impacted through their participation in CISP.

I want to start by describing the program that has changed my life. CISP was started in 1990 and is run by the Juvenile Section of the Family Division of the Court of Common Pleas of County. It serves as both an alternative to institutionalization and an aftercare program for those youth who have been subject to institutional placements. CISP offers programming, including drug screening, in five neighborhood centers during the afternoon and evening, seven days a week. CISP also electronically monitors the youth at night. CISP's staff are traditional probation department personnel and paraprofessional "Community Monitors" who live in the same neighborhoods where we live.

The CISP Program is designed to reach male juvenile offenders (ages 10-18) from the targeted neighborhoods who are on probation, continue to recidivate and would be institutionalized but for the existence of this alternative. In other words, young men like me. Property offenders make up for the majority of youth placed into the CISP Program but other youth are also eligible. Since the CISP Program is neighborhood based, a youth must live in one of the designated neighborhoods to be placed in CISP. One of the most important parts of the CISP program is that we remain in our own communities, continue to attend our own schools, and are introduced to positive community resources. All the kids who participate in CISP are required to complete community service, which is important because it makes us feel like a positive part of the community. 


\title{
RUNAWAY AND HOMELESS YOUTH
}

\section{Appendix G:Meeting \#1 Agenda}

\author{
$1^{\text {st }}$ Group Agenda (60 minutes)
}

- Welcome and introductions

- Team building activity

- Review

- Informed consent and limits of confidentiality

- Ability to waive consent for authorship

$\circ$ The purpose of the project

- Pass out one-page overview of project to take home

- How the data was gathered (i.e., stakeholders, how the agencies were chosen, the focus group process, how the questions were derived, etc.)

- The plan for analysis

- Participatory action research methods

- This can take as long as you like - you are in control of the process (after training)

- Content analysis methods

- Possible ways share the findings

- What their role will be

- What my role will be

- Expectations around participation

- Agenda and protocols for;

- $2^{\text {nd }}$ meeting

- Analysis meetings

- Final focus group meeting

○ Payment

- Questions?

- My needs for publication

$\bigcirc \quad$ If any come up, write down for next meeting

- Does anyone want to withdraw?

- Set day and time for second meeting

These first two meetings will also be used to insure the tenets and principles of participatory research are being employed: engaging the youth in dialogue, establishing power sharing, getting to know participants, determining appropriate strategies to facilitate an empowering experience for participants, etc. 


\section{RUNAWAY AND HOMELESS YOUTH}

\section{Appendix H: Meeting \#2 Agenda}

$2^{\text {nd }}$ Group Agenda (2 hours)

At the conclusion, a second meeting will be scheduled. The second meeting will include training on the following topics;

- Welcome

- Team building activity (easy)

- Training

- Participatory action research methods

- Content analysis methods

- Descriptive phase

- Pre-assigned Codes for Indexing Data by;

$$
\begin{array}{ll}
\circ & \text { Agency } \\
\circ & \text { Program } \\
\circ & \text { Question }
\end{array}
$$

- Interpretive phase

- Code for concepts

- Determine convergence/divergence with indexes

- Create new indexes/sub-indexes if necessary

- Examine outlier responses for possible new indexes

- Code for patterns

- Develop themes and constructs

$\circ$ Formulate inferences

- Tape recording

○ This is the piece I'm adding

- Ethical issues

○ Present findings to YAG

- Bias and strategies to manage bias

- Possible ways share the findings

- Ability to waive consent

○ Questions?

- Hand out examples of transcripts and code

- Hand out $1^{\text {st }}$ set of transcripts

- Analyze this material prior to the next scheduled YAG meeting

- Prepare to present your findings, and for

- Discussions around interpretation, coding, and directions for next steps discussed.

- Set day/time for next meeting

- Questions?

These first two meetings will also be used to insure the tenets and principles of participatory research are being employed: engaging the youth in dialogue, establishing power sharing, getting to know participants, determining appropriate strategies to facilitate an empowering experience for participants, etc. 


\section{RUNAWAY AND HOMELESS YOUTH}

\section{Appendix I: Take-Home Document}

\section{HOW WE GOT HERE}

\section{COMMUNities EMPoWering YouTh PROJECT}

The goal of the Communities Empowering Youth project to develop a community based model which will permit the state to responsibly address the needs of RHY. Goals include;

1. A list of evidence-based practices and innovative practices for RHY agencies.

2. A detailed qualitative study of each of the federally funded RHY programs in Oregon, which will provide a logic model for each program.

3. Determine which practices are a good match for different communities.

4. Conduct focus groups with youth to understand RHY perspectives and include their voice in program development.

\section{Focus Group PARTICIPANTS}

There are three types of federally funded programs for RHY.

Basic Center Program: provides outreach, short-term shelter, and counseling to RHY under the age of 18.

Transitional Living Program: assists homeless youth ages 16 through 21 (24) with up to 18 (24) months of shelter and skill development; transition to independent living.

Street Outreach Program: works with RHY 21 (24) years of age and younger, providing services to prevent sexual exploitation of youth living on the street.

There are 10 federally funded RHY agencies in Oregon. Participants for the focus groups include youth from each of these agencies.

\section{FocUS GROUP QUESTIONS}

Questions were asked in two categories, program design and program philosophy.

- Program Design

$\circ$ Think about everything (PROGRAM) does. What do you get out of being involved here?

○ How does the program give you that?

- Who is this program ideal for?

- How would someone from the outside know this program works? 


\section{RUNAWAY AND HOMELESS YOUTH}

- Program Philosophy

○ Think about why (PROGRAM) does what it does. Why do you think they do it the way they do it?

Focus groups were audio-taped and then transcribed

\section{INFORMED CONSENT FOR THIS PROJECT}

\section{CONFIDENTIALity}

Any information that is obtained in connection with this study and that can be linked to you will be kept confidential.

I am asking that each YAG member sign a statement of confidentiality, and to honor it. However, I cannot control the behavior of members once the meetings are over. I want you to speak freely, but for your safety and comfort, please do not disclose any personal information or viewpoints that you would not want shared outside the group.

The only time I will be legally obligated to report confidential information is:

1. If I know or suspect child abuse or abuse of older people is occurring.

2. If you tell me about being a danger to yourself or other people.

\section{WHAT YOU WILL GET FROM BEING IN THE STUDY}

1. Contribute your unique insight and experience to the development of runaway and homeless youth programs.

2. Payment of $\$ 600$ for your work.

3. If you provide your consent, you may be listed on any publication, presentation, etc.

\section{RISKS FROM BEING A MEMBER}

- You may, at times, feel uncomfortable during discussion.

- At any point, you can choose to not participate, to not answer questions, and/or leave the discussion.

- There may individuals who disagree with our findings.

Your participation in this Youth Advisory Group is voluntary. If you decide not to be in the group, that's OK. You do not have to participate and can choose to withdraw at any time without affecting your relationship with this agency or Portland State University. 


\section{RUNAWAY AND HOMELESS YOUTH}

\section{RESEARCH BIAS}

\section{WHAT IS BIAS?}

- Affects the validity and reliability of the findings - it misrepresent the truth!

- It's always there

○ The design of the project

- The methods chosen for data collection

- Who was chosen to participate (who wasn't chosen?)

- What questions were they asked (what weren't they asked?)

- How did the facilitator ask them

- Who analyzed the data

- What methods were used to analyze the data

\section{Minimizing ReSEARCHER BIAS}

- Harder for QUAL research

- There's too much data to fit into tables and charts

- The process we have set up helps; individual findings first, then as a group.

- Awareness of one's beliefs, values, perspectives and assumptions.

- Don't compromise in the discussion if you don't believe it!

- Journal the process.

- Record decisions and the reasons for them and reflection on what is happening in terms of your own values and interests. YOU DO NOT HAVE TO SHARE WHAT YOU WROTE FOR THIS TO BE HELPFUL.

Make sure we thoroughly write up the findings and how we came to them AND our beliefs, values, perspectives and assumptions. 


\section{RUNAWAY AND HOMELESS YOUTH}

\section{Appendix J: Analysis Review Sheet}

1. To help with analysis, ask yourself these questions;

- What did original respondents find helpful or important?

- What did the original respondents find as barriers or challenges?

2. Look for examples of really good practices and where they could be improved.

Line \# What do you think this means? Why do you think that? 


\title{
RUNAWAY AND HOMELESS YOUTH
}

\section{Appendix K: Draft of Human Subjects Application}

\author{
Project Title and Prospectus
}

TITLE: Runaway and Homeless Youth Voice: Effective Programs and Practices

PROSPECTUS: This proposed project is the analysis of secondary data consisting of focus group interviews obtained through the Communities Empowering Youth project (CEY), which is a project previously approved by the PSU Human Subjects Research Review Committee (see section IX. Appendices, HSRRC Proposal \#07389). The mission of the CEY project is to assist Runaway and Homeless Youth (RHY) agencies and their community partners throughout Oregon develop a community based capacity building and sustainability model which will permit the state to responsibly address the needs of RHY. In order to build a mutual culture of engagement between agencies, communities, and youth, the CEY project seeks ways to include the voice of RHY in program and system development. The CEY project believes RHY agencies must engage in relationships with youth and identify their needs and recognize how youth can contribute to an overall system of care for RHY.

RHY are among the most disadvantaged and underserved children and youth in Oregon and there is very little legislative oversight in how the state can best meet their needs. Partners across the state have united to address this issue holistically, understanding that building capacity for RHY involves every member of the community at every level.

For this particular project (analysis of secondary data) transcribed interviews from 12 focus groups will be analyzed using qualitative methods. To add credibility to the findings, a Youth Advisory Group (YAG) will be recruited to provide RHY voice, insight and understanding.

Exemption Claim for Waiver of Review

Not Applicable for this application

Subject Recruitment (Youth Advisory Group) 


\section{RUNAWAY AND HOMELESS YOUTH}

For this project, three to five youth, age 18 and older, who are currently participating or who have participated in a Transitional Living Program $\left(\mathrm{TLP}^{11}\right)$ will be recruited and paid \$15 per hours for membership in a Youth Advisory Group (YAG). Because youth participating in this type of program could possibly have personal histories that might potentially increase risk to them if they participated, program staff, who work with RHY on a daily basis, will assist with determining the appropriateness of a youth to join the YAG. Staff will be requested to not exclude youth who may not be "doing well" in the program. Additionally, efforts will be made to recruit a group of youth who reflect the diversity often found in the RHY population. Subsequently, program staff will facilitate a meeting between the researcher and youth. At that meeting, the researcher will describe the following;

- Informed consent and confidentiality

- The purpose of the project

- How the project came to be

- Stakeholders and partnerships

- How the agencies were chosen

- Focus group process

- How the youth for the focus groups were chosen

- How the questions were derived, etc.

- The plan for analysis

- What their role will be

- The researcher's role

- Expectations around participation

- Protocols

- Payment

- My needs for publication

- Answer any questions the youth may have.

This meeting will also serve as a final screening by the researcher to insure participant appropriateness for YAG participation and obtain a signed copy of the informed consent. At the conclusion, a second meeting will be scheduled. The second meeting with the YAG will begin with an overview of the first meeting and will include training on the following topics;

${ }^{11}$ Transitional Living Programs: assists homeless youth ages 16 through 21 with up to 18 months of shelter and skill development as part of a comprehensive program to help in the transition to independent living. 


\section{RUNAWAY AND HOMELESS YOUTH}

- Participatory action research methods

- Content analysis methods

- Ethical issues

- Bias and strategies to manage bias

- Possible ways share the data

Additionally, to help youth between meetings, youth will be provided with a one-page take home document that has key information about the project on it;

- Brief description of study

- Questions asked in focus group

- Which programs focus group members participated in

- Bullets with informed consent highlights

- Information about bias

Youth will also be informed about the role of the researcher and how that will affect analysis and dissemination needs. These first two meetings will also be used to insure the tenets and principles of PAR are being employed: engaging the youth in dialogue, establishing power sharing, getting to know participants, determining appropriate strategies to facilitate an empowering experience for participants, etc. At the end of this meeting, a subsequent meeting will be scheduled and youth will be provided with portions of stripped ${ }^{12}$ transcripts for analysis.

Youth will analyze this material, described in detail later, prior to the next scheduled YAG meeting where discussions around interpretation, coding, and directions for next steps will be discussed. Meetings will be recorded to keep track of key decision points and areas of agreement and disagreement with respect to the analysis.

\section{Informed Consent}

Once potential YAG members have been recruited by the agency, as the researcher meets with them, he will again explain the purposes and benefits of the project and provide assurances that information shared will be held in confidence and that information will not be reported in any way that could identify the person. However, participants will be explained the limits of confidentiality with work conducted in a group. Additionally,

\footnotetext{
${ }^{12}$ The researcher will insure the removal of any identifying information
} 


\section{RUNAWAY AND HOMELESS YOUTH}

respondents will be afforded the opportunity to ask any additional questions. When the above has been completed with each potential YAG member, the research team will obtain a signed copy of the informed consent. Moreover, all participants will be given ongoing opportunities to reaffirm consent during, or discontinue participation in, the project without any negative consequences.

Finally, in the event the findings from this project are published, presented at a conference, or disseminated in other ways to promote understanding of the needs of youth and programs that serve them, youth will be afforded the opportunity to waive consent to privacy (see section IX. Appendices, Informed Consent)

\section{First-Person Scenario}

A few weeks ago, when (STAFF NAME) met with a group of us from (AGECNY NAME), she told us about a research project that someone from PSU was doing. She went on to tell us this researcher would be visiting (AGENCY NAME) to ask some of us if we would like to help him with his research. She told us the research had something to do with services provided to runaway and homeless youth and asked if any of us would like to meet with the researcher. I told (STAFF NAME) I would like to chip in and others said they would like to help too. (STAFF NAME) went on to tell us the purpose of the project and asked if we had any other questions. When we said we didn't, (STAFF NAME) scheduled a day and time to meet with the researcher.

When the researcher got to agency he met with all of us and explained what YAG meant and what kind of commitment it would take. He then asked to see if we had any questions about YAG. One kid asked how long each meeting would last. He said probably around two hours. Another kid asked if they could take breaks in the middle and the researcher said we could take breaks as often as we needed. He also talked to us about how he could only guarantee confidentiality with them, that he couldn't be certain that some of the other youth in the group wouldn't talk. One kid decided not to stay, but that was okay with me, so I signed the form and we scheduled a second meeting.

At the second meeting, the researcher asked us if any questions had come up since we met last. One kid asked if he could quit later if he wanted to and the researcher told him he could quit anytime he liked. After that, the researcher taught about all kinds of research things like how to evaluate data and how to be careful for prejudice. At times, it seemed way over my head, but the researcher had really good examples and took his time so I felt pretty good at the end of the meeting. Also at the end of the meeting, the researcher gave me a packet of transcripts that I was supposed to analyze before the next meeting. I got kind of nervous at that point but the researcher reassured us that we were 


\section{RUNAWAY AND HOMELESS YOUTH}

all more than capable of doing this. That made me feel good and I became real eager to start working.

I did all that and then at the following meeting with the whole group, we had a super discussion that lasted about an hour and a half. I enjoyed giving my opinions of what I thought other youth meant when they answered questions. It was tough at times, but thinking about it gave me a chance to realize I might actually be helping other homeless youth, that made it worth it. Towards the end of the meeting, I said some things the others didn't agree with, but the researcher helped us see how everyone's opinion is valuable. I really enjoyed the meeting. I thought I was able to give a fair picture, and the meeting gave me a chance to reflect on a very important part of my life. I felt respected and glad to help out. I look forward to our next meeting and to find out what we learn from all this. Sometimes I wonder how I could help make changes happen for homeless youth in my town and this study will help me answer that question.

\section{Potential Risks and Safeguards}

There are no physical risks posed to the subjects of from this project. The subject matter is not in an arena of human experience that would be considered emotionally traumatic or place subjects in a vulnerable position. There is limited risk that someone might say something politically sensitive (in terms of intra-agency politics) and that the researchers would not notice and might put that quoted in the report and that it might be traceable back to the respondent.

TLPs, by the agreement to accept federal funds, provide some level of mental health services to the RHY they serve. Therefore, youth have access to trained crisis counselors 24 hours a day. If a youth feels pained, upset, frightened, angry, etc. from the YAG sessions, they will be afforded access to a crisis counselor. If a higher level of care is needed, the agency's on-duty mental health professional will be contacted and if need be, refer youth to community psychiatric crisis center.

\section{Potential Benefits}

Although difficult to confirm, researchers in the field of RHY are consistent in their conviction that the vast majority of RHY never access social services leaving them at risk for a multitude of disease and infection, mental health disorders, as well as victimization both physically and sexually. Understanding what programs are doing well, from the perspective of youth who utilize those services, is critical to improving services and/or developing new interventions for this particularly vulnerable population. This proposed project begins to create a knowledge base which can inform direct service providers, 


\section{RUNAWAY AND HOMELESS YOUTH}

program administrators, and policy makers. Additionally, these findings have the potential to shore up funding for this population here in Oregon, which for the most part, have been nonexistent.

\section{Records \& Distribution}

For this project, the youth will be recruited as researchers. Each week transcripts of the responses to one questions will be provided to them that have been stripped of any identifying information such as names of participants, staff, programs, etc. by the PI. At the end of each meeting, the researcher will collect selected portions provided to the YAG for storage and distribute the next meetings transcripts. Tapes will be used during the YAG meetings to supplement researcher notes for clarification and will be stored and archived with the project.

At the end of the active analysis period, transcripts will be archived in a locked file, and be kept on file for a maximum of three (3) years.

\section{Appendices}

See Attached;

1. HSRRC Proposal \#07389

2. Informed Consent - Youth Advisory Group (YAG)

3. Communities Empowering Youth (CEY) Human Subjects Application 


\title{
RUNAWAY AND HOMELESS YOUTH
}

\author{
Informed Consent - Youth Advisory Group (YAG)
}

\section{Purpose}

In order to learn more about runaway and homeless youth programs in Oregon, we would like to invite you to participate in a Youth Advisory Group facilitated by Don Schweitzer from the School of Social Work at Portland State University. I am searching for runaway and/or homeless youth who can help me learn about which programs are most helpful and why. You are being asked to participate because you are a community expert who can provide important insight and understanding that could benefit future generations of youth seeking help from Oregon agencies.

\section{What will happen in the Youth Advisory Group?}

If you decide to participate, you will be asked to become a member of a Youth Advisory Group (YAG). As a YAG member, you will be asked analyze interviews from focus groups with runaway and homeless youth (RHY). The information you provide will assist us in learning what works best for services being provided to RHY. These meetings will last approximately two hours and will take place at the location of the program you are participating in or other agreed upon location. Because it is important that our research be based on everyone's opinions, we will use audio tapes to record the discussion.

From the interviews, you will be mostly looking for general themes central to those youth's experiences in RHY programs here in Oregon. I will be looking for your feedback on these themes. As you develop these themes, I will meet with you as a group to discuss them and find those that are common to all of you. Each week I will provide you transcripts of interviews, which you will read and write down what stands out to you as important, and then meet as a group and discuss them. We will work through one question at a time. This process will be repeated until we have finished.

My estimate for your time on this project will be;

- Overall, this project should last no more than 4 months

- We will meet 5 times for 2 hours

- The first meeting will be for training

- I will provide you with transcripts and the end of each meeting, which should take 2-3 hours to analyze

- Total time commitment $=$ approximately 25 hours 


\section{RUNAWAY AND HOMELESS YOUTH}

\section{Confidentiality}

My primary concern is to protect your privacy. Any information that is obtained in connection with this study and that can be linked to you will be kept confidential. If, however, you would like to be personally named as a partner in this project, and if you would like to have your comments identified as yours, you can sign a waiver of confidentiality at the end of this document.

I am asking that each participant maintain the confidentiality of fellow YAG members as well as any information from the focus group interviews.

Discussions will focus on your findings from focus group interviews. Taken out of context, some statements may cause problems for others. For example, if YAG members discuss another member's comments outside of the group, that member could be subject to gossip or social/professional repercussions. If this happens, then confidentiality will be broken.

I am asking that each YAG member sign a statement of confidentiality, and to honor it. However, I cannot control the behavior of members once the meetings are over. I want you to speak freely, but for your safety and comfort, please do not disclose any personal information or viewpoints that you would not want shared outside the group.

The only time I will be legally obligated to report confidential information is if either of the following happens:

1. If I know or suspect child abuse or abuse of older people. Examples of child abuse include things like physical injury, neglect, or sexual abuse of a child. Legally, child abuse could also include having sex with someone under 18 if you are older than 18. Child abuse does not include using drugs or alcohol during pregnancy unless it has injured the child.

2. If you tell me about being a danger to yourself or other people such as intending to take your own life or someone else's life.

What you will get from being in the study 


\section{RUNAWAY AND HOMELESS YOUTH}

You will have the opportunity to contribute your unique insight and experience to the development of runaway and homeless youth programs. You will also be paid a stipend of $\$ 15 / \mathrm{hr}$ for your work.

The results of this project may be published. If they are published, reported data will not include names or contain identifying information of participants who were involved in any part of the project, including this YAG, unless you provide your consent to do so.

Other than the stipend, you may not receive any direct benefit from being a YAG member. However, your participation may help to increase knowledge for programs trying to best help runaway and homeless youth, which may help other youth in the future.

\section{Risks from being a member}

While participating in the YAG, it is possible that you might feel uncomfortable or anxious as a result of being asked to discuss opinions and listen to experiences of others talking about programs or services you may have used and who help homeless and runaway youth. Sometimes talking about these things can be stressful. If you feel uncomfortable at any point in the group, you can choose to not participate, to not answer questions, and/or leave the discussion at any time. Also, if you choose to allow your name to be associated with any publication, presentation, etc., there may individuals who disagree with our findings. If this were to happen, this too might feel uncomfortable or stressful.

\section{Your participation in this Youth Advisory Group is voluntary. If you decide not to be in the group, that's OK. You do not have to participate and can choose to withdraw at any time without affecting your relationship with this agency or Portland State University.}

If you have concerns or problems about your participation in this study or your rights as a research participant, please contact the Human Subjects Research Review Committee, Office of Research and Sponsored Projects, 600 Unitus Bldg., Portland State University, (503) 725-4288 / 1-877-480-4400.

\section{Questions}




\section{RUNAWAY AND HOMELESS YOUTH}

If you have questions about the study itself, you can contact me, Don Schweitzer at University Center Building, 540 SW Harrison Street, Suite 440, Portland, OR 97201, (503) 725-8010.

Please take a few minutes to decide if you wish to participate in this Youth Advisory Group.

Do you have any questions?

If you agree to take part in the Youth Advisory Group, read the following statements. If you agree with them, then print and sign your name and put the date on the form.

I understand that taking part in this project is voluntary. I can refuse to participate, refuse to answer specific questions, or can stop participating at any time. I have been given a copy of this consent form to keep. When I am in the group, I will only share the amount of information I feel comfortable sharing.

I understand that it is VERY IMPORTANT that I do not share information from this project with others or identify people who have participated in the project. I will honor the privacy of my fellow participants.

Please Print Name

Signature

Date

In the event this project is published, presented at a conference, or disseminated in other similar ways I would like to be offered the chance to be publicly recognized for specific contributions that I make to the project.

Signature

Date 